\title{
AHMAD AGHAZADEH PERI-IMPLANTITIS: RISK FACTORS AND OUTCOME OF RECONSTRUCTIVE THERAPY
}
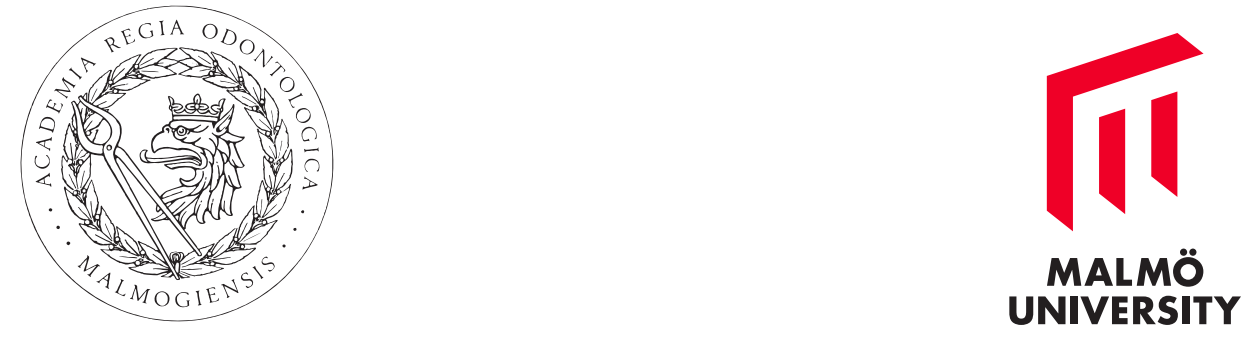

PERI-IMPLANTITIS: RISK FACTORS AND OUTCOME OF RECONSTRUCTIVE THERAPY 
Malmö University, Faculty of Odontology Doctoral Dissertations 2021

(C) Copyright Ahmad Aghazadeh ISBN 978-91-7877-196-7(print) ISBN 978-91-7877-197-4(pdf)

Holmbergs, Malmö 2021 


\section{AHMAD AGHAZADEH PERI-IMPLANTITIS: RISK FACTORS AND OUTCOME OF RECONSTRUCTIVE THERAPY}

Malmö University, 2021

Faculty of Odontology Department of Periodontology 
This publication is also available at: doi $10.24834 /$ isbn. 9789178771974 
To Samira, Parisa, Parasto and my parents 



\section{CONTENTS}

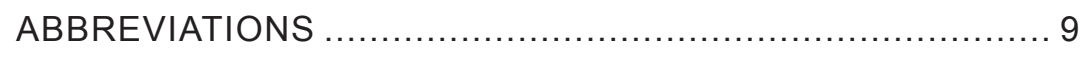

LIST OF PAPERS ..................................................

THESIS AT A GLANCE .......................................... 12

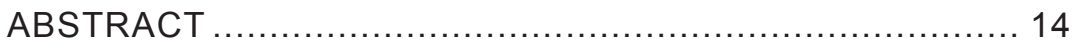

POPULÄRVETENSKAPLIG SAMMANFATTNING.............. 17

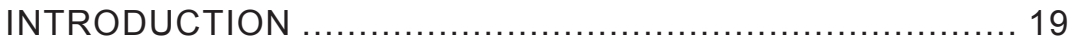

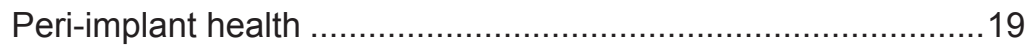

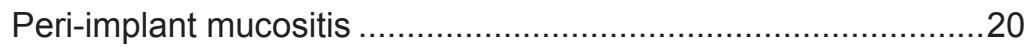

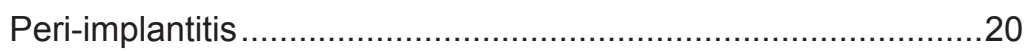

Prevalence of peri-implant diseases ........................................21

General factors of importance for the development

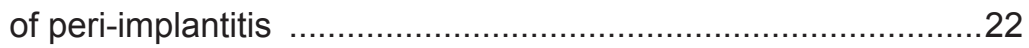

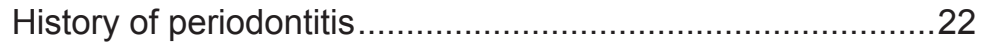

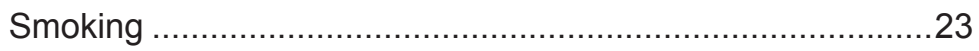

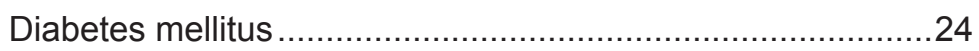

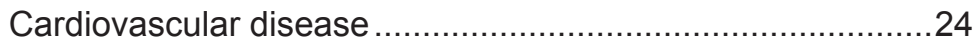

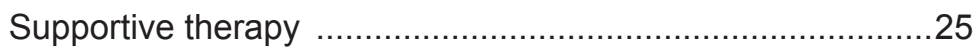

Local factors of importance for the development

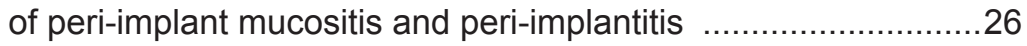

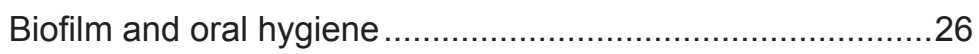

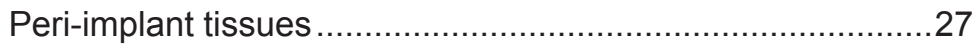

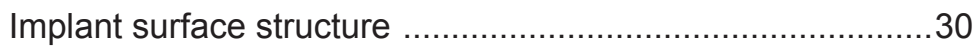

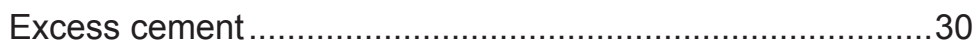




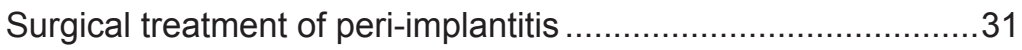

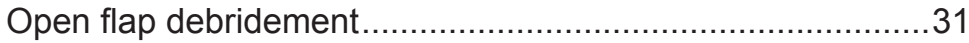

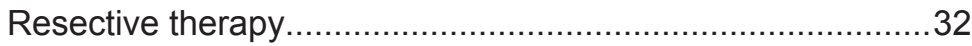

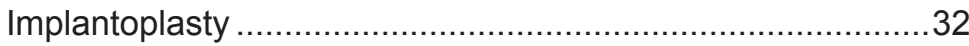

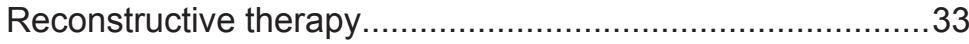

Enamel matrix derivative (EMD).......................................... 33

Augmentation materials and techniques ...............................33

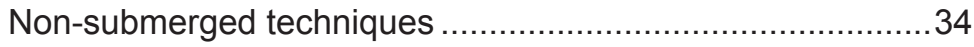

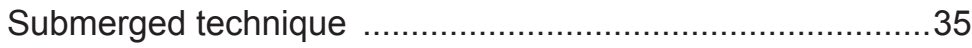

The effect of defect morphology on healing following therapy of peri-implantitis ........................................36

Long-term results of reconstructive

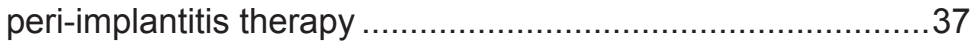

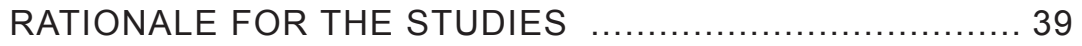

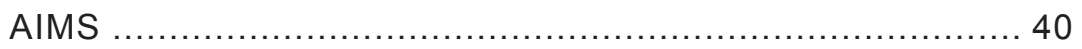

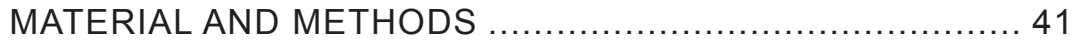

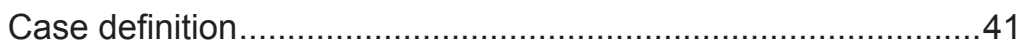

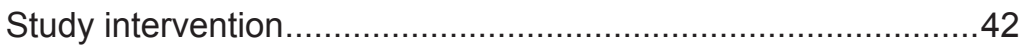

Outcome parameters and analyses …………….....................

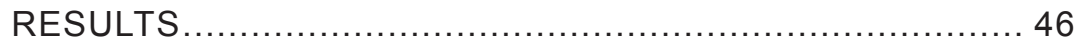

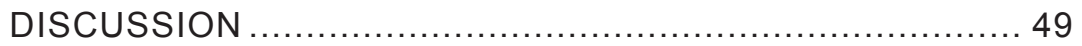

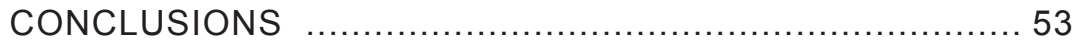

CLINICAL RECOMMENDATIONS ............................ 54

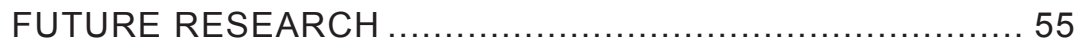

ACKNOWLEDGEMENTS ........................................ 56

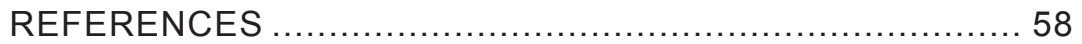

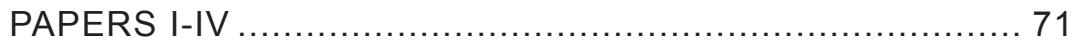




\section{ABBREVIATIONS}

$\begin{array}{ll}\text { AB } & \text { Autogenous bone } \\ \text { BDX } & \text { Bovine derived xenograft } \\ \text { BOP } & \text { Bleeding on Probing } \\ \text { CI } & \text { Confidence Interval } \\ \text { CVD } & \text { Cardiovascular diseases } \\ \text { DM } & \text { Diabetes mellitus } \\ \text { EMD } & \text { Enamel matrix derivative } \\ \text { PPD } & \text { Probing Pocket Depth } \\ \text { LPS } & \text { Local plaque score } \\ \text { LBS } & \text { Local bleeding score } \\ \text { MR } & \text { Mucosal recession } \\ \text { OFD } & \text { Open flap debridement } \\ \text { Pi } & \text { Peri-implantitis } \\ \text { PiM } & \text { Peri-implant mucositis } \\ \text { PI } & \text { Plaque Index } \\ \text { RCT } & \text { Randomized controlled trial } \\ \text { RDF } & \text { Radiographic defect fill } \\ \text { SD } & \text { Standard Deviation } \\ \text { SUP } & \text { Suppuration }\end{array}$




\section{LIST OF PAPERS}

This thesis is based on the following papers, which will be referred to by their roman numerals as listed below.

I. Aghazadeh A, Persson GR, Renvert S. A single-centre randomized controlled clinical trial on the adjunct treatment of intra-bony defects with autogenous bone or a xenograft: results after 12 months. Journal of Clinical Periodontology 2012; 39: 666-673. doi:10.1111/j.1600051X.2012.01880.x.

II. Renvert S, Aghazadeh A, Hallström H, Persson GR. Factors related to peri-implantitis-a retrospective study. Clinical Oral Implants Research 00, 2013, 1-8. doi: 10.1111/clr.12208

III. Aghazadeh A, Persson GR, Renvert S. Impact of bone defect morphology on the outcome of reconstructive treatment of peri-implantitis International. Journal of Implant Dentistry (2020) 6:33. https://doi. org/10.1186/s40729-020-00219-5

IV. Aghazadeh A, Persson GR, Stavropoulos A, Renvert S. Long term stability of treatment results obtained following reconstructive treatment of peri-implant defects - Results after five years.

In manuscript. 


\section{THESIS AT A GLANCE}

\begin{tabular}{|c|c|c|}
\hline Study & Aim & Study design \\
\hline I & $\begin{array}{l}\text { To: clinically and radiographically } \\
\text { evaluate surgical treatment outcomes with an } \\
\text { adjunct placement of autologous bone or a bovine- } \\
\text { derived bone xenograft in peri-implant defects } \\
\text { covered by a resorbable collagen membrane over } 12 \\
\text { months. }\end{array}$ & RCT \\
\hline II & $\begin{array}{l}\text { To: assess the risk of having a diagnosis of } \\
\text { periodontitis, a history of systemic disease, and a } \\
\text { smoking habit in relation to peri-implantitis. }\end{array}$ & Retrospective \\
\hline III & $\begin{array}{l}\text { To: assess if } \\
\text { (I) the alveolar bone defect configuration at dental } \\
\text { implants diagnosed with peri-implantitis is related } \\
\text { to clinical parameters at the time of surgical } \\
\text { intervention } \\
\text { (II) the outcome of surgical intervention of peri- } \\
\text { implantitis is dependent on defect configuration at } \\
\text { the time of treatment. }\end{array}$ & Prospective \\
\hline IV & $\begin{array}{l}\text { To: compare long-term efficacy of reconstructive } \\
\text { surgery of peri-implantitis using an autogenous bone } \\
\text { graft, or a bovine-derived xenograft combined with a } \\
\text { resorbable membrane. }\end{array}$ & $\mathrm{RCT}$ \\
\hline
\end{tabular}




\begin{tabular}{|c|c|c|}
\hline Sample & Outcome parameters & Main findings \\
\hline $\begin{array}{l}22 \text { subjects in the } A B \\
\text { group } \\
23 \text { subjects in the } \\
\text { BDX group }\end{array}$ & $\begin{array}{l}\text { BOP } \\
\text { PI } \\
\text { LPS } \\
\text { LBS } \\
\text { SUP } \\
\text { PPD } \\
\text { RDF } \\
\text { MR }\end{array}$ & $\begin{array}{l}\text { Bovine xenograft provided more } \\
\text { radiographic evidence of defect fill } \\
\text { than } A B \text {. } \\
\text { The success for both surgical } \\
\text { regenerative procedures was limited. } \\
\text { Decreases in } P D, B O P, \\
\text { and SUP were observed. }\end{array}$ \\
\hline $\begin{array}{l}172 \text { individuals with } \\
\text { peri-implantitis } \\
98 \text { individuals with } \\
\text { peri-implant health } \\
\text { or peri-implant } \\
\text { mucositis }\end{array}$ & $\begin{array}{l}\text { CVD } \\
\text { Periodontitis } \\
\text { DM } \\
\text { Rheumatoid arthritis } \\
\text { Lung disease } \\
\text { Osteoporosis } \\
\text { Cancer } \\
\text { Depression } \\
\text { Smoking } \\
\text { Gender }\end{array}$ & $\begin{array}{l}\text { In relation to a diagnosis of peri- } \\
\text { implantitis, a high likelihood of } \\
\text { comorbidity was expressed by a } \\
\text { history of periodontitis and a history } \\
\text { of cardiovascular disease. }\end{array}$ \\
\hline $\begin{array}{l}39 \text { patients with } 74 \\
\text { implants with peri- } \\
\text { implant defects with } \geq \\
2 \text { bone walls }\end{array}$ & $\begin{array}{l}\text { BOP } \\
\text { PI } \\
\text { LPS } \\
\text { LBS } \\
\text { SUP } \\
\text { PPD } \\
\text { RDF } \\
\text { MR }\end{array}$ & $\begin{array}{l}\text { (I) The buccal-lingual width of the } \\
\text { alveolar bone crest was explanatory } \\
\text { to defect configuration. } \\
\text { (II) Four-wall defects demonstrated } \\
\text { more radiographic evidence of defect } \\
\text { fill. } \\
\text { (III) Deeper defects resulted in more } \\
\text { defect fill. }\end{array}$ \\
\hline $\begin{array}{l}16 \text { patients and } 25 \\
\text { implants in the } A B \\
\text { group } \\
23 \text { patients and } 37 \\
\text { implants in the BDX } \\
\text { group }\end{array}$ & $\begin{array}{l}\text { BOP } \\
\text { PI } \\
\text { LPS } \\
\text { LBS } \\
\text { SUP } \\
\text { PPD } \\
\text { RDF } \\
\text { MR }\end{array}$ & $\begin{array}{l}\text { Reconstructive surgical treatment } \\
\text { of peri-implant defects can lead to } \\
\text { successful clinical outcomes, that } \\
\text { can be maintained over at least } \\
\text { five years. The use of BDX is more } \\
\text { predictable than harvested bone from } \\
\text { the patient. }\end{array}$ \\
\hline
\end{tabular}




\section{ABSTRACT}

This thesis is focused on (I) the outcome of reconstructive treatment of peri-implant defects and (II) risk factors for the development of periimplantitis.

\section{Background}

An increasing number of individuals have dental implant-supported reconstructions. The long-time survival rate of dental implants is good, but complications do occur. Accumulation of bacteria on oral implants and the development of a pathogenic biofilm at the mucosal margin will result in inflammatory responses diagnosed as peri-implant mucositis (PiM). Furthermore, PiM may progress to peri-implantitis (Pi) involving the implant-supporting bone and potentially result in a severe inflammatory process resulting in alveolar bone destruction and consequently implant loss. Currently, $\mathrm{Pi}$ is a common clinical complication following implant therapy. The prevalence of peri-implantitis has been reported to be around $20 \%$. Susceptibility to infections and a history of periodontitis are considered as important risk indicators for peri-implantitis. It seems logical that a past history of periodontitis is linked to an increased risk of peri-implantitis. It is possible that other patient-associated factors such as a smoking habit, and presence of general diseases may also be linked to a higher risk for developing peri-implantitis.

Treatment of peri-implantitis is difficult. Non-surgical treatment modalities may not be sufficient to resolve the inflammatory process to obtain healthy conditions.

Surgical treatment of peri-implantitis has commonly been employed in clinical practice to obtain access to the implant surface thereby increasing the possibility to effectively decontaminate the implant surfaces. The 
effectiveness and long-term outcomes of reconstructive surgical treatments of peri-implantitis has been debated. The scientific evidence suggests that regular supportive care is an essential component in order to maintain and secure long-term results following treatment of peri-implantitis.

\section{Aims}

1. To assess the short-term efficacy of reconstructive surgical treatment of peri-implantitis (Study I).

2. To analyse risk factors related to the occurrence of peri-implantitis (Study II).

3. To assess the importance of defect configuration on the healing response after reconstructive surgical therapy of peri-implantitis (Study III).

4. To assess the long-term efficacy of reconstructive surgical treatment of peri-implantitis (Study IV).

\section{Methods}

\section{Four studies were designed to fulfil the aims:}

- A single-blinded prospective randomised controlled longitudinal human clinical trial evaluating the clinical and radiographic results of reconstructive surgical treatment of peri-implantitis defects using either $\mathrm{AB}$ or $\mathrm{BDX}$.

- A retrospective analysis of individuals with either peri-implantitis, or presenting with either peri-implant health, or peri-implant mucositis assessing the likelihood that peri-implantitis was associated with a history of systemic disease, a history of periodontitis, and smoking.

- A prospective study evaluating if the alveolar bone defect configuration at dental implants diagnosed with peri-implantitis is related to clinical parameters at the time of surgical intervention and if the short- and long-term outcome of surgical intervention of peri-implantitis is dependent on defect configuration at the time of treatment.

- A prospective 5-year follow-up of patients treated either with $\mathrm{AB}$ or BDX. 


\section{Results}

- The success for both surgical reconstructive procedures was limited. Nevertheless, bovine xenograft provided evidence of more radiographic bone fill than $\mathrm{AB}$. Improvements in $\mathrm{PD}, \mathrm{BOP}$, and SUP were observed for both treatment modalities

- In relation to a diagnosis of peri-implantitis, a high likelihood of comorbidity was expressed in the presence of a history of periodontitis and a medical history of cardiovascular disease

- The buccal-lingual width of the alveolar bone crest was explanatory to defect configuration

- 4-wall defects and deeper defects demonstrated more radiographic evidence of defect fill

- Reconstructive surgical treatment of peri-implant defects may result in successful clinical outcomes, that can be maintained over at least five years

- The use of BDX is more predictable than use of harvested bone from the patient $(\mathrm{AB})$

\section{Conclusions}

The study results suggest that a bovine xenograft provides better radiographic evidence of defect fill than the use of autogenous bone harvested from cortical autologous bone grafts.

Treatment with bone grafts to obtain radiographic evidence of defect fill is more predictable at 3- and 4-wall defects than at peri-implantitis bone defects with fewer bone walls.

In relation to a diagnosis of peri-implantitis, a high likelihood of comorbidity was found for a history of periodontitis and a history of cardiovascular disease. 


\section{POPULÄRVETENSKAPLIG SAMMANFATTNING}

Tänder som har förlorats kan idag ersättas med dentala implantat. Generellt sett har dentala implantat en hög lyckande frekvens, men såväl tekniska som biologiska komplikationer förekommer. Om orala patogena mikroorganismer (biofilm) får möjlighet att ansamlas kring implantaten under en längre tid reagerar vävnaden med en inflammatorisk process. Om inflammationen endast omfattar mjukvävnaden och ingen benförlust har uppstått benämns det inflammatoriska tillståndet som peri-implantär mukosit. Om den peri-implantära mukositen inte behandlas kan den progrediera till en peri-implantit och då innefatta en förlust av ben kring implantatet. I förlängningen kan implantatet förloras. Peri-implantit är vanligt och cirka $20 \%$ av de installerade implantaten har rapporterats med peri-implantit efter en 5-10 års period.

Individer som har förlorat sina tänder på grund av parodontit löper en större risk att också drabbas av peri-implantit. Andra individrelaterade faktorer som har förknippats med en ökad risk för utvecklingen av periimplantit inkluderar bland annat rökning, diabetes, hjärtkärlsjukdom och dålig munhygien.

Behandling av peri-implantit är svår. Implantatens gängade och ofta råa yta retinerar den dentala biofilmen. Biofilmen kan också mineraliseras i och på den råa implantatytan och blir då svår att avlägsna. Flera studier har rapporterat att icke-kirurgisk behandling av peri-implantit inte är effektiv.

Genom att utföra ett kirurgiskt ingrepp skapas insyn och tillträde till fixturytan för effektivare dekontaminering av implantatytan. Olika kirurgiska metoder kan användas för behandling av peri-implantit. Resektiva metoder är inriktade på att åstadkomma en reduktion av mjukvävnaden och på så sätt reducera fickdjupet för att underlätta rengöring kring implantaten. 
Rekonstruktiva kirurgiska ingrepp syftar till att eliminera infektionen och återskapa det förlorade benfästet runt implantaten. Ben som under kirurgin tagits från ett annat ställe på patienten, konstgjorda benersättningsmaterial eller ben från djur har använts för att fylla ut bendefekter kring implantaten och bidra till en utläkning. Vid användning av konstgjort benmaterial eller ben från djur, kan patientens post-operativa besvär reduceras eftersom patienten inte behöver utsättas för ytterligare ett kirurgiskt ingrepp i syfte att samla benmaterial. Det är därför viktigt att undersöka om ett kommersiellt tillgängligt benersättningsmaterial resulterar i jämförbara eller bättre läknings resultat jämfört med ben som tagits från patienten.

Det kirurgiska utfallet vid rekonstruktiva behandlingar beror sannolikt inte bara på vilket benersättningsmaterial som används vid det kirurgiska ingreppet, utan också på hur bendefektens morfologi ser ut. Antal kvarvarande benväggar kan ha betydelse för utfallet av regenerativa behandlingar och det finns indikationer på att antalet kvarvarande benväggar är relaterat till behandlingens utfallet.

Regelbundna stödbehandlingar är betydelsefulla för att bibehålla och säkerställa resultatet efter kirurgisk behandling av peri-implantit. Behandlingsutfallet efter behandling av en peri-implantit är också beroende av att patienten utför en god munhygien och kommer på sina stödbehandlingsbesök.

Målet med denna avhandling är att utvärdera, i det korta och långa perspektivet, utfallet av rekonstruktiv kirurgisk behandling av peri-implantit, att undersöka om bendefektens utseende påverkar utfallet samt att analysera vilka faktorer som är relaterade till förekomsten av peri-implantit.

Resultaten av avhandlingens delarbeten visar att;

1, rekonstruktiv kirurgisk behandling kan resultera i en läkning av peri-implantit

2, behandlingsresultatet kan bibehållas under minst 5 år

3, användningen av ett benersättningsmedel baserat på kalvben $\left(\right.$ Bio-Oss $\left.^{\circledR}\right)$ ger ett mera förutsägbart resultat än att använda bensubstans som tagits från patientens eget käkben

4, en tidigare diagnos av parodontit och/eller hjärt- och kärlsjukdomar medför en högre risk att drabbas av peri-implantit

5, käkbenets bredd vid fixturinstallation påverkar vilken typ av bendefekt som bildas om implantatet drabbas av peri-implantit

6, bendefekter med fyra kvarvarande benväggar visar bäst defektutfyllnad efter rekonstruktiv behandling enligt analys av röntgenbilder 


\section{INTRODUCTION}

\section{Peri-implant health}

Tissues around natural teeth and dental implants have some anatomical and histological similarities but there are also differences affecting the host's responses to various biological complications (Araujo \& Lindhe, 2018). An osseointegrated dental implant is surrounded by the alveolar bone, in direct contact with the implant surface. The soft tissue is the peri-implant mucosa covering the enclosing bone and the implant neck. The healthy peri-implant mucosa consists of connective tissues covered by either a keratinised or non-keratinised epithelium. The peri-implant mucosa averages about 3 to $4 \mathrm{~mm}$ in height (Araujo \& Lindhe, 2018). In a healthy clinical situation, the peri-implant mucosa forms a tight seal around the trans-mucosal component of the implant, the abutment, or the restoration. At the World Workshop on the Classification of Periodontal and Peri-Implant Diseases and Conditions in Chicago 2017, peri-implant health was defined. A healthy mucosa lacks clinical signs of inflammation, i.e. redness, swelling, and bleeding following probing (Berglundh et al., 2018). The following clinical and radiological examinations were proposed when diagnosing peri-implant health (Renvert et al., 2018a).

1) Registration of oral hygiene in general, with a specific focus on the presence of biofilm on implants and their restorations.

2) Annual examinations, including pocket depth measurements using a light force (about $0.25 \mathrm{~N}$ ).

3) BOP should not occur at healthy peri-implant tissues. Bleeding "spots" should be interpreted carefully as this may represent bleeding due to tissue damage and not bleeding associated with tissue inflammation. 
4) Intra-oral X-ray examination is essential to distinguish healthy implant bone configuration from what is typical for cases with peri-implantitis. An X-ray image when the supra structure is mounted on the implant is warranted.

5) Absence of bone loss beyond bone level changes resulting from initial bone remodelling. Thus, bone level changes $\geq 2 \mathrm{~mm}$ at any time during or after the first year should be considered pathological (Lindquist et al., 1996, Cochran et al.,2009, Gholami et al., 2014).

\section{Peri-implant mucositis}

Accumulation of a biofilm around an osseointegrated implant cause periimplant mucositis (Pontoriero et al., 1994, Salvi et al., 2012). Peri-implant mucositis was defined as an inflammation of the mucosa without loss of peri-implant supporting bone tissue (Lindhe \& Meyle, 2008). The inflammatory response to experimental plaque accumulation tends to be stronger in peri-implant mucositis than in gingivitis (Zitzmann et al., 2001). However, just like gingivitis, peri-implant mucositis is a reversible disease (Salvi et al., 2012). Peri-implant mucositis, if not treated, is considered to be the precursor to peri-implantitis.

The outcome of PPD measurement around dental implants has been studied in animal experiments. Studies have shown that probing in healthy peri-implant tissue or peri-implant mucositis reaches the apical part of the epithelial barrier (Ericsson et al., 1993). Although probing can jeopardize the adhesion between the epithelium and the implant surface, it has been documented that after 5 to 7 days, the adhesion is restored to a healthy and normal situation (Abrahamsson \& Soldini, 2006).

Peri-implant mucositis is defined by;

(I) presence of clinical signs of bleeding and/or suppuration on gentle probing with or without increased probing depth compared to previous examinations and (II) absence of bone loss crestal bone level changes resulting from initial bone remodelling.

\section{Peri-implantitis}

Peri-implantitis may occur when peri-implant mucositis has not been treated (Jepsen et al., 2015). Clinically, peri-implantitis is evidenced by bleeding and/or suppuration on gentle probing, an increased probing depth compared to previous examinations and radiographic evidence of bone loss beyond bone level changes resulting from initial bone remodelling. In the 
absence of previous examination data, a diagnosis of peri-implantitis can be based on the combination of the presence of bleeding and/or suppuration on gentle probing, probing depths of $\geq 6 \mathrm{~mm}$, and bone levels $\geq 3 \mathrm{~mm}$ apical of the most coronal portion of the intra-osseous part of the implant (Berglundh et al., 2018).

\section{Prevalence of peri-implant diseases}

Over the last decades dental implants have been used to replace teeth lost due to several reasons. Survival rates exceeding 95\% over 10 years have been reported (Jemt 2018). There are several reasons for non-successful implants being lost with technical/mechanical problems being the most common reasons for implant loss. In the context of the present thesis only biological reasons will be considered. Biological complications compromise implant longevity. Peri-implantitis is a clinical complication following treatment with dental implants and is considered an infectious disease resulting in complex inflammatory responses with extensive alveolar bone loss around implants (Lang et al., 2008, Sanz et al., 2012).

Since peri-implantitis was described and defined in 1993, at the First European Workshop on Periodontology, the prevalence of peri-implantitis has been studied extensively but unfortunately with great variations in disease definition between studies. As a consequence, a wide range of prevalence rates has been reported and the impact of different case definitions has been highlighted in the literature (Renvert et al., 2018a). In a study by Roos-Jansåker et al. (2006 b), using BOP + bone level change $>1.8 \mathrm{~mm}$ after the first year in function to define peri-implantitis, the presence of peri-implantitis was reported at $6.6 \%$ at implant level and $16.6 \%$ at patient level. Daubert et al. (2015) using bone level change $>2 \mathrm{~mm}$ after remodelling + BOP or SUP + PPD $\geq 4 \mathrm{~mm}$, reported peri-implantitis to occur in $16 \%$ of the implants and $26 \%$ of the patients. Koldsland et al. (2010) reported on 109 subjects attending a clinical and radiographic examination of their implants. The mean functional loading time was 8.4 years. Two different definitions for peri-implantitis were used; a) presence of BOP at PPD of $4 \mathrm{~mm}$ and radiographic peri-implant bone loss of 2.0 $\mathrm{mm}$, or b) presence of BOP at PPD of $6 \mathrm{~mm}$ and radiographic peri-implant bone loss of $3.0 \mathrm{~mm}$. The authors concluded that assessing peri-implantitis at different levels of severity yielded a substantial variance in prevalence (11.3\% to $47.1 \%$ ). Similarly, Derks et al. (2016) reported that $14,5 \%$ of patients had a diagnosis of moderate/severe peri-implantitis (bone level 
change $>2 \mathrm{~mm}+\mathrm{BOP} / \mathrm{SUP})$. However, if the criteria for defining periimplantitis was changed (BOP/SUP and bone loss $>0.5 \mathrm{~mm}$ ) $45 \%$ of the individuals would have been diagnosed with peri-implantitis. Due to the significant heterogeneity in case definitions as exemplified above, the prevalence of peri-implantitis has been reported to vary between $1 \%$ and $47 \%$ with an estimated weighted mean prevalence of peri-implantitis on patient level of $22 \%$ (Derks \& Tomasi, 2015).

Due to the increased use of dental implants it is anticipated that the number of dental implants suffering from peri-implantitis will increase and peri-implantitis will become a problem not only for the patients but also for the dental community. Currently, following the World Workshop of Periodontal and Peri-implant Diseases and Conditions in 2017, the diagnosis of peri-implantitis is defined as a plaque-associated pathological condition occurring in tissues around dental implants, characterised by inflammation in the peri-implant mucosa and subsequent progressive loss of supporting bone (Berglundh et al., 2018).

\section{General factors of importance for the development of peri-implantitis}

Dental implants have become a routine treatment to replace lost teeth. For a "healthy" patient, the survival rates for turned oral implants after $>15$ years have been reported to be $91.5 \%$ (Dierens et al., 2012). Despite this high success rate, biological complications do occur. The aetiology of periimplantitis is multifactorial. Some individuals seem to be more prone to develop peri-implantitis than others. Conditions related to the development of disease are considered risk factors and can be either general or local. General risk factors are factors that are related to the patient's susceptibility to getting the disease. Risk factors that are often highlighted include a history of periodontitis, smoking habits, and systemic disease comorbidity.

\section{History of periodontitis}

Bacteria in peri-implant pathological pockets are comparable to bacteria found in periodontitis pockets and consists of a complex and predominantly anaerobic microbiota (Ferreira et al., 2018).

These bacteria may result in the development of peri-implantitis (Quirynen et al., 2002, Renvert \& Quirynen, 2015, Kumar et al., 2018). Patients with periodontal disease have been associated with a higher prevalence of peri-implantitis compared to non-periodontitis patients 
(Karoussis et al., 2003, Roos-Jansåker et al., 2006c, Renvert \& Persson, 2009, Simonis et al., 2010, Roccuzzo et al., 2012, 2014, Derks et al., 2016). A recent systematic review and metanalysis concluded that history of, or the presence of, periodontitis were identified as risk factors for periimplantitis (Dreyer et al., 2018).

\section{Smoking}

Cigarettes contain more than 4,000 toxic substances that affect the soft tissues and the bone negatively. Nicotine is the main component in cigarettes, and nicotine concentrations can be measured in saliva and gingival fluid (Takamiya et al., 2014). Both osteoblast activity and the amount of collagen are reduced by nicotine. The blood circulation deteriorates, resulting in ischemia, which affects the possibility of the immune cells reaching the area of infection (Lambert et al., 2000). Smoking affects the immune response at the cellular level, reduces antibody production, impairs the vascularisation and alters the bacterial flora in periodontal pockets (Fredriksson et al., 1999). Smoking negatively affects the subgingival microbiome in periodontal health and disease (Kumar et al., 2011). The peri-implant microbiome in smokers exhibited a significantly lower diversity than in non-smokers (Tsigarida et al., 2015). Smoking harm periodontal health and impairs periodontal treatment outcomes (Palmer et al., 2005, Heasman et al., 2006). Smokers are nearly seven times more prone to tooth loss than non-smokers (Tsigarida et al., 2015).

Smoking also negatively affects the initial healing phase following implant installation (Strietzel et al., 2007) and smoking is considered a risk factor for the development of peri-implantitis (Renvert \& Quirynen 2015, Gurlek et al., 2018). It is also associated with reduced implant survival (Renvert \& Quirynen 2015). Several papers have, however, been unable to verify smoking as a risk factor for peri-implantitis (Koldsland et al., 2010, 2011, Marrone et al., 2013, Casado et al., 2013, Canullo et al., 2016, Delago et al., 2017). In spite of this a recent review concluded that smoking is a risk factor for the development of peri-implantitis (Casado et al. 2019). Another recent review, however, concluded that data identifying smoking as potential risk factor/indicator for peri-implantitis are inconclusive (Schwarz et al., (2018). Further research is clearly needed to assess the impact of both smoking and diabetes mellitus (DM) on the development of peri-implantitis. 


\section{Diabetes mellitus}

The prevalence of DM is increasing worldwide, and the disease is associated with severe systemic complications. In 2017, approximately 450 million adult individuals in the world were affected by DM, and this figure is expected to increase to 693 million people by 2045 (Cho et al., 2018). Global health spending on DM in 2019 was $\$ 760$ billion and is expected to grow to $\$ 825$ billion in 2030 and $\$ 845$ billion in 2045 (Williams et al., 2020).

DM is a risk factor in periodontal diseases (Genco \& Borgnakke, 2013). Studies have also shown that certain common diseases combined with bacterial biofilm in susceptible patients increase the risk of a dental implant suffering from peri-implantitis (Renvert \& Polyzois, 2015). Therefore, it is essential to identify susceptible individuals and design a preventive treatment plan to reduce the risk of the development of peri-implant diseases (Tonetti et al., 2015).

The healing processes following the installation of dental implants are affected by the patient's general health conditions such as DM. Previous systematic reviews have shown that patients with excellent and controlled blood sugar levels show as good osseointegration of the implant as nondiabetic patients do (Javed \& Romanos, 2009). Individuals with DM have been reported to have an increased risk of developing peri-implantitis (Ferreira et al., 2006, Renvert et al., 2014, Daubert et al., 2015). In a recent review and meta-analysis, DM hyperglycaemia was associated with an increased risk of peri-implantitis. Clinicians were recommended to carefully consider the increased risk of peri-implantitis development among individuals with hyperglycaemia (Monje et al., 2017). In another recent meta-analysis, a positive association was also reported between DM and peri-implantitis. The patients with DM were twice as likely to have peri-implantitis than those without DM (Dreyer et al., 2018). A recent review concluded that data identifying diabetes as a potential risk factor/ indicator for peri-implantitis are inconclusive (Schwarz et al., 2018).

\section{Cardiovascular disease}

Several studies in recent decades have shown an association between cardiovascular disease (CVD) and periodontitis (Froum et al., 2020). Studies have shown that patients with periodontitis also seem to develop CVD diseases (Albandar et al., 2018). The relationship between CVD and periodontitis has been explained by the presence of periodontal bacteria 
that directly and indirectly affect vessel walls. Increased production of proinflammatory cytokines results in increased production of C-reactive protein, contributing to the development of atherosclerotic plaque in the artery walls and an increased risk of blood clot formation in the coronary arteries of the heart (Pietiäinen et al., 2018).

A retrospective study (Renvert et al., 2014) reported an odds ratio (OR) of 8.7 for the relationship between CVD and peri-implantitis. Saaby et al. (2016) reported that $44 \%$ of patients referred for treatment of periimplantitis had some systemic disease and that the incidence of CVD in the group was 26\%. Froum et al. (2018) reported that 48 of 100 patients treated for peri-implantitis had a history of hypertension. The authors concluded that there has been little or no mention of hypertension (controlled) as a risk factor for peri-implantitis. Due to the limited number of studies, it is not easy to draw any firm conclusions regarding the association of CVD and peri-implantitis. More well-controlled studies are needed.

\section{Supportive therapy}

The role and success of supportive periodontal therapy (SPT) in the longterm treatment of periodontitis is well established. A large number of studies have demonstrated that treatment results obtained following nonsurgical periodontal therapy can be maintained for a long time (Axelsson \& Lindhe, 1981, Lindhe \& Nyman, 1984, Axelsson et al., 2004). In a recent meta-analysis, the authors identified that fair to poor individual oral hygiene can be associated with a two to five-fold increased risk of periodontitis, but the analysis also showed that dental visits and regular adequate tooth-brushing can reduce this risk (Lertpimonchai et al., 2017).

Lack of adequate plaque control has also been identified as an essential risk factor for the occurrence of peri-implant diseases (Jepsen et al., 1996, Konstantinidis et al., 2015, Salvi \& Lang, 2004, Zangrando et al., 2015, Hu et al., 2020). The results from a recent study suggest that patients without regular maintenance exhibit a four-fold increased risk for peri-implantitis over seven years (Frisch et al., 2020). A systematic review and metaanalysis, including nine studies, has revealed that patients who do not have a regular SPT are 11 times more likely to get peri-implantitis (Atieh et al., 2013). Another review demonstrated that around $35 \%$ of patients without maintenance developed peri-implantitis and for patients receiving regular supportive care the equivalent figure was approximately 10\% (Monje et al., 2016). Thus, lack of adequate plaque control has been identified as an 
essential risk factor for the occurrence of peri-implant diseases (Jepsen et al., 1996, Konstantinidis et al., 2015, Salvi \& Lang 2004, Zangrando et al., 2015). SPT aims to maintain implant health and to prevent recurrence of the disease. It is well established that regular supportive care is an important factor in maintaining peri-implant health (Roccuzzo et al., 2010, Roccuzzo et al., 2014, Roccuzzo et al., 2018, Serino, et al., 2015, HeitzMayfield et al., 2018, Hu et al., 2020).

Converting mucositis to peri-implantitis was associated with a lack of annual supportive therapy in patients diagnosed with peri-implant mucositis (Costa et al., 2012).

The 11th European Workshop on primary and secondary prevention of periodontal and peri-implant diseases concluded that prevention must be tailored to the individual's needs through diagnosis and risk profiling (Tonetti et al., 2015). At an SPT visit, peri-implant probing is performed, and BOP and PI are registered. If needed, the patient is re-motivated and re-instructed on how to perform adequate oral hygiene measures. It is also essential to check the prosthetic structure's hygienic design so that it is possible for the patient to perform daily oral hygiene measures accessing the implant surface.

\section{Local factors of importance for the development of peri-implant mucositis and peri-implantitis}

Replacement of teeth and the reestablishment of functional and aesthetic conditions are in many cases predictable and successful when dental implant therapy is used. Nevertheless, both technical and biological complications/failures occur. Prospectively over 10 years, data suggest that the likelihood of technical failures are higher than complications caused by biological (infectious) aetiology with implant borne reconstructions having the lowest number of complications (Brägger et al., 2005).

\section{Biofilm and oral hygiene}

As soon as dental implants are installed in the oral cavity, they are exposed to a colonisation by the oral microflora (Quirynen et al., 2006, Fürst et al., 2007). The ecological environment around implants facilitates the accumulation of anaerobic bacterial species which destroys the periimplant supportive tissues (Koyanagi et al., 2010). When dental implants in individuals with a healthy dentate underwent an experimental undisturbed plaque accumulation over three weeks, the study demonstrated that periimplant soft tissues developed a stronger inflammatory response to 
experimental plaque accumulation compared with what occurred in the gingiva at teeth (Salvi et al., 2012). Plaque accumulation around dental implants due to poor oral hygiene has been associated with peri-implant mucositis (Renvert \& Polyzois, 2015). The risk for developing periimplant diseases due to poor oral hygiene has been reported to be very high (Ferreriea et al., 2006). Peri-implant mucositis does not always result in the development of peri-implantitis. The bacterial infection has, however, been shown to initiate the development (Salvi et al., 2012). In a prospective study, patients with good oral hygiene showed a bone loss of $0.65 \mathrm{~mm}$ compared to $1.65 \mathrm{~mm}$ in patients with poor oral hygiene (Lindqvist et al., 1996). Hygienically designed supra constructions on implants play a significant role in preventing these diseases. Serino and Ström (2009) reported that $65.4 \%$ of implants with limited access for oral hygiene and $17.9 \%$ of the implant with access to oral hygiene measures developed peri-implantitis. In another study, $77.2 \%$ of cases diagnosed with periimplantitis had inadequate access for oral hygiene measures (Monje et al., 2019). An unhygienic design of the implant-supported prostheses is a risk factor for the development of peri-implantitis. Hard-to-reach surfaces around implant structures have been associated with a higher frequency of peri-implantitis (Katafuchi et al., 2018). The fact that implant constructions are challenging to clean are associated with the development of periimplantitis (Hu et al., 2020). Furthermore, dental implants with intracoronal compartments of screw-retained fixed restorations may provide a pathway for bacterial leakage resulting in bacterial contamination via the implant-abutment interface (Cosyn et al., 2011). This may contribute to reinfection of tissues at dental implants and pose a challenge when it comes to controlling bacterial colonisation.

Over-contoured implant prosthesis is also a critical local confounder for peri-implantitis (Yi et al., 2020). In such cases, adjustments of the prosthesis are warranted. If indicated, mechanical instrumentation and professional removal of the biofilm is also performed.

\section{Peri-implant tissues}

Anatomically, there are similarities between peri-implant and periodontal tissues. The keratinised epithelium attaches via hemidesmosomes in the junctional epithelium to the implant component (Welander et al., 2008). The firm keratinised mucosa that binds to the underlying bone acts as a barrier between the dental implant and the oral environment. After removing natural teeth, both soft tissues and the surrounding bone levels/contours 
are altered, and the dimension of the keratinised tissue is reduced. The importance of having a tight keratinised mucosa around dental implants has been noted (Schroeder et al., 1981, Lin et al., 2013, Giovannoli et al., 2019) but the significance of a firmly attached keratinised mucosa around dental implants is controversial. Implants that do not have keratinised mucosa show an increased mucosal recession and more attachment loss (Lin et al., 2013). Lack of keratinised tissue has also been associated with problems with toothbrushing, affecting daily oral hygiene (Souza et al., 2016). Soft tissues around dental implants and natural teeth have a keratinised oral epithelium and a junctional epithelium of about $2 \mathrm{~mm}$.

Collagen fibers in soft tissues around natural teeth are oriented in horizontal and vertical directions, partly originating from the supra-crestal bone and the root cementum. At implants, however, the collagen fibers originating at the level of the crestal bone are oriented parallel to the long axis of dental implants (Fig 1). Peri-implant mucosa contains more collagen fibers and fewer fibroblasts than soft tissues around natural teeth (Berglundh et al., 1991). It has also been reported that the blood supply to the soft tissues at dental implants is reduced compared to the blood supply at soft tissues around natural teeth (Berglundh et al., 1994).

The inflammatory cell response at implants diagnosed with peri-implantitis and teeth with periodontitis is similar (Berglundh et al., 2004, Berglundh \&

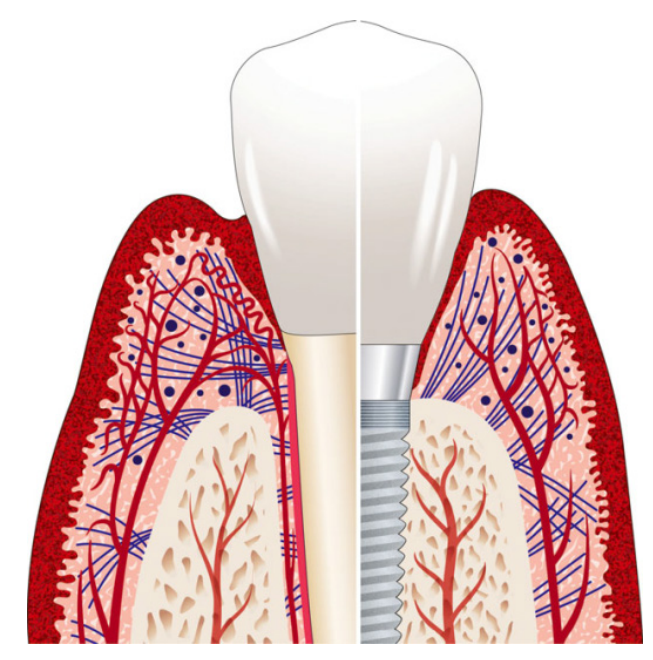

Fig. 1. Schematic illustration of healthy tissues around a tooth and an implant (Copyright; Renvert-Giovannoli Periimplantitis, Quintessence International, 2012 with permission). 
Donati, 2005, Pongnarisorn et al., 2007). The inflammatory bacterial lesion is initiated in the marginal part of the mucosa (Berglundh et al., 1992). If the microorganisms are not eliminated, the lesion progresses, and a white blood cell infiltrate can be observed in the soft tissue. However, tissue damage is more significant in the mucosa than in the gingiva. The gingiva's defense mechanism is more effective than in the mucosa around implants, and the progression is more extensive around implants and involves the marginal bone (Berglundh et al., 2004, Berglundh \& Donati, 2005). The peri-implant lesion progress apically and is not encapsulated by collagen fibers, unlike the periodontitis lesion (Lindhe et al.,1992) (Fig 2).

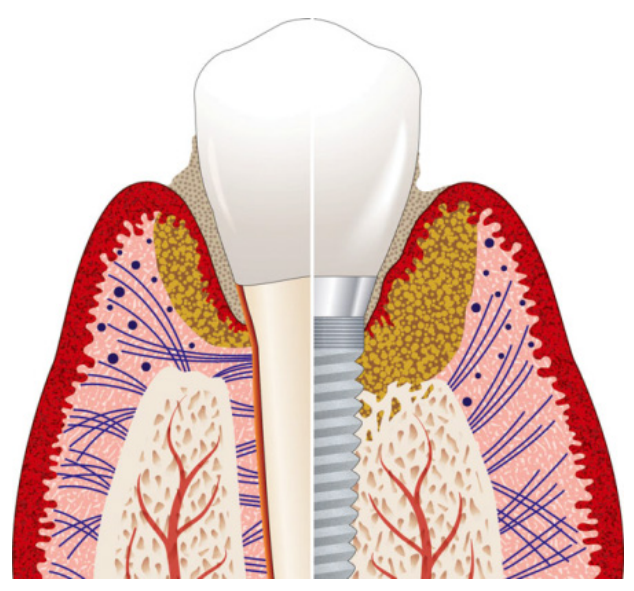

Fig. 2. Schematic illustration of a lesion at a tooth and an implant (Copyright; Renvert-Giovannoli Peri-implantitis, Quintessence International, 2012 with permission).

As around natural teeth, the inflammation and bone loss will eventually result in an increased probing depth (Ponteriero et al., 1994). Local conditions around implants may influence the load of the surrounding microbiota. Data from one follow-up study over, on average, 18 years suggest that bacterial presence and distributions at dental implants and teeth in individuals with healthy periodontal conditions are, in general, similar, but with the exception of higher levels of Prevotella intermedia, Porphyromonas gingivalis, and Tannerella forsythia with no evidence of peri-implant mucositis (Dierens et al., (2013). The pocket depth may influence the nature of the microbiome (Renvert et al., 2007). Consequently, the presence of deep pockets may represent a risk for disease development. 


\section{Implant surface structure}

Human and animal experimental studies have shown significantly more bone contact at dental implants with rough surfaces than at implants with turned surfaces (Lazzara et al., 1999). Various clinical methods developed to improve primary stability, osseointegration and to reduce early implant loss have been proposed (Jungner et al., 2014). Most modern implants have a medium rough surface structure aimed at increasing the bone-implant contact area thus increasing the amount and quality of osseointegration. The roughness of the implant surface has a significant effect on plaque accumulation. When the coronal part of implants is exposed to the oral environment, implants with rough surfaces facilitate plaque accumulation (Quirynen et al., 1993, Teughels et al., 2006). A study from 2012 showed no difference in bacteria around moderately rough surfaces and turned surfaces (Quirynen \& Van Assche, 2012). Implant surface characteristics do not seem to have a significant effect on the initiation of peri-implantitis (Renvert et al., 2012). In the presence of subgingival biofilm, a similar biological complication outcome has been demonstrated around both rough and turned surfaces (Jungner et al., 2014). In several animal studies dental implants with rough surfaces have been shown to lose more bone due to peri-implantitis than implants that have a turned surface (Albouy et al., 2008, 2011, Marrone et al., 2013) and may also respond less favourably to peri-implantitis therapy (Albouy et al., 2012, Carcuac et al., 2016).

\section{Excess cement}

Fixed prosthetic implant constructions are either cemented or screwretained at the implant level. The deeper the position of the margin, the greater amount of undetected cement was discovered (Lincevikius et al., 2013a). Implants with cement remnants in patients with a history of periodontitis were more likely to develop peri-implantitis than patients without a history of periodontal infection (Lincevikius et al., 2013b). The occurrence of fistula formations is also more common adjacent to cemented structures than at screw-retained implants (Wittneben et al., 2014). It is more common to see bone loss of $2 \mathrm{~mm}$ or more due to peri-implant disease around cemented prostheses than screw-retained ones (Sailer et al., 2012). Cemented supra-constructions show an odds ratio of 3.6 for more peri-implantitis than screw-retained constructions (Dalago et al., 2017).

Since excess cement is identified as a risk indicator for peri-implant disease, the cervical crown border is recommended to be at the same height as the marginal soft tissue, thus providing sufficient access to eliminate the excess and for patient self-hygiene (Staubli et al., 2017). 


\section{Surgical treatment of peri-implantitis}

Access to implant surfaces for non-surgical decontamination can be extremely challenging. The threads of the implant and the roughness of the surface make it difficult to remove the biofilm and the calcified deposits from the implant surface. Although a significant reduction on bleeding index can be achieved, probing pocket depths may not improve after non-surgical treatment of peri-implantitis (Renvert et al., 2008) and non-surgical therapies alone have generally been shown to be inadequate for treating moderate and severe forms of peri-implantitis (Barootchi et al., 2020). In advanced cases, complete resolution of the disease is not predictable and in cases demonstrating signs of remaining disease following an initial non-surgical treatment, surgical treatment should be considered. Before surgical intervention is initiated non-surgical treatment should, however, always be performed with the aim to achieve healthier peri-implant soft tissue conditions (Renvert \& Polyzois, 2018). Surgical methods used in the treatment of peri-implantitis include access flap and debridement, resective surgery (access flap and bone recontouring) and reconstructive surgery using different types of bone augmentation with or without the use of membranes to cover the augmented material.

\section{Open flap debridement}

The main purpose of a surgical intervention is to gain access to the implant surface, to remove inflamed tissue, to detoxify the implant surface and to obtain probing pocket depth reduction. For decontamination of the implant surface, hand instruments, rotary instruments, such as a titanium brush, or lasers have been used. Following mechanical treatment, the implant surface is often chemically cleaned with substances such as hydrogen peroxide, saline, citric acid, ethyl diamine tetra acetic or chlorhexidine gluconate. There are, however, limited clinical evidence that any of these substances are superior in detoxifying the implant surface (Claffey et al., 2008, Carral, 2016). Application of hydrogen peroxide for 2 minutes and then rinsing with saline is often used as chemical cleaning of the debrided implant surface. Although better access is obtained during surgical intervention data suggest that limited levels of radiographic evidence of bone level gain can be achieved (Hallström et al., 2017). Accordingly, even after open flap debridement the implant site often remains devoid of its original supporting bony structures. However, open flap debridement combined with antibiotics in cases of a limited extent of peri-implantitis demonstrated high effectiveness (Heitz-Mayfield et al., 2012). 


\section{Resective therapy}

Resective therapy during surgical treatment of peri-implantitis is employed when the clinician re-contours the bone edges and places the flap at an apical level compared to pre-surgery levels aiming to reduce the probing pocket depth. Another aim could be to facilitate the patient's daily oral hygiene. The aesthetic outcome after such surgery is, however, often dissatisfactory due to the gingival retraction following surgery. The position of the implant in the mouth therefore often determines the type of surgery that can be applied in peri-implant treatment. Resective surgery can be used in areas where aesthetics is not so crucial. The outcome of resective surgery of peri-implantitis is reported to be inadequate. Thus, one year following resective surgery in 100 patients and 179 implants, with or without the use of antibiotics, treatment success (probing pocket depth $\leq 5 \mathrm{~mm}$, absence of bleeding/suppuration on probing, and no additional bone loss) was obtained in $45 \%$ of all implants (Carcuac et al., 2016). After five years, 73 patients with 130 implants remained. During follow-up, 57 implants (44\%) displayed recurrence/progression of peri-implantitis. Among these, 27 implants were removed. The authors concluded that implants with (a) residual deep probing pocket depth, (b) reduced marginal bone level, or (c) modified surfaces following surgical therapy of peri-implantitis present with increased risk for recurrence/progression of disease. Peri-implantitis treatment was also reported to be unsuccessful in $57 \%$ of implants and $67 \%$ of patients 12 months following resective surgical treatment of periimplantitis (de Waal et al., 2016).

\section{Implantoplasty}

When resective therapy is employed, implant modification / implantoplasty is sometimes done to avoid exposed threads and a rough implant surface. Using this treatment method, Romeo et al. (2007) demonstrated that 50\% of treated patients did not demonstrate signs of peri-implant disease after two years. Recently, Englezos et al. (2018) published results from a 2-year follow-up of resective treatment of peri-implantitis, including an apically positioned flap, osteoplasty, and implantoplasty. All implants survived, probing pocket depth was reduced by $5,7 \mathrm{~mm}$, and bone level remained stable in $92.5 \%$ of the implants. This suggests that an apically positioned flap combined with osteoplasty and implantoplasty may be an effective strategy against peri-implantitis. Implantoplasty, however, reduces the flexural strength of especially narrow implants. When making the decision 
whether or not to perform implantoplasty it is important to consider that narrow implants and implants that are more exposed to chewing forces may run an increased risk for fractures following implantoplasty (Ramel et al., 2016).

\section{Reconstructive therapy}

In the treatment of peri-implantitis where the morphology of the bone defect is crater shaped or with a 3-wall bone defect design, reconstructive therapy is often the preferred treatment option. Reconstructive surgical treatment of peri-implantitis aims to rebuild lost bone support around implants using for example the addition of a bone graft/bone substitute, an enamel matrix protein, with or without the use of membranes. In the presence of 1- or 2-wall bone defects, the remaining bone walls may not allow the graft material to remain in the defect during the healing period. Therefore, a membrane is often used. The effect of an augmentation material in combination with a membrane has also been studied. The use of membranes, however, does not appear to improve the healing (RoosJansåker et al., 2007a, Schwarz et al., 2006. The exposure of membranes is a common complication (Roos-Jansåker et al., 2007a, Schwarz et al., 2006).

\section{Enamel matrix derivative (EMD)}

EMD is an enamel matrix protein-derived gel product containing amelogenins. When using EMDs as an adjunct to surgical treatment of periodontitis accelerated wound healing and periodontal regeneration has been reported (Esposito et al., 2009). Few studies have reported on the adjunct use of EMD in the treatment of peri-implantitis. One year after treatment, minor improvements of bone levels $(0,9 \mathrm{~mm})$ have been reported (Isehed et al., 2016). At the 5-year follow-up no difference in bone level gain between EMD-treated defects and controls were found (Isehed et al., 2018).

\section{Augmentation materials and techniques}

Bone augmentation has become a common treatment in the attempt to increase deficient bone volume, for example after resorption of an edentulous ridge, fill of an alveolar socket following tooth extraction, in conjunction with implant placement, during periodontal surgery and in peri-implant bone defects. 
Bone augmentation materials can, according to Kolk et al. (2012), be classified as:

- $\quad$ Autograft (Autogenous graft): Bone taken from one place in the patient and transferred to another place in the same individual.

- Allograft: Bone taken from another living person or from a cadaver i.e. bone from the same species but a different genetic setup.

- Xenograft: The graft is taken from another species.

- Alloplastic: Synthetically produced bone substitute material, for example calcium phosphate-based ceramics or tricalcium phosphate.

The transplant used can also be classified according to its bone augmentation process.

- Osteogenic: The transplant contains viable cells.

- Osteo-inductive: The material stimulates mesenchymal cells to differentiate into osteoblasts.

- Osteo-conductive: The transplant acts as a frame that allows osteoblasts from the wound margin to infiltrate the defect.

To receive successful treatment after bone grafting, the following conditions are required:

1) osteoblasts are present in the area where the material is transplanted,

2) there is sufficient blood circulation in the area,

3) the graft must be stable during the healing time and

4) there should be no tension in the soft tissue covering the graft.

\section{Non-submerged techniques}

Short-term clinical improvements following reconstructive therapy using different bone augmentation materials have been reported (Roos-Jansåker et al., 2007a, Aghazadeh et al., 2012, Jepsen et al., 2016, Roccuzzo et al., 2016, La Monaca et al., 2018, Renvert et al., 2018 b, Clem \& Gunsolley, 2019). In a 5-year follow-up of reconstructive therapy of peri-implantitis lesions using mineralised dehydrated bone allograft and a resorbable membrane a 100\% success rate (absence of additional marginal periimplant bone loss $\geq 1.0 \mathrm{~mm}$ absence of probing depth $\geq 5 \mathrm{~mm}$, and absence 
of bleeding on probing /suppuration) was reported after one year. The success rate was reduced over time and at 5 years $57 \%$ was reported to be successfully treated. It should, however, be highlighted that the authors allowed bone loss of up to $1 \mathrm{~mm}$ in their definition of success which differs from many other reports. At 5 years only BOP reduction was statistically significant compared to baseline $(\mathrm{p}<0.001)$, and no difference was found in PPD and in marginal peri-implant bone level (La Monaca et al., 2018).

In a meta-analysis of treatment outcome for surgical management of peri-implantitis, 1306 studies were initially identified, 12 of them were included in the final meta-analysis. The conclusion of that study was that the application of grafting materials and barrier membranes resulted in greater PPD reduction and radiographic bone fill (Chan et al., 2014). Another recent systemic review on the effectiveness of surgical regenerative treatment for peri-implantitis reported the highest mean reduction of PPD in a group treated with a xenograft. There is, however, a lack of scientific evidence regarding the type of bone material that is superior when it comes to the treatment of peri-implantitis defects (Aljohani et al., 2020).

\section{Submerged technique}

Allowing the implant to heal under the mucosa without any disturbance may be an advantage when trying to reconstruct peri-implantitis intraosseous defects and favourable healing results following use of a submerged surgical method has been demonstrated in an animal model where implants in the submerged group achieved better outcomes and demonstrated greater potential for re-osseointegration (Schwarz et al., 2006). The implant crown has to be removed but this may not always be possible. If the implant is submerged following the procedure the suprastructure may not be used during the healing phase and some suprastructures are cemented and cannot be removed. Submerged healing in humans was reported by Roos-Jansåker et al. (2007b). Bone level changes was assessed after submerged healing of Brånemark implant in 12 patients with peri-implantitis. A mean defect fill of $2.3 \mathrm{~mm}$ was reported. This study was performed in a similar way as a previous study in which the implants were not submerged. The defect fill in the non-submerged study amounted to 1.5 and $1.4 \mathrm{~mm}$, respectively (Roos-Jansåker et al., 2007a). The authors concluded that the undisturbed wound healing obtained by a submerged approach may have led to the differences in treatment outcomes. 


\section{The effect of defect morphology on healing following therapy of peri-implantitis}

Peri-implantitis is an inflammatory disease resulting in bone loss around dental implants. Partly depending on the morphology of the alveolar process, bone loss may occur in the form of intraosseous defects. Such defects may have different anatomical configurations (Figure 3).
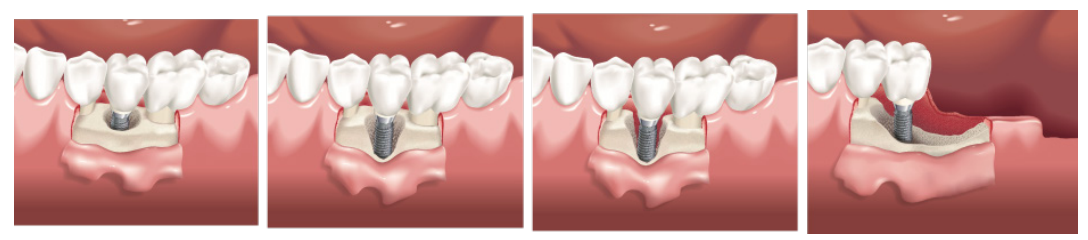

Fig. 3. Schematic illustration of different intraosseous lesions at a single implant. From left to right: 4-wall or circumferential defect, 3-wall defect, 2-wall defect and 1-wall defect (Copyright; Renvert-Giovannoli Periimplantitis, Quintessence International, 2012 with permission).

Successful outcome after surgical treatment of peri-implantitis has been related to the morphology of the bone defect. Circumferential or 4-wall bony defects have been reported to demonstrate more bone fill after therapy than other types of defects (Schwarz et al., 2010). Circumferential periimplant bone defects also demonstrated more significant pocket depth changes and clinical attachment level gain after 6-12 months compared with other types of bone defects (Schwarz et al., 2010). Accordingly, the morphology of the bone defect is a factor to consider when choosing between reconstructive and resective surgical procedures.

It has been shown that the buccolingual width of the alveolar bone crest is related to the type of bone defects in peri-implantitis cases. For example, the likelihood that a 4-wall or circular bone defect will develop was found to be related to the width of the alveolar crest (Aghazadeh et al., 2020). The incidence of circumferential bone defects has been reported as being as high as $55 \%$ (Schwarz et al., 2007). The percentages of circumferential defects may be dependent on where in the oral cavity the implant is placed As an example, circumferential defects are less common in the anterior front area.

A recent publication could not verify that lack of keratinised mucosa affected bone defect morphology. However, in the same study, the researchers demonstrated that age and smoking habits were associated with 
the morphology of the defects and that smoking habits, type of prosthesis and distance to adjacent implants were associated with the severity of the defects (Monje et al., 2019).

\section{Long-term results of reconstructive peri-implantitis therapy}

The scientific evidence of long-term treatment outcomes following different treatment modalities is limited. However, in recent years a few studies with at least a 5-year follow-up have reported their results. Roos-Jansåker et al. (2014) carried out a 5-year follow-up of a RCT evaluating the adjunctive use of a resorbable membrane with or without a bone fill. Over the 5-year follow-up no implants were lost due to progression of peri-implantitis. In both treatment groups, radiographic evidence of defect fill was reported. At year 5, the average defect fill was $1.3 \mathrm{~mm}$ in the group treated with a combination of bone augmentation, and a collagen membrane and $1.1 \mathrm{~mm}$ in the group treated with a bone graft alone. Basically, the average defect fill reported at year 1 was maintained until the 5-year examination. In a recent 7-year follow-up on 15 patients treated with a combined resective and regenerative approach clinically stable PD and a BOP reduction was reported (Schwarz et al., 2017). In another 7-year follow-up study of reconstructive treatment of peri-implantitis using porous titanium granules as graft material 12 out of the original 32 patients (6 in each group) were available at the 7-year follow-up (Andersen et al., 2017). The radiographic defect depth changes were comparable to the results after one year with no difference when compared to the open flap debridement group. Similar results have been reported by Isehed et al. (2018), who investigated the efficacy of EMD to treat peri-implantitis. At the 5-year follow-up of EMD treatment, only 14 out of 29 patients remained for analysis. No statistically significant difference was found between test (OFD + EMD) and control (OFD).

A tendency to relapse following reconstructive treatment of peri-implant defects has, however, also been reported. The $91 \%$ of implants assessed as successfully treated at year 1 dropped to $59 \%$ at the 5-year evaluation (La Monaca et al., 2018). In a recent study evaluating the 10 -year outcomes of a regenerative surgical treatment using deproteinised bovine bone mineral with $10 \%$ collagen, 14 out of 26 patients ( 8 sandblasted and acidetched (SLA) and 6 titanium plasma-sprayed (TPS) were re-examined (Roccuzzo et al., 2020). The implant survival rate was $80 \%$ for the SLA, and $55 \%$ for the TPS implants. Treatment success was reported in 5 of the 
SLA and in 4 of the TPS treated implants demonstrating the difficulties in maintaining initial short-term results. So, even if evidence from RoosJansåker et al. (2014), and Heitz-Mayfield et al. (2018) highlight that it is possible to maintain good treatment outcomes following peri-implantitis therapy for at least five years, it should be noted that available long-term data is often based on a limited number of individuals and that individuals lost to follow-up may have had a less favourable treatment outcome. 


\section{RATIONALE FOR THE STUDIES}

Peri-implantitis is a biological complication that may occur around dental implants that have replaced missed natural teeth.

The incidence of peri-implantitis at the patient level is reported to be high (Derks \& Tomasi, 2015). Some individuals are more prone to develop peri-implantitis than others. It is, therefore, necessary to assess risk factors for the development of peri-implantitis. Peri-implantitis is caused by microorganisms initiating an inflammatory response resulting in alveolar bone loss (Berglund et al., 2018). The bone loss can be horizontal or vertical in shape, or a combination of the two. In cases with vertical bone destructions, so-called intraosseous defects occur. To treat peri-implantitis, both non-surgical and surgical treatment modalities have been used. It is difficult to remove bacterial colonisation due to treaded and often rough structure of dental implants. The rough surface structure may be one reason why the non-surgical treatment of peri-implantitis is ineffective (Renvert et al., 2008). Therefore, different surgical treatment strategies have been used to improve access to the implant surface and, thus, more efficiently clean the implant surface (Carcuac et al., 2016, Hallström et al., 2017, Renvert et al., 2018b). Accordingly, there is a need to evaluate surgical techniques to treat peri-implant bony defects and assess their long-term efficacy. It is also essential to evaluate what type of intraosseous lesions are most suitable for a reconstructive surgical intervention. Categorising the intraosseous lesions is essential. Using a reconstructive approach involves additional surgical trauma when obtaining a bone graft from the patient or adding additional costs by using a commercially available product.

Increased knowledge is needed for both risk assessments and treatment of peri-implantitis in order to improve health at the individual level and thereby reduce patient and societal costs. 


\section{AIMS}

The series of studies presented below aimed to;

- $\quad$ assess risk factors for the development of peri-implantitis

- $\quad$ assess clinical and radiographical short- and long-term treatment outcomes after reconstructive surgical treatment of intrabony peri-implantitis

- $\quad$ evaluate the impact of defect configuration on the healing results 


\section{MATERIAL AND METHODS}

The Regional Ethics Committee in Lund, Sweden, approved the studies I, III, IV (ID nr 89/2007 and $108 / 2007$ ). The studies were performed at the Oral Surgery Clinic in Uppsala during the period 2007-2013.

The study participants in studies I, II, and IV were recruited from individuals diagnosed with peri-implantitis at Uppsala Oral Surgery Clinic or from patients referred to this clinic for treatment of peri-implantitis.

The retrospective clinical study II was based on material and data collected between 2007 and 2011 at the University of Kristianstad, Sweden (Centre 1), at the Specialty Clinic for Periodontology, Region Halland, Halmstad, Sweden (Centre 2), and at the Uppsala Käkkirurgiska Centrum, Uppsala, Sweden (Centre 3).

The Regional Ethics Review Board at Lund University, Sweden, approved the protocols for the studies performed at these three clinical centres (LU 182-01, LU 183-01, Dnr 550/2006, Dnr 89/2007, Dnr 615/2007, Dnr 233/2007). All enrolled subjects gave their written consent.

\section{Case definition}

Peri-implantitis was defined as an osseointegrated implant with loss of bone $\geq 2.0 \mathrm{~mm}$ assessed from the implant platform level (IPL) to the most apical level of bone-to-implant contact as defined by digital intra-oral radiographs. In addition, BOP, or SUP from at least one implant surface area, and probing pocket depth (PPD) $\geq 4 \mathrm{~mm}$ had to be present. 
Subjects included in papers I, III and IV with a diagnosis of peri-implantitis were included if they presented with;

(I) a minimum of 1 osseointegrated implant with radiographic evidence of bone loss $\geq 2 \mathrm{~mm}$, when comparing radiographs taken at the time of screening with radiographs taken at the time of placement of the implant suprastructure

(II) probing pocket depth $\geq 5 \mathrm{~mm}$ combined with BOP/suppuration on probing

(III) an angular peri-implant bone defect $(\geq 3 \mathrm{~mm}$ in depth as determined from intra-oral digital radiographs)

(IV) In studies III and IV, only cases with clinical evidence of 2-, 3-, or 4-wall defects at the time of surgical intervention were included

Before study enrolment, study individuals received periodontal therapy such that no periodontal pockets $>5 \mathrm{~mm}$ remained at existing teeth and that the oral hygiene was under control.

The population in studies I, III and IV included 45 patients with 75 implants diagnosed with peri-implantitis, surgically treated during 2007-2011 at Uppsala Oral Surgery Centre, Sweden.

In study II, 172 individuals diagnosed with peri-implantitis, and 98 individuals diagnosed with implant health or peri-implant mucositis were included. Implant health was defined as no bleeding, or only bleeding at one surface, no suppuration, and bone loss $<2.0 \mathrm{~mm}$.

Peri-implant mucositis was defined for implants with bone loss $<2.0 \mathrm{~mm}$ but with clinical evidence of overt BOP, tissue oedema, and or suppuration.

Studies I, III, IV were based on a single-blinded human prospective randomised clinical trial.

Study II was a retrospective study.

\section{Study intervention}

\section{Study I}

Surgical intervention for study purposes was performed when good patient motivation and compliance were identified. Following administration of local anaesthetics, a sulcular incision was made around the neck of the implant abutments. Full-thickness flaps were raised to access the peri- 
implant defects. Granulomatous tissue was removed, and the threads were carefully cleaned from mineralised calculus. The implant surface was cleaned with $3 \%$ hydrogen peroxide followed by rinsing with saline. The baseline assessments of defect characteristics were measured. Assignment to test and control group was made using pre-prepared randomisation in groups A or B. Cards with group identification were prepared and placed in number-coded envelopes. Following surgical entry and debridement of implants, the envelope with the code was opened, and the subject was treated with bone/bone substitute material as assigned by the code instruction. Depending on the assigned treatment, the defect was either filled with the patient's bone obtained using a bone scraper or Bio-Oss ${ }^{\circledR}$ (Geistlich Pharma, Wolhusen, Switzerland). A resorbable membrane (OsseoGuard®; Biomet3I Inc., Palm Beach, FL, USA) was used to cover the bone or bone substitute, and the flaps were sutured using 4.0 sutures.

\section{Study II}

Data on PPD, BOP, and radiographic bone levels were obtained from individuals with dental implants. Control individuals were either diagnosed as peri-implant healthy or with peri-implant mucositis. In addition, information on the history of periodontitis, systemic diseases, and smoking habits was obtained.

\section{Study III}

Following the administration of local anaesthetics, a sulcular incision was made around the neck of the implant abutments, and full-thickness flaps were raised at the buccal and lingual surfaces to access peri-implant defects. After removing the granulomatous tissues and carefully cleaning the implants from mineralised calculus, the implant surfaces were chemically cleaned with hydrogen peroxide (3\%) followed by rinsing with saline. Assessments of defect characteristics were performed, including the extent of bone loss/vertical defects from the implant platform to the most apical bone defect. The extent of bone loss/vertical defects from the implant platform to the most apical bone defect and the distance from the implant platform to the most coronal part of the bone was measured (in millimetres) at the mesial, buccal, distal, and lingual surfaces around the implant. In addition, the number of bone walls was assessed. These measurements were used to calculate the defect depth and classify the defect as a 2-, 3-, or 4-wall defects. 


\section{Study IV}

Individuals included in Study I were given maintenance therapy every third month for an additional four years following the examination one year after therapy. Successful treatment outcome (no bone loss, no PPD > $5 \mathrm{~mm}$, no suppuration, no or one implant surface with evidence BOP was allowed) was used as the primary outcome. Clinical measurements and dental radiographs were obtained at 3 and 5 years.

\section{Outcome parameters and analyses}

\section{Clinical data}

In studies, I, III, IV presence/absence of peri-implant soft tissue hyperplasia, full mouth plaque score, local plaque score, PPD, BOP, SUP and MR were assessed. A complete set of intraoral radiographs was obtained at baseline unless recent radiographs taken within the last three months were available. Standardised intra-oral radiographs were obtained using an Eggen holder and long cone equipped dental X-ray unit. Pre- and postoperative radiographs showing the study implants were digitalised, coded and evaluated using a computer program (OsiriX Imaging software 3.9 for MAC OS 10.6, Osirix Foundation, Geneva, Switzerland). The mesial and distal distances from the implant platform to the bottom of the defect were measured on radiographs taken at baseline, 12, and 60 months. One calibrated examiner who was masked to study allocation assessed all radiographs. The most coronal confluent aggregation of bone or bonelike material was used to define the marginal bone level. Single strands or islets of bone or bone-like material were not considered. Radiographs/ measurements were calibrated based on the known distance between implant threads (Figure 4).

In Study II, data on PPD, BOP, and radiographic bone levels were obtained from individuals with dental implants. Radiographs were assessed as described above. Peri-implantitis was defined as described by Sanz et al. (2012). Control individuals had healthy conditions or peri-implant mucositis. In addition, information on a past history of periodontitis, systemic diseases, and smoking habits was obtained. 


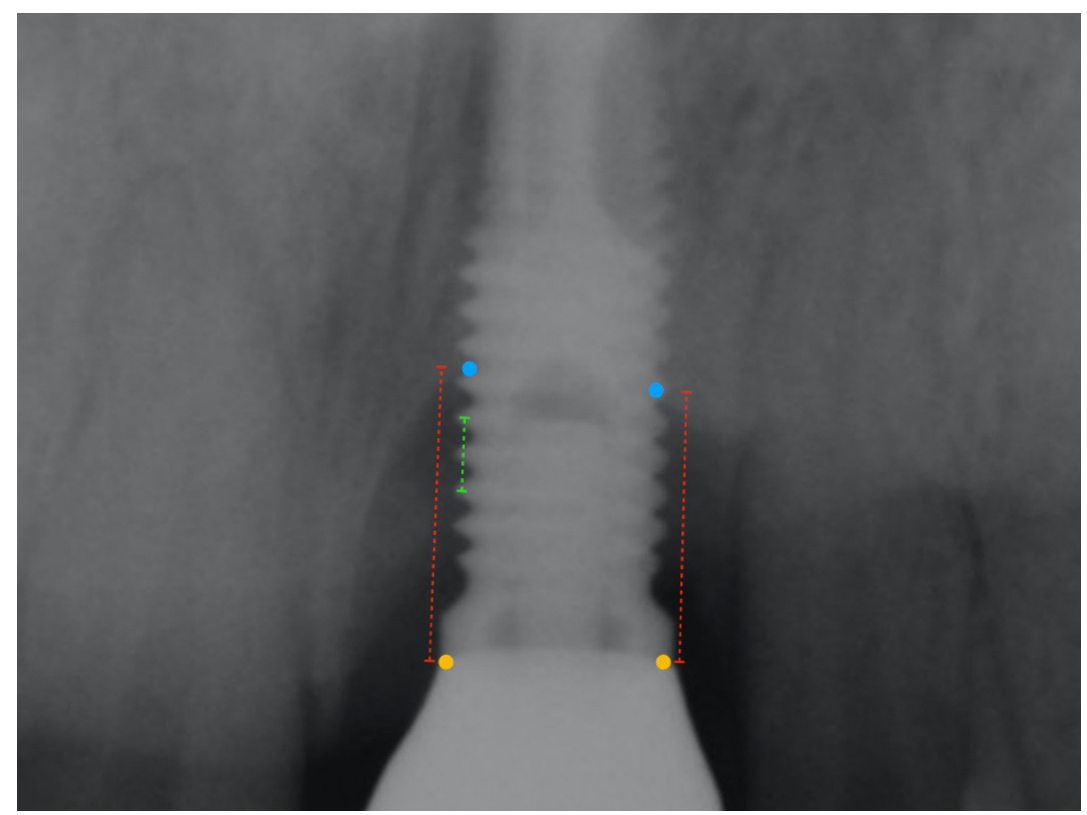

Figure 4. Illustration of the measurements on radiographs. The yellow points represent the implant-abutment junction, and the blue points the most coronal bone-to-implant contact. The red dotted lines represent the distance from the implant platform to the bottom of the defect. The green dotted line represents the distance between three threads, used for calibration. 


\section{RESULTS}

\section{Study I}

Twenty-two subjects were included in the $\mathrm{AB}$ group and 23 subjects in the BDX group. Statistical analysis failed to demonstrate differences for $38 / 39$ variables assessed at baseline. Analysis by paired t-test identified a $0.1 \mathrm{~mm}(\mathrm{SD} \pm 0.4)$ bone level change difference between the two sets of measurements on the radiographs $(95 \% \mathrm{CI}: 0.2$ to $0.1, \mathrm{p}=0.36)$. The intraclass correlation coefficient was 0.97 (95\% CI: 0.95 to $0.99, \mathrm{p}<0.001$ ).

At 12 months, adjusting for the number of implants, significantly better improvements were obtained in the BDX group for defect fill $(\mathrm{p}<0.01)$, PPD reduction $(\mathrm{p}<0.01$, and suppuration $(\mathrm{p}<0.01)$ (Table 1$)$.

\begin{tabular}{|l|l|l|l|l|}
\hline Variables & Mean & SE & $95 \% \mathrm{CI}$ & Sign. \\
\hline Defect fill & 0.8 & 0.4 & $0.1-1.7$ & 0.05 \\
\hline PPD decrease & 1.1 & 0.3 & $0.5-1.7$ & 0.01 \\
\hline$\%$ BOP change & 3.3 & 19.7 & $-24.3-18.0$ & NS \\
\hline \% PI change & 3.4 & 6.2 & $-9.0-15.9$ & NS \\
\hline SUP reduction & 16.3 & 6.5 & $3.4-20.2$ & 0.01 \\
\hline
\end{tabular}

Table 1. Mean changes in BOP, PI, suppuration, PPD and bone level change (adjusted for the number of implants per subject in the study) between treatment groups.

Also, when adjusting for the number of implants treated per subject, successful treatment outcome ( $\mathrm{PD} \leq 5.0 \mathrm{~mm}$ ), no pus, no bone loss and BOP at 1/out of 4 or fewer sites and gain or no loss of bone), the likelihood of defect fill was higher in the BDX group (LR: 3.2, 95\% CI: 1.0-10.6, $\mathrm{p}<0.05$ ). 


\section{Study II}

One hundred and seventy-two individuals had peri-implantitis (mean age: 68.2 years, $\mathrm{SD} \pm 8.7$ ), and 98 individuals (mean age: 44.7 years, $\mathrm{SD} \pm 15.9$ ) had implant health/peri-implant mucositis. Implants classified as healthy were defined as those with no bleeding, or only bleeding at one surface, no suppuration, and bone loss $<2.0 \mathrm{~mm}$. Peri-implant mucositis was defined for implants with bone loss $<2.0 \mathrm{~mm}$ but with clinical evidence of overt BOP, tissue oedema, and/or suppuration.

The mean PPD at implants with peri-implantitis were $5.5 \mathrm{~mm}$ compared to $4.2 \mathrm{~mm}$ at implants characterised as healthy or with peri-implant mucositis with a mean difference of $1.2 \mathrm{~mm}$ (SE $0.2 \mathrm{~mm}, 95 \% \mathrm{CI}$ : 3.1, $3.9, \mathrm{P}<0.001)$, P-value $=0.001)$. The mean difference in bone levels at implants between groups was $3.5 \mathrm{~mm}$ (SE mean 0.4, 95\% CI: 2.8, 4.3, $\mathrm{P}<0.001)$.

Implant bone levels related to a history of periodontitis, general diseases, and smoking status. When adjusting for age, smoking, and gender, the OR of having implants diagnosed with peri-implantitis and history of periodontitis was 4.5 (95\% CI 2.1, 9.7, $\mathrm{P}<0.001)$.

A history of cardiovascular disease was found in $27.3 \%$ of individuals with peri-implantitis and $3.0 \%$ in the implant health/peri-implant mucositis group. When adjusting for age, smoking, and gender, OR of having periimplantitis and a history of cardiovascular disease was 8.7 (95\% CI: 1.9, $40.3 \mathrm{P}<0.006)$. Smoking, DM or gender did not significantly contribute to the outcome.

\section{Study III}

A total of 74 dental implants diagnosed with peri-implantitis with bone lesions involving two or more bone walls were included. No baseline differences between treatment groups were found regarding the distribution of defect configuration, PPD at implants, distances to adjacent teeth/ implants, defect depth or if attached/non-attached mucosa was not present. Most study implants $(70.7 \%, \mathrm{n}=53)$ had been placed in the maxilla. Few implants were placed in molar regions. The mesial and distal crestal width at surgery was greater at 4 -wall defects than at 2 -wall defects $(\mathrm{p}<0.001)$. In addition, the defect depth was more significant at 4 -wall defects both at buccal and lingual aspects than at 2-wall defects (mean diff: $1.5 \mathrm{~mm}, \mathrm{p}$ $<0.001$, and mean diff: $1.8, \mathrm{p}=0.002$ ). 
Probing depths were also greater at 4-wall defects than at 2-wall defects $(\mathrm{p}<0.01)$. In addition, defect fill was correlated to initial defect depth ( $p$ $<0.001)$. There was no difference in changes in the proportions of implants with BOP or the presence of plaque related to defect classification. Statistical analyses could not confirm that changes in defect fill were correlated with changes in BOP, changes in plaque scores, or changes in PPD.

When treatment groups were merged, the analysis identified radiographic evidence of defect fill at 4-wall defects (mean diff: $1.2 \mathrm{~mm}, \mathrm{p}=0.05$ ). Over time, probing depth reductions (mean diff: 2.4, $\mathrm{p}<0.001$ ), and BOP \% reductions were also significant (mean diff: 34.6, $\mathrm{p}<0.01$ ).

\section{Study IV}

At baseline, no difference in clinical measurements between study groups was identified. Eleven implants were lost to follow-up in the AB group leaving 16 patients and 25 implants for analysis at year 5 . The reduction in BOP and PPD between baseline and year 1 and between baseline and year 5 was significant, but no significant improvements occurred for plaque scores or bone level changes over time in the AB group.

In the BDX group at year 5, all 23 patients with 37 implants remained. The improvements at implants of BOP, PPD and bone defect depth (assessed radiographically) in the $\mathrm{BDX}$ group were significant between baseline and year 1 and between baseline and year $5(\mathrm{p}<0.001)$. In contrast, plaque level scores improved only between baseline and year 1 , with no difference between baseline and year 5 .

The changes in BOP and PI over time did not differ between study groups. However, the PPD reductions were more significant in the AB group (approximately $0.5 \mathrm{~mm}$ difference at 1 and 5 years). Bone defect fill was more significant in the BDX group at 1 and 5 years.

BOP and PPD were reduced between baseline and year $5(\mathrm{p}<0.001)$. A successful treatment outcome was observed in $16 \%$ of implants in the AB group and $43 \%$ in the BDX group. There was a 3.1 (95\% CI 1.2, 8.4, $\mathrm{p}<0.02$ ) likelihood of achieving a better result for implant treatment in the BDX group. 


\section{DISCUSSION}

In Study II, we identified a high probability of comorbidity expressed as a history of periodontitis. In previous studies, periodontitis has been associated with a higher prevalence of peri-implantitis compared to patients with no evidence of periodontitis (Karoussis et al., 2003, Roos-Jansåker et al., 2006c, Renvert \& Persson 2009, Simonis et al., 2010, Roccuzzo et al. 2012, 2014, Derks et al., 2016). Recent reviews also concluded that a past history or presence of periodontitis were risk factors for peri-implantitis (Dreyer et al., 2018, Schwarz et al., 2018). In addition, other studies have shown that residual pockets following periodontal treatment are a risk of developing peri-implantitis (Cho-Yan Lee et al., 2012, Pjetursson et al., 2012). In Study II, we also found that a history of cardiovascular disease was associated with peri-implantitis. Many individuals referred for periimplantitis have some systemic disease, and the incidence of CVD in the group with peri-implantitis was high (26\%) (Saaby et al., 2016). Froum et al. (2018) reported that 48 of 100 patients treated for peri-implantitis had a history of hypertension. In a recent retrospective analysis, $59 \%$ of the patients with peri-implantitis were also diagnosed with hypertension (Andersson et al., 2020). Available data on the association between periimplantitis and CVD are minimal. It is therefore not easy to draw any firm conclusions. However, the data reported in Study II are in line with several studies demonstrating that periodontitis is associated with cardiovascular disease (Sanz et al., 2020).

Ferreira et al., (2006) and Daubert et al., (2015) reported an association between peri-implantitis and DM. In Study II, we also demonstrated an association between peri-implantitis and DM in a univariable analysis but failed to find a significant odds ratio using a multi-level analysis. A history of smoking has also been associated with an elevated risk of peri- 
implantitis in some studies (Ferreira et al., 2006; Roos-Jansåker et al., 2006 a,b, Rinke et al., 2011) whereas others have not found such an association( Koldsland et al., 2010,2011, Marrone et al., (2012). In Study II a significant association between smoking and peri-implantitis was observed in an unadjusted analysis but not in an adjusted analysis, which is in line with a study by Derks et al. (2016). In a recent review it was concluded that data identifying smoking and diabetes as potential risk factor/indicator for peri-implantitis are inconclusive (Schwarz et al., 2018).

In studies 1 and 4, we assessed the outcome of reconstructive treatment of peri-implantitis both in the short and long term. The short-term outcome using an autologous bone graft as an adjunct to reconstructive treatment resulted in limited defect fill. Previous reports by Behneke et al. (2000) and Khoury \& Buchmann (2001) found considerable defect fill using autologous bone. In the study by Behneke et al. (2000), bone blocks stabilised with mini-screws instead of bone chips obtained by a bone scraper were used. A bone block may not be resorbed as quickly as a granulated graft, accounting for the differences in results reported. The differences compared to the results reported by Khoury \& Buchmann (2001) may depend, at least partly, on differences in the post-operative healing, and submerged versus non-submerged healing. Other studies have shown that better results have been reported using a submerged healing model (Roos-Jansåker et al., 2007 b) as compared to using a nonsubmerged model Roos-Jansåker et al. (2007a).

In Study I, the use of BDX as an augmentation material resulted in a mean defect fill of $1.1 \mathrm{~mm}$. This amount of defect fill is somewhat lower, but in the range of what was reported using a bone augmentation material harvested from ocean algae (Algiporeß)(Roos-Jansaåker et al., 2007 a). The defect fill in Study I was also lower than what was reported in a recent multi-centre study using deproteinised bovine bone mineral (Renvert et al., 2021). In the study by Renvert et al. (2021), the mean radiographic defect fill was $2.3 \mathrm{~mm}$ in the group treated with a combination of BDX and a native bilayer collagen membrane. It should, however, be pointed out that only 3-and 4-wall defects were included in this study (Renvert et al., 2021). Defect anatomy may be a critical factor defining the outcome of reconstructive procedures (Roccuzzo et al., 2016). It has previously been reported that defect fill is related to defect configuration, suggesting that treatment of circumferential defects will result in more defect fill (Schwarz et al., 2010). In Study III, one aim was to assess if the alveolar bone defect 
configuration was related to the outcome of surgical intervention of periimplantitis. The results demonstrated that 4-wall defects healed better and that more profound defects also resulted in more defect fill (Aghazadeh et al., 2020). The limitation to 3- and 4-wall defects as in the paper by Renvert et al. (2021) may at least partly explain the differences in result between the study by Renvert et al. (2021) and Study IV. However, in another recently published clinical trial (Renvert et al., 2018), also using a bovine-derived xenograft $\left(\right.$ Endobon $\left.^{\circledR}\right)$, the radiographic defect fill was lower $(0.7 \pm 0.9$ $\mathrm{mm}$ ) than what was reported in Study I despite that only 3- and 4-wall defects were included. In the study by Renvert et al. (2018), however, no membrane was used to cover the augmentation material, and it could be challenging to keep the graft material in place in the non-contained defects. The use of membranes has also been reported to be related to post-surgical complications (membrane exposure and infections) (Heitz-Mayfield et al., 2014). No such complications were, however, observed in Study I.

It should be highlighted that the value of radiographs to evaluate and describe defect fill has limitations. Defect fill assessed on dental radiographs is limited to describing defect fill and not integrated bone fill.

Several definitions of successful treatment outcomes have been employed (Aghazadeh et al., 2012, Heitz-Mayfield et al., 2014, Roccuzzo et al., 2017, Isler et al., 2018, Mercado et al., 2018, Renvert et al., 2018), many using the absence of bone loss, PPD $\leq 5 \mathrm{~mm}$ at the implant sites, no or limited BOP, and absence of SUP. For example, the success rate obtained after one year in Study I was 20,5\% but increased to 38,5 \% in the BDX group if BOP at one implant surface was accepted. A success rate of $35 \%$ was reported in the study by Renvert et al. (2021). Other studies employing a reconstructive approach of peri-implant defects have demonstrated higher success rates (Isler et al., 2018. Roccuzzo et al., 2017). Different definitions of successful treatment outcome have been used making comparisons between studies difficult. If a reconstructive approach is used it may be reasonable to require a defect fill of at least $\geq 1 \mathrm{~mm}$ and absence of suppuration, no BOP, and no residual PPD $\mathrm{s} \geq 5 \mathrm{~mm}$ at all four sites to define the therapy as successful (Renvert et al., 2018) whereas la Monaca et al. (2018), also evaluating a reconstructive treatment approach, allowed a bone loss of $1 \mathrm{~mm}$ and still considered the treatment result as a successful outcome.

At the 5-year follow-up reported in Study IV, a successful treatment (no bone loss, no PPD $>5 \mathrm{~mm}$, no SUP, maximum one implant surface with 
evidence of BOP allowed) was observed in $16 \%$ of implants in the $A B$ group, and $43 \%$ of implants in the BDX group. The likelihood ratio of a better result in the BDX group was 3.1 (95\% CI 1.2, 8.4, $\mathrm{p}<0.02)$. These findings are in agreement with previously published studies (Roos-Jansåker et al., 2014, Roccuzzo et al., 2017, Heitz-Mayfield et al., 2018). It is also interesting to note that the success rates using a similar definition in Study I and Study IV demonstrated that the achieved treatment results could be maintained over time. It should, however, be noted that the patients attended a three-month recall program during the five years. Regular supportive care is essential to retain and secure the results following treatment of peri-implantitis (Serino et al., 2015, Heitz-Mayfield et al., 2018, Roccuzzo et al., 2018)

The use of bone augmentation materials in peri-implant defects (Studies I and IV) resulted in radiographic evidence of bone defect fill consistent with recent literature reviews (Daugela et al., 2016; Khoshkam et al., 2016). Both Study I and Study IV demonstrated a higher degree of successful treatment outcome using BDX as an augmentation material as compared to adjunct treatment with AB. In addition, the results from Study IV are also consistent with the results from another long-term follow-up study following bone augmentation of peri-implant defects (Froum et al., 2012). It should, however, also be pointed out that the results from Study I and Study IV are consistent with studies using a bovine bone-derived augmentation material, suggesting that complete defect fill may not be possible (Roccuzzo et al., 2011; Sahrmann et al., 2011). 


\section{CONCLUSIONS}

- A history of periodontitis and cardiovascular disease was associated with a risk of peri-implantitis with age as a contributory factor.

- The success of both reconstructive surgical procedures $(\mathrm{AB}$ and BDX) was limited.

- The use of BDX has a higher likelihood of successful clinical outcomes than the use of autogenous bone.

- The buccal-lingual width of the alveolar bone crest was explanatory to defect configuration.

- Four-wall defects demonstrated more defect fill.

- More profound defects resulted in more defect fill.

- Reconstructive surgical treatment of peri-implant intraosseous defects can result in successful clinical outcomes, maintainable over at least five years. 


\section{CLINICAL RECOMMENDATIONS}

Patients with a diagnosis of periodontitis should be treated, and the patient should be motivated and instructed in oral hygiene measures before reconstructive surgery is performed.

Intraosseous peri-implantitis defects can be reconstructed using either the patient's own bone or a xenograft bone augmentation material. However, to minimise the surgical trauma and to increase the defect fill a xenograft is preferred.

To maintain the treatment result following therapy, the patient should follow a regular maintenance schedule. 


\section{FUTURE RESEARCH}

Treatment of peri-implantitis is difficult. Following surgical therapy with currently available methods, only success rates in the range of 40-50\% is reported. This is of course discouraging, and future research needs to focus on developing and refining surgical methods to increase the success rates. One possible method of improving success rates would be to develop augmentation materials combining osteoconductive and osseo-inductive properties. This is necessary to acquire both flap support and to initiate the biological healing process.

It is of importance to evaluate if and how patient related factors such as smoking and systemic diseases influence the healing response following of different therapeutic regimens of peri-implantitis. It is also important to evaluate the importance of peri-implantitis on the patients' general health. 


\section{ACKNOWLEDGEMENTS}

\section{Stefan Renvert}

I want to express my gratitude and show my deep appreciation to my main supervisor, Stefan Renvert who with his unique personality, full knowledge, good pedagogy, patience and kindness guided me and helped me complete my dissertation.

Thank you for sharing your knowledge with me which I will use in the future. I will definitely do my best to be as good a person to my colleagues and the people around me as you have been to me.

\section{Rutger Person}

Thanks for your advice, analysis of X-rays and your enormous knowledge of statistics, control and your involvement in scientific corrections of my articles that helped me ensure the publication and my dissertation.

\section{Andreas Stavropolous}

For enriching constructive advice and active involvement in my project.

\section{Ulla Lundström}

For her friendly personality, structured care of patients in the project, order and enormously careful clinical work.

\section{Torsten Mattsson and Ulf Bongenhielm}

Thank you for your friendship and thank you for all the support and opportunity to be in your clinic with friendly staff to carry out my entire project. 


\section{The staff at Uppsala Oral Surgery Center (UKKC)}

For their friendly way of receiving me in the clinic. I am grateful to each and every one of them, especially Agneta Hörner and Nina Frohm for professional surgical assistance.

\section{Christel Lindahl}

For her close collaboration in digitisation of X-ray images in my project.

\section{Christina Stenervik}

For her friendly attitude and help with secretarial matters.

\section{My beloved family, Samira, Parisa \& Parasto}

Thank you for the love and strength I have received from you and thank you for the encouragement and support you have given me since you came into my life.

\section{My parents}

Thank you for always being by my side and encouraging me throughout my upbringing and career. Thank you for the bond between us and for creating our wonderful family with good values. 


\section{REFERENCES}

Abrahamsson I, \& Soldini C.(2006) Probe penetration in periodontal and periimplant tissues. An experimental study in the beagle dog. Clinical Oral Implants Research. 17: 601-605.

Aghazadeh A, Persson GR, Renvert S. (2012) A single-centre randomized controlled clinical trial on the adjunct treatment of intra-bony defects with autogenous bone or a xenograft: results after 12 months Journal of Clinical Periodontology 39: $666-673$.

Aghazadeh A, Persson GR, Renvert S. (2020) Impact of bone defect morphology on the outcome of reconstructive treatment of peri-implantitis. International Journal of Implant Dentistry 6: 33.

Albandar JM, Susin C, Hughes FJ. (2018) Manifestations of systemic diseases and conditions that affect the periodontal attachment apparatus: Case definitions and diagnostic considerations. Journal of Clinical Periodontology 45(suppl 20): 171189.

Albouy JP, Abrahamsson I, Persson LG, Berglundh T. (2008) Spontaneous progression of peri-implantitis at different types of implants. An experimental study in dogs. I: clinical and radiographic observations Clinical Oral Implants Research 19: 997-1002.

Albouy JP, Abrahamsson I, Persson LG, Berglundh T.J (2011) Implant surface characteristics influence the outcome of treatment of peri-implantitis: an experimental study in dogs. Journal of Clinical Periodontology 38: 58-64.

Albouy JP, Abrahamsson I, Berglundh T. (2012) Spontaneous progression of experimental peri-implantitis at implants with different surface characteristics: an experimental study in dogs. Journal of Clinical Periodontology 39: 182-187.

Andersen H. Aass AM. Wohlfahrt JC (2017). Porous titanium granules in the treatment of peri-implant osseous defects-a 7-year follow-up study. International Journal of Implant Dentistry, 3(1), 50.

Araujo MG \& Lindhe J. (2018) Peri-implant health. Journal of Periodontology 89(Suppl 1): 249- 256. 
Atieh M A, Alsabeeha NH, Faggion GM Jr., W. J. Duncan WJ. (2013) The frequency of peri-implant diseases: a systematic review and meta-analysis, Journal of Periodontology 84: 1586-1598.

Axelsson P. \& Lindhe J. (1981) The significance of maintenance care in the treatment of periodontal disease. Journal of Clinical Periodontology 8: 281-294.

Axelsson P, Nystrom B, \& Lindhe J. (2004) The long-term effect of a plaque control program on tooth mortality, caries and periodontal disease in adults. Results after 30 years of maintenance. Journal of Clinical Periodontology 31: 749-757.

Barootchi S, Ravidà A, Tavelli L, Wang HL. (2020) Nonsurgical treatment for periimplant mucositis: A systematic review and meta-analysis. International Journal of Oral Implantology (Berl) 13 : 123-139.

Berglundh T, Lindhe J, Ericsson I, Marinello CP, Liljeberg B, Thomsen P. (1991) The soft tissue barrier at implants and teeth. Clinical Oral Implants Research 22: 81-90.

Berglundh T, Ericsson I, Dahlén G, Leonhardt A. (1992) Putative periodontal pathogens on titanium implants and teeth in experimental gingivitis and periodontitis in beagle dogs. Clinical Oral Implants Research 3: 112-119.

Berglundh T, Lindhe J, Jonsson K, Ericsson I. (1994) The topography of the vascular systems in the periodontal and peri-implant tissues in the dog. Journal of Clinical Periodontology 21: 189-193.

Berglundh T, Gislason O, Lekholm U, Sennerby L, Lindhe J. (2004) Histopathological observations of human periimplantitis lesions. Journal of Clinical Periodontology 31: 341-347.

Berglundh T, Donati M. (2005) Aspects of adaptive host response in periodontitis. Journal of Clinical Periodontology 32 (Suppl. 6): 87-107.

Berglundh T, Armitage G, Araujo MG, Avila-Ortiz G, Blanco J, Camargo PM, Chen S, Cochran D, Derks J, Figuero E, Hämmerle CHF, Heitz-Mayfield LJA, HuynhBa G, Iacono V, Koo KT, Lambert F, McCauley L, Quirynen M, Renvert S, Salvi GE, Schwarz F, Tarnow D, Tomasi C, Wang HL, Zitzmann NJ (2018). Periimplant diseases and conditions: Consensus report of workgroup 4 of the 2017 World Workshop on the Classification of Periodontal and Peri-Implant Diseases and Conditions. Journal of Clinical Periodontology 45 Suppl 20: 286-291.

Brägger U, Ioannis Karoussis I, Persson GR, Pjetursson P, Salvi G, Lang NP. (2005)Technical and biological complications/failures with single crowns and fixed partial dentures on implants: a 10-year prospective cohort study. Clinical Oral Implants Research 16: 326-334.

Canullo L, Penarrocha-Oltra D, Covani U, Botticelli D, Serino G, Penarrocha M. (2016) Clinical and microbiological findings in patients with peri-implantitis: a cross-sectional study. Clinical Oral Implants Research 27: 376-382. 
Carcuac O, Derks J, Charalampakis G, Abrahamsson I, Wennström J, Berglundh T. (2016) Adjunctive Systemic and Local Antimicrobial Therapy in the Surgical Treatment of Peri-implantitis: A Randomized Controlled Clinical Trial. Journal of Dental Research 95: 50-57.

Casado PL, Pereira MC, Duarte ME, Granjeiro JM. (2013) History of chronic periodontitis is a high risk indicator for peri-implant disease. Brazilian Dental Journal 24:136-141.

Casado PL, Aguiar T, Fernandes Pinheiro MP, Machado A, da Rosa Pinheiro A. (2019) Smoking as a risk factor for the development of Periimplant Diseases. Implant Dentistry 28:120-124.

Chan HL, Lin GH, Suarez F, MacEachern M, Wang HL. (2014) Surgical management of peri-implantitis: a systematic review and meta-analysis of treatment outcomes. Journal of Periodontology 85: 1027-1041.

Cho NH, Shaw JE, Karuranga S, Huang Y, Fernandes JDR, Ohlrogge AW, et al. (2018) IDF Diabetes Atlas: global estimates of diabetes prevalence for 2017 and projections for 2045. Diabetes Research and Clinical Practice 138: 271-281.

Claffey N, Clarke E, Polyzois I, Renvert S. (2008) Surgical treatment of periimplantitis. Journal of Clinical Periodontology 35(8 Suppl): 316-332.

Carral C, Muñoz F, Permuy M, Liñares A, Dard M, Blanco J. (2016) Mechanical and chemical implant decontamination in surgical peri-implantitis treatment: preclinical "in vivo" study. Journal of Clinical Periodontology 43: 694-701.

Clem D. \& Gunsolley, JC. (2019) Peri-implantitis Treatment Using Er: YAG Laser and Bone Grafting. A Prospective Consecutive Case Series Evaluation: 1 Year Posttherapy. International Journal of Periodontics and Restorative Dentistry 39: 479-489.

Cochran DL, Nummikoski PV, Schoolfield JD, Jones AA, Oates TW. (2009) A prospective multicenter 5-year radiographic evaluation of crestal bone levels over time in 596 dental implants placed in 192 patients. Journal of Periodontology 80: 725-733.

Costa F O, Takenaka-Martinez,S, Cota LO, Ferreira S D, Silva G L, Costa JE. (2012). Peri-implant disease in subjects with and without preventive maintenance: A 5-year follow-up. Journal of Clinical Periodontology 39: $173-181$.

Cosyn J, Van Aelst L, Collaert, B. Persson GR, De Bruyn H. (2011) The periimplant sulcus compared with internal implant and suprastructure components: a microbiological analysis. Clinical Implant Dental Related Research 13: 286-295.

Dalago HR, Schuldt Filho G, Rodrigues MA, Renvert S, Bianchini MA. (2017) Risk indicators for peri-implantitis. A cross-sectional study with 916 implants. Clinical Oral Implants Research 28: 144-150. 
Daubert DM, Weinstein BF, Bordin S, Leroux BG, Flemming TF. (2015) Prevalence and predictive factors for peri-implant disease and implant failure: a crosssectional analysis. Journal of Periodontology 86: 337-347.

Derks J, \&Tomasi C. (2015) Peri-implant health and disease. A systematic review of current epidemiology. Journal of Clinical Periodontology 42: 158-171.

Derks J, Schaller D, Håkansson J, Wennström JL, Tomasi C, Berglundh T. (2016) Effectiveness of implant therapy analyzed in a Swedish population: prevalence of peri-implantitis. Journal of Dental Research 95:43-49.

de Waal YC, Raghoebar GM, Meijer HJ, Winkel EG, van Winkelhoff AJ. (2016) Prognostic indicators for surgical peri-implantitis treatment. Clinical Oral Implants Research 27: 1485-1491.

Dierens M, Vandeweghe S, Kisch J, Nilner K, \& De Bruyn H. (2012) Long-term follow-up of turned single implants placed in periodontally healthy patients after 16-22 years: Radiographic and peri-implant outcome. Clinical Oral Implants Research 23: 197-204.

Dierens M, Vandeweghe S, Kisch J, Persson GR, \& De Bruyn H. (2013) Long-term follow-up of turned single implants placed in periodontally healthy patients after 16 to 22 years: microbiologic outcome. Journal of Periodontology 84: 880-894.

Dreyer H, Grischke J, Tiede C, et al. (2018) Epidemiology and risk factors of periimplantitis: A systematic review. Journal of Periodontal Research 53: 657-681.

Englezos E, Cosyn J, Koole S, Jacquet W, De Bruyn H. (2018) Resective Treatment of Peri-implantitis: Clinical and Radiographic Outcomes After 2 Years. International Journal of Periodontics and Restorative Dentistry 38: 729-735.

Ericsson I, Lindhe J. (1993) Probing depth at implants and teeth. An experimental study in the dog. Journal of Clinical Periodontology 20: 623-627.

Esposito M, Grusovin MG, Papanikolaou N, Coulthard P, Worthington HV. (2009) Enamel matrix derivative (Emdogain) for periodontal tissue regeneration in intrabony defects. A Cochrane systematic review. European Journal of Oral Implantology $2: 247-266$.

Ferreira SD, Silva GL, Cortelli JR, Costa JE, Costa FO. (2006) Prevalence and risk variables for peri-implant disease in Brazilian subjects. Journal of Clinical Periodontology 33: 929-935.

Ferreira SD, Martins CC, Amaral SA, Vieira TR, Albuquerque BN, Cota LOM, et al. (2018) Periodontitis as a risk factor for periimplantitis: systematic review and meta-analysis of observational studies. Journal of Dentistry 79: 1-10.

Fredriksson MI, Figueredo CM, Gustafsson A, Bergstrom KG, Asman BE. (1999) Effect of periodontitis and smoking on blood leukocytes and acute-phase proteins. Journal of Periodontology 70: 1355-1360.

Frisch E, Vach K, Ratka-Krueger P. (2020) Impact of supportive implant therapy on peri-implant diseases: A retrospective 7-year study. Journal of Clinical Periodontology 47: 101-109. 
Froum SJ, Froum SH, Rosen PS. (2012) Successful management of peri-implantitis with a regenerative approach: a consecutive series of 51 treated implants with 3- to 7.5-year follow-up. International Journal Periodontics and Restorative Dentistry 32 : 11-20.

Froum SJ, Rosen PS, Wang WC, Froum SH, Vinayak S (2018) Retrospective Evaluation of Factors Related to the Outcomes of Regenerative Therapy for Implants Affected by Peri-implantitis. International Journal Periodontics and Restorative Dentistry 38 : 181-187.

Froum SJ, Hengjeerajaras P, Liu KY, Maketone P, Patel V, Shi Y. (2020) The Link Between Periodontitis/Peri-implantitis and Cardiovascular Disease: A Systematic Literature Review. International Journal of Periodontics and Restorative Dentistry 40: 229-233.

Fürst MM, Salvi GE, Lang NP, Persson GR. (2007). Bacterial colonization immediately after installation on oral titanium implants. Clinical Oral Implants Research 18: 501-508.

Genco R J. \& Borgnakke WS. (2013). Risk factors for periodontal disease. Periodontology 2000: 62, 59-94.

Gholami H, Mericske-Stern R, Kessler-Liechti G, Katsoulis J. (2014) Radiographic bone level changes of implant-supported restorations in edentulous and partially dentate patients: 5-year results. International Journal of Oral and Maxillofacial Implants 29: 898-904.

Giovannoli J-L, Roccuzzo M, Albouy J-P, Duffau, F, Lin G-H, Serino G. (2019) Local risk indicators - Consensus report of working group 2, International Dental Journal 69: (Supplement 2) 7-11.

Gurlek O, Gumus P, Buduneli N. (2018) Smokers have a higher risk of inflammatory peri-implant disease than non-smokers. Oral Diseases 24: 30-32.

Hallström H, Persson GR, Lindgren S, Renvert S. (2017) Open flap debridement of peri-implantitis with or without adjunctive systemic antibiotics: A randomized clinical trial. Journal of Clinical Periodontology 44 : 1285-1293.

Heasman L, Stacey F, Preshaw PM, McCracken GI, Hepburn S, Heasman PA. (2006) The effect of smoking on periodontal treatment response: A review of clinical evidence. Journal of Clinical Periodontology 33: 241-253.

Heitz-Mayfield LJA, Salvi GE, Mombelli A, Faddy M, Lang NP. (2012) Antiinfective surgical therapy of peri-implantitis. A 12-month prospective clinical study. Clinical Oral Implants Research 23: 205-210.

Heitz-Mayfield, L. J. A., Salvi, G.E., Mombelli, A., Loup, P.J., Heitz, F., Kruger, E., Lang, N.P. (2018) Supportive peri-implant therapy following anti-infective surgical peri-implantitis treatment: 5-year survival and success. Clinical Oral Implants Research 29: 1-6. 
Hu C, Lang NP, Ong MM-A, Lim LP, Tan WC. (2020) Influence of periodontal maintenance and periodontitis susceptibility on implant success: A 5-year retrospective cohort on moderately rough-surfaced implants. Clinical Oral Implants Research 31: 727-736.

Isehed C, Holmlund A, Renvert S, Svenson B, Johansson I, Lundberg P. (2016) Effectiveness of enamel matrix derivative on the clinical and microbiological outcomes following surgical regenerative treatment of peri-implantitis. A randomized controlled trial. Journal of Periodontology 43: 863-873.

Isehed C, Svenson B, Lundberg P, Holmlund A. (2018) Surgical treatment of periimplantitis using enamel matrix derivative, an RCT: 3- and 5-year follow-up. Journal of Clinical Periodontology 45: 744-753.

Javed F. \& Romanos GE. (2009). Impact of diabetes mellitus and glycemic control on the osseointegration of dental implants: A systematic literature review. Journal of Periodontology, 80: 1719-1730

Jemt T. Implant Survival in the Edentulous Jaw-30 Years of Experience. Part I: A Retro-Prospective Multivariate Regression Analysis of Overall Implant Failure in 4,585 Consecutively Treated Arches. (2018) International Journal of Prosthodontics 31: 425-435.

Jepsen S, Ruhling A, Jepsen K, Ohlenbusch B, \& Albers H K. (1996). Progressive periimplantitis. Incidence and prediction of peri-implant attachment loss. Clinical Oral Implants Research 7: 133- 142.

Jepsen S, Berglundh T, Genco R, et al. (2015) Primary prevention of periimplantitis: managing peri-implant mucositis. Journal of Clinical Periodontology 42 (Suppl 16): 152-157.

Jepsen K, Jepsen S, Laine M L, Anssari Moin D, Pilloni A, Zeza B, Sanz M, OrtizVigon A, Roos-Jansåker A M, Renvert, S.(2016) Reconstruction of Peri-implant Osseous Defects: A Multicenter Randomized Trial. Journal of Dental Research 95: 58-66.

Jungner M, Lundqvist P, Lundgren S. (2014) A retrospective comparison of oxidized and turned implants with respect to implant survival, marginal bone level and peri-implant soft tissue conditions after at least 5 years in function. Clinical Implant Dentistry and Related Research 16: 230-237.

Karoussis IK, Salvi GE, Heitz-Mayfield LJA, Brägger U, Hämmerle CHF, Lang NP(2003) Long-term implant prognosis in patients with and without a history of chronic periodontitis: a 10-year prospective cohort study of the ITI Dental Implant System. Clinical Oral implants Research 14: 329-339.

Katafuchi M, Weinstein BF, Leroux BG, Chen YW, Daubert DM. (2018) Restoration contour is a risk indicator for peri-implantitis: A cross-sectional radiographic analysis. Journal of Clinical Periodontology 45: 225-232.

Koldsland OC, Scheie AA, Aass AM. (2010) Prevalence of peri-implantitis related to severity of the disease with different degrees of bone loss. Journal of Periodontology 81: 231-238. 
Koldsland OC, Scheie AA, Aass AM. (2011))The association betweenselected risk indicators and severity of peri-implantitis using mixed model analyses. Journal of Clinical Periodontology 38: 285-292.

Kolk A, Handschel J, Drescher W, Rothamel D, Kloss F, Blessmann M, Heiland M, Wolff KD, Smeets R. (2012) Current trends and future perspectives of bone substitute materials - from space holders to innovative biomaterials. Journal of Craniomaxillofacial Surgery 40: 706-718.

Konstantinidis IK, Kotsakis GA, Gerdes S, Walter MH. (2015) Cross-sectional study on the prevalence and risk indicators of peri-implant diseases. European Journal of Oral Implantology 8: 75-88.

Koyanagi T, Sakamoto M, Takeuchi Y, Ohkuma M. \& Izumi, Y. (2010) Analysis of microbiota associated with peri-implantitis using 16s rRNA gene clone library. Journal of Oral Microbiology 24: 2.

Kumar PS, Matthews CR, Joshi V, de Jager M, Aspiras M. (2011) Tobacco smoking affects bacterial acquisition and colonization in oral biofilms. Infection and Immunity 79: 4730-4738.

Kumar PS, Dabdoub SM, Hegde R, Ranganathan N, Mariotti A. (2018) Site-level risk predictors of peri-implantitis: a retrospective analysis. Journal of Clinical Periodontology 45: 597-604.

Lambert PM, Morris HF, Ochi S. (2000). Influence of smoking on 3-year clinical success of osseointegrated dental implants. Annals of Periodontology5: 79-89.

La Monaca G, Pranno N, Annibali S, Cristalli MP, Polimeni A. (2018) Clinical and radiographic outcomes of a surgical reconstructive approach in the treatment of peri-implantitis lesions: A 5-year prospective case series. Clinical Oral Implants Research 29: doi: 10.1111/clr.13369.

Lang NP, Kinane DF, Lindhe J, Sanz M, Tonetti MS. (2008) Sixth European Workshop on Periodontology of the European Academy of Periodontology at the Charterhouse at Ittingen, Thurgau, Switzerland. Journal of Clinical Periodontology 35: 1-2.

Lazzara R J, Testori T, Trisi P. Porter SS. \& Weinstein R L. (1999) A human histologic analysis of Osseotite and machined surfaces using implants with two opposing surfaces. International Journal of Periodontics and Restorative Dentistry 19: 117-129.

Lertpimonchai A, Rattanasiri S,,S Arj-Ong Vallibhakara S, A,O, Attia J, Thakkinstian. (2017) A The association between oral hygiene and periodontitis: a systematic review and meta-analysis. International Dental Journal 67: 332-343.

Lin GH, Chan LH, Wang HL. (2013) The significance of keratinized mucosa on implant health: a systemic review. Journal of Clinical Periodontology 84: 17551767.

Lindhe J, \& Nyman S. (1984) Long-term maintenance of patients treated for advanced periodontal disease. Journal of Clinical Periodontology 11, 504-514. 
Lindhe J, Berglundh T, Ericsson I, Liljenberg B, Marinello C. (1992) Experimental breakdown of peri-implant and periodontal tissues. A study in the beagle dog. Clinical Oral Implants Research 3: 9-16.

Lindhe J, Meyle J, Group D of European Workshop on Periodontology. (2008) Periimplant diseases: consensus report of the sixth European workshop on periodontology. Journal of Clinical Periodontology 35: 282-285.

Lindquist LW, Carlsson GE, Jemt T.(1996) A prospective 15-year follow-up study of mandibular fixed prostheses supported by osseointegrated implants. Clinical results and marginal bone loss. Clinical Oral Implants Research. 7: 329-336.

Linkevicius T, Vindasiute E, Puisys A, Linkeviciene L, Maslova N, \& Puriene A. (2013a)The influence of the cementation margin position on the amount of undetected cement. A prospective clinical study. Clinical Oral Implants Research 24: 71-76.

Linkevicius T, Puisys A, Vindasiute E, Linkeviciene L, \& Apse P. (2013b) Does residual cement around implant-supported restorations cause peri-implant disease? A retrospective case analysis. Clinical Oral Implants Research 24: $1179-1184$.

Rinke S, Ohl S, Ziebolz D, Lange K, Eickholz P. (2011) Prevalence of periimplant disease in partially edentulous patients: a practice based cross-sectional study. Clinical Oral Implants Research 22: 826-833.

Marrone A, Lasserre J, Bercy P, Brecx MC. (2013) Prevalence and risk factors for peri-implant disease in Belgian adults. Clinical Oral Implants Research 24: 934940.

Monje A, Aranda L, Diaz KT, Alarcón MA, Bagramian,RA. Wang HL, Catena A. (2016) Impact of Maintenance Therapy for the Prevention of Peri-implant Diseases: A Systematic Review and Meta-analysis. Journal of Dental Research 95: 372-379.

Monje A, Catena A, Borgnakke WS (2017) Association between diabetes mellitus/ hyperglycaemia and peri-implant diseases: systematic review and meta-analysis. Journal of Clinical Periodontology 44: 636-648.

Monje A, Pons R, Insua A, Nart J, Wang HL, Schwarz F. (2019). Morphology and severity of periimplantitis bone defects. Clinical Implant Dentistry Related Research 1-9.

Palmer RM, Wilson RF, Hasan AS, Scott DA. (2005) Mechanisms of action of environmental factors-tobacco smoking. Journal of Clinical Periodontology 32(Suppl 6):180-195.

Pietiäinen M, Kopra KAE, Vuorenkoski J, Salminen A, Paju S et al. (2018) A. actinomycetemcomitans serotypes associate with periodontal and coronary artery disease status. Journal of Clinical Periodontology 45: 413-421.

Pongnarisorn NJ, Gemmell E, Tan AE, Henry PJ, Marshall RI, Seymour GJ. (2007) Inflammation associated with implants with different surface types. Clinical Oral Implants Research 18: 114-125. 
Pontoriero R, Tonelli MP, Carnevale G, Mombelli A, Nyman SR, Lang NP. (1994) Experimentally induced peri-implant mucositis. A clinical study in humans. Clinical Oral Implants Research 5: 254-259.

Quirynen M, van der Mei HC, Bollen CM, Schotte A, Marechal M, Dornbusch GI, Naert I, Busscher HJ, van Steenberghe D. (1993) An in vivo study of the influence of the surface roughness of implants on the microbiology of supra- and subgingival plaque. Journal of Dental Research 72 : 1304-1309.

Quirynen M, De Soete M, van Steenberghe D. (2002) Infectious risks for oral implants: A review of the literature. Clinical Oral Implants Research 13: 1-19.

Quirynen M, Vogels R, Peeters W, van Steenberghe D, Naert I. \& Haffajee A. (2006) Dynamics of initial subgingival colonization of 'pristine'peri-implant pockets. Clinical Oral Implants Research 17: 25-37.

Quirynen M, \& Van Assche N. (2012) RCT comparing minimally with moderately rough implants. Part 2: microbial observations. Clinical Oral Implants Research 23: $625-34$.

Ramel CF, Lüssi A, Özcan M, Jung RE, Hämmerle CH, Thoma DS.(2016) Surface roughness of dental implants and treatment time using six different implantoplasty procedures Clinical Oral Implants Research 27: 776-781.

Renvert S, Roos-Jansåker A-M, Lindahl, C, Renvert H. \& Persson GR. (2007) Infection at titanium implants with or without a clinical diagnosis of inflammation. Clinical Oral Implants Research 18, 509-516.

Renvert S, Roos-Jansåker A-M, Claffey N.(2008) Non-surgical treatment of periimplant mucositis and peri-implantitis: a literature review. Journal of Clinical Periodontology 35 (Suppl.8): 305-315.

Renvert S, Persson GR.(2009) Periodontitis as a potential risk factor for periimplantitis. Journal of Clinical Periodontology 36 (Suppl 10): 9-14.

Renvert S \& Giovannoli JL. Peri-implantitis, Quintessence International, 2012

Renvert S, Lindahl C, Rutger Persson G. (2012) The incidence of peri-implantitis for two different implant systems over a period of thirteen years.Journal of Clinical Periodontology 39: 1191-1197.

Renvert S, Aghazadeh A, Hallström H, Persson GR. (2014) Factors related to periimplantitis - a retrospective study. Clinical Oral Implants Research 25: 522-529

Renvert S, Quirynen M. Risk indicators for peri-implantitis. A narrative review. (2015) Clinical Oral Implants Research 26 (Suppl 11): 15-44.

Renvert S, \& Polyzois I. (2015). Risk indicators for peri-implant mucositis: A systematic literature review. Journal of Clinical Periodontology 42 (Suppl. 16): $172-186$.

Renvert S, Polyzois I. (2018) Treatment of pathologic peri-implant pockets. Periodontology 2000 76: 180-190. 
Renvert S, Persson, GR, Pirih FQ, \& Camargo PM (2018a). Peri-implant health, peri-implant mucositis, and peri-implantitis: Case definitions and diagnostic considerations. Journal of Periodontology 89 (Suppl 1): 304-312.

Renvert S, Roos-Jansåker A-M, Persson GR. (2018b). Surgical treatment of periimplantitis lesions with or without the use of a bone substitute-a randomized clinical trial. Journal of Clinical Periodontology, 45: 1266-1274.

Renvert S, Giovannoli JL, Roos-Jansåker AM, Rinke S. (2021)Surgical treatment of peri-implantitis with or without a deproteinized bovine bone mineral and a native bilayer collagen membrane: A randomized clinical trial. Journal of Clinical Periodontology $48: 1312-1321$.

Roccuzzo M, Bonino F, Bonino L, Dalmasso P. (2011) Surgical therapy of periimplantitis lesions by means of a bovine-derived xenograft: comparative results of a prospective study on two different implant surfaces. Journal of Clinical Periodontology 38: 738-745.

Roccuzzo M, De Angelis N, Bonino L, \& Aglietta, M. (2010) Ten-year results of a three-arm prospective cohort study on implants in periodontally compromised patients. Part 1: Implant loss and radiographic bone loss. Clinical Oral Implants Research 21: 490-496.

Roccuzzo M, Bonino F, Aglietta M, \& Dalmasso P. (2012) Ten-year results of a three arms prospective cohort study on implants in periodontally compromised patients. Part 2: Clinical results Clinical Oral Implants Research 23: 389-395.

Roccuzzo M, Bonino L, Dalmasso P, \& Aglietta M. (2014) Long-term results of a three arms prospective cohort study on implants in periodontally compromised patients: 10-year data around sandblasted and acid-etched (sla) surface. Clinical Oral Implants Research 25: 1105-1112.

Roccuzzo M, Gaudioso L, Lungo M, Dalmasso P. (2016) Surgical therapy of single peri-implantitis intrabony defects, by means of deproteinized bovine bone mineral with 10\% collagen. Journal of Clinical Periodontology 43: 311-318.

Roccuzzo M, Pittoni D, Roccuzzo A, Charrier L, Dalmasso P. (2017) Surgical treatment of peri-implantitis intrabony lesions by means of deproteinized bovine bone mineral with 10\% collagen: 7-year-results. Clinical Oral Implants Research 12: $1577-1583$.

Roccuzzo M, Layton DM, Roccuzzo A, Heitz-Mayfield LJ. (2018) Clinical outcomes of peri-implantitis treatment and supportive care: A systematic review. Clinical Oral Implants Research Suppl 16: 331-350.

Roccuzzo M, Fierravanti L, Pittoni D, Dalmasso P, Roccuzzo A. (2020) Implant survival after surgical treatment of peri-implantitis lesions by means of deproteinized bovine bone mineral with 10\% collagen: 10-year results from a prospective study. Clinical Oral Implants Research 31: 768-776.

Roos-Jansåker A-M, Lindahl C, Renvert H, Renvert S. (2006b) Nine-to fourteenyear follow-up of implant treatment. Part II: presence of peri-implant lesions. Journal of Clinical Periodontology 33: 290-295. 
Roos-Jansåker A-M, Renvert H, Lindahl C, \& Renvert S. (2006c) Nine- to fourteenyear follow up of implant treatment. Part III: Factors associated with peri-implant lesions. Journal of Clinical Periodontology 33: 296-301.

Roos-Jansåker A-M, Renvert H, Lindahl C, Renvert S. (2007a) Surgical treatment of peri-implantitis using a bone substitute with or without a resorbable membrane: a prospective cohort study. Journal of Clinical Periodontology 34: 625-632.

Roos-Jansåker A-M, Renvert H, Lindahl C, Renvert S. (2007b) Submerged healing following surgical treatment of peri-implantitis: a case series. Journal of Clinical Periodontology 34: 723-727.

Roos-Jansåker A-M, Persson GR, Lindahl C, Renvert S. (2014) Surgical treatment of peri-implantitis using a bone substitute with or without a resorbable membrane: a 5-year follow-up Journal of Clinical Periodontology 41: 1108-1114.

Romeo E, Lops D, Chiapasco M, Ghisolfi M, Vogel G. (2007) Therapy of periimplantitis with resective surgery. A 3-year clinical trial on rough screw-shaped oral implants. Part II: radiographic outcome. Clinical Oral Implants Research 18: $179-87$.

Saaby M, Karring E, Schou S, Isidor F. (2016) Factors influencing severity of periimplantitis. Clinical Oral Implants Research 27: 7-12.

Sailer I, Muhlemann S, Zwahlen M, Hammerle CH, \& Schneider D. (2012) Cemented and screw-retained implant reconstructions: a systematic Review of the survival and complication rates. Clinical Oral Implants Research 23 (Suppl. 6): $163-201$.

Salvi G, \& Lang N. (2004) Diagnostic parameters for monitoring peri-implant conditions. International Journal of Oral and Maxillofacial Implants 19: 116-127.

Salvi GE, Aglietta M, Eick S, Sculean A, Lang NP, Ramseier CA. (2012) Reversibility of experimental peri-implant mucositis compared with experimental gingivitis in humans. Clinical Oral Implants Research 23: 182-190.

Sanz M, Chapple IL, Working Group 4 of the VIII European Workshop on Periodontology. (2012) Clinical research on peri-implant disease: consensus report of Working Group 4. Journal of Clinical Periodontology 39 (Suppl 12): 202-206.

Sanz M, Marco Del Castillo A, Jepsen S, Gonzalez-Juanatey JR, D’Aiuto F, Bouchard P, Chapple I, Dietrich T, Gotsman I, Graziani F, Herrera D, Loos B, Madianos P, Michel JB, Perel P, Pieske B, Shapira L, Shechter M, Tonetti M, Vlachopoulos C, Wimmer G.Periodontitis and cardiovascular diseases: Consensus report. Journal of Clinical Periodontology 2020 47: 268-288.

Schroeder A, van der Zypen E, Stich H, Sutter F. (1981)The reactions of bone, connective tissue, and epithelium to endosteal implants with titanium-sprayed surfaces. Journal of Oral and Maxillofacial Surgery 9: 15-25. 
Schwarz F, Bieling K, Latz T, Nuesry E, Becker J. (2006) Healing of intrabony peri-implantitis defects following application of a nanocrystalline hydroxyapatite (Ostim) or a bovine-derived xenograft (Bio-Oss) in combination with a collagen membrane (Bio-Gide). A case series. Journal of Clinical Periodontology 33 : 491-499.

Schwarz F, Herten M, Sager M, Bieling K, Sculean A, Becker J. (2007) Comparison of naturally occurring and ligature-induced peri-implantitis bone defects in humans and dogs. Clinical Oral Implants Research;18: 161-170.

Schwarz F, Sahm N, Schwarz K, Becker J. (2010) Impact of defect configuration on the clinical outcome following surgical regenerative therapy of periimplantitis. Journal of Clinical Periodontology 37: 449-455.

Schwarz, F., John, G., Schmucker, A., Sahm, N., \& Becker, J. (2017) Combined surgical therapy of advanced peri-implantitis evaluating two methods of surface decontamination: A 7-year follow-up observation. Journal of Clinical Periodontology 44: 337-342.

Schwarz F, Derks J, Monje A, Wang HL. (2018)Peri-implantitis. Journal of Periodontology 89 (Suppl 1) :267-S290.

Serino G, \& Ström,C. (2009) Peri-implantitis in partially edentulous patients: association with inadequate plaque control. Clinical Oral Implants Research, 20, $169-174$.

Serino, G., Turri, A., Lang, N.P. (2015) Maintenance therapy in patients following the surgical treatment of peri-implantitis: a 5-year follow-up study. Clinical Oral Implants Research 26, 950-956.

Simonis P, Dufour T. \& Tenenbaum H. (2010) Long-term implant survival and success: a 10-16- year follow-up of non-submerged dental implants. Clinical Oral Implants Research 21: 772-777.

Souza AB, Tormena M, Matarazzo F, Araujo MG. (2016) The influence of periimplant keratinized mucosa on brushing discomfort and peri-implant tissue health. Clinical Oral Implants Research 27: 650-655.

Staubli N, Walter C, Schmidt JC, Weiger R, Zitzmann NU.(2017) Excess cement and the risk of peri-implant disease - a systematic review. Clinical Oral Implants Research. 28: 1278-1290.

Strietzel FP, Reichart PA, Kale A, Kulkarni M, Wegner B, Kuchler I. (2007) Smoking interferes with the prognosis of dental implant treatment: A systematic review and meta-analysis. Journal of Clinical Periodontology 34: 523-544.

Takamiya AS, Goiato MC, Filho HG. (2014) Effect of smoking on the survival of dental implants. Biomed Pap Med Fac Univ Palacky Olomouc Czech Repub. 158: 650-653.

Teughels W, Van Assche N, Sliepen I, Quirynen M. (2006) Effect of material characteristics and surface topography on biofilm development. Clinical Oral Implants Research 17 (Suppl.2): 68-81. 
Tonetti MS, Chapple IL, Jepsen S, Sanz M. (2015) Primary and secondary prevention of periodontal and peri-implant diseases: Introduction to and objectives of the 11th European Workshop on Periodontology consensus conference. Journal of Clinical Periodontology 42 (Suppl 16): 1-4.

Tsigarida AA, Dabdoub SM, Nagaraja HN, et al. (2015) The influence of smoking on the peri-implant microbiome. Journal of Dental Research 94: 1202-1217.

Welander M, Abrahamsson I, Berglundh T. (2008) The mucosal barrier at implant abutments of different materials. Clinical Oral Implants Research 19: 635-641.

Williams R, Karuranga S, Malanda B, et al. (2020) Global and regional estimates and projections of diabetes-related health expenditure: results from the international diabetes federation diabetes atlas. Diabetes Research and Clinical Practice.162.

Wittneben JG, Millen C \& Bragger U. (2014) Clinical performance of screw- versus cement-retained fixed implant-supported reconstructions-a systematic review. The International Journal of Oral and Maxillofacial Implants 29 (Suppl.): 84-98.

Yi Y, Koo K-T, Schwarz F, Ben AmaraH, Heo S-J. (2020) Association of prosthetic features and periimplantitis: A cross-sectional study. Journal of Clinical Periodontology 47: 392-403.

Zangrando MS, Damante CA, Sant'Ana AC, Rubo de Rezende ML, Greghi SL, Chambrone, L. (2015) Long-term evaluation of periodontal parameters and implant outcomes in periodontally compromised patients: A systematic review. Journal of Periodontology 86: 201-221.

Zitzman N, Berglundh T, Marinello CP, Lindhe. (2001) . Experimental peri-implant mucositis in man. Journal of Clinical Periodontology 28: 517-523. 
PAPERS I-IV 
I 



\section{A single-centre randomized controlled clinical trial on the adjunct treatment of intra-bony defects with autogenous bone or a xenograft: results after 12 months}

Aghazadeh A, Persson GR, Renvert S. A single-centre randomized controlled clinical trial on the adjunct treatment of intra-bony defects with autogenous bone or a xenograft: results after 12 months. J Clin Periodontol 2012; 39: 666-673. doi: $10.1111 / j .1600-051 X .2012 .01880 . x$.

\section{Abstract}

Background: Limited evidence exists on the efficacy of regenerative treatment of peri-implantitis.

Material and Methods: Subjects receiving antibiotics and surgical debridement were randomly assigned to placement of autogenous bone (AB) or bovine-derived xenograft (BDX) and with placement of a collagen membrane. The primary outcome was evidence of radiographic bone fill and the secondary outcomes included reductions of probing depth (PD) bleeding on probing (BOP) and suppuration. Results: Twenty-two subjects were included in the $\mathrm{AB}$ and 23 subjects in the BDX group. Statistical analysis failed to demonstrate differences for 38/39 variables assessed at baseline. At 12 months, significant better results were obtained in the BDX group for bone levels $(p<0.001)$, BOP $(p=0.004)$, PI $(p=0.003)$ and suppuration $(p<0.01)$. When adjusting for number of implants treated per subject, a successful treatment outcome PD $\leq 5.0 \mathrm{~mm}$, no pus, no bone loss and BOP at $1 / 4$ or less sites the likelihood of defect fill was higher in the BDX group (LR: $3.2,95 \%$ CI: $1.0-10.6, p<0.05$ ).

Conclusions: Bovine xenograft provided more radiographic bone fill than AB. The success for both surgical regenerative procedures was limited. Decreases in $\mathrm{PD}, \mathrm{BOP}$, and suppuration were observed.
Ahmad Aghazadeh ${ }^{1}$,

G. Rutger Persson ${ }^{2,3,4}$ and Stefan Renvert $^{2,5,6}$

${ }^{1}$ Uppsala Käkkirurgiska Centrum, Uppsala, Sweden; ${ }^{2}$ Department of Oral Sciences, Kristianstad University Kristianstad, Kristianstad, Sweden; ${ }^{3}$ Departments of Periodontics and Oral Medicine, University of Washington, Seattle, WA; ${ }^{4}$ Department of Periodontology, University of Bern, Bern, Switzerland; ${ }^{5}$ School of Dental Sciences, Trinity Collage, Dublin, Ireland; ${ }^{6}$ Blekinge Institute of Technology, Karlskrona, Sweden
Key words: antibiotics; bone grafting; peri-implant disease; peri-implantitis; surgical therapy

Accepted for publication 11 March 2012
Conflict of interest and source of funding statement

The authors declare that they have no conflict of interests.

This study was funded by BIOMET3i.
Peri-implantitis resulting in bone loss around implants is difficult to treat. In studies evaluating the effects of different non-surgical therapies of peri-implantitis, decreases in (BOP and some reductions in PD have been reported (Schwarz et al. 2006a,b,
Renvert et al. 2009, Persson et al. 2010, Sahm et al. 2011). In cases with bone loss exposing parts of the implant surface to microbial colonization, either an osseous surgery approach, open flap debridement, or a regenerative procedure may be 
appropriate to obtain access for effective cleaning of the implant surfaces. A Cochrain review has identified that there is no reliable evidence suggesting the most effective interventions for treating peri-implantitis although it cannot be said that currently used interventions are not effective on a short-term basis (Esposito et al. 2012).

Three-year data have demonstrated clinical benefits by a resective surgical approach involving implantoplasty (Romeo et al. 2007). Osteoplasty of the buccally and supracrestally exposed implant surfaces combined with augmentation of the intraosseous part using a natural bone mineral, covered with a collagen membrane have shown improvements of clinical parameters 6 months following therapy (Schwarz et al. 2011). Resective bone therapy in conjunction with apically positioned flaps may also be an effective treatment model in approximately $50 \%$ of cases with periimplantitis (Serino \& Turri 2011). Similar results have been reported in a retrospective study including various surgical procedures and also including administration of antibiotics (Charalampakis et al. 2011).

Data suggest that treatment with autogenous bone $(\mathrm{AB})$ is an appropriate treatment regimen to augment open crater-formed peri-implant defects (Khoury \& Buchmann 2001). Evidence of bone fill using regenerative techniques with bone substitutes and collagen membranes have been reported (Roos-Jansåker et al. 2007a,b, 2011, Schwarz et al. 2009 , 2010). Others have demonstrated that surgical treatment of bone lesions at implants can be treated with a mixture of autogenous and xenogenous bone (Wiltfang et al. 2010). Almost complete bone fill of bone lesions at implants has been reported following surgical intervention with the application of a bone graft covered by a collagen membrane (Romanos \& Nentwig 2008).

The aim of the present study was to clinically and radiographically evaluate surgical treatment outcomes with an adjunct placement of autologous bone or a bovine-derived bone xenograft in peri-implant defects covered by a resorbable collagen membrane over 12 months.

\section{Material and Methods}

\section{Study design}

The study design was a single blinded prospective randomized controlled longitudinal human clinical trial.

\section{Study population}

The Regional Institutional Review Board in Lund, Sweden approved the study. The participants signed an informed consent. The CONSORT guidelines for clinical trials were followed and the study flow chart is presented (Fig. 1). Study subjects were recruited from (i) patients treated at a specialist centre for oral surgery and periodontology in Uppsala, Sweden (Uppsala Käkkirurgiska Centrum), and (ii) subjects referred to this centre for the treatment of peri-implant disease. The study was performed between 2007 and 2010 . Forty-five consenting patients with a diagnosis of peri-implantitis were enrolled.

\section{Inclusion criteria}

- A minimum of one osseo-integrated implant with loss of bone $\geq 2 \mathrm{~mm}$ defined by comparing digital intra-oral $(26 \times 37 \mathrm{~mm})$ radiographs at the time of screening for this study with bone loss from radio-

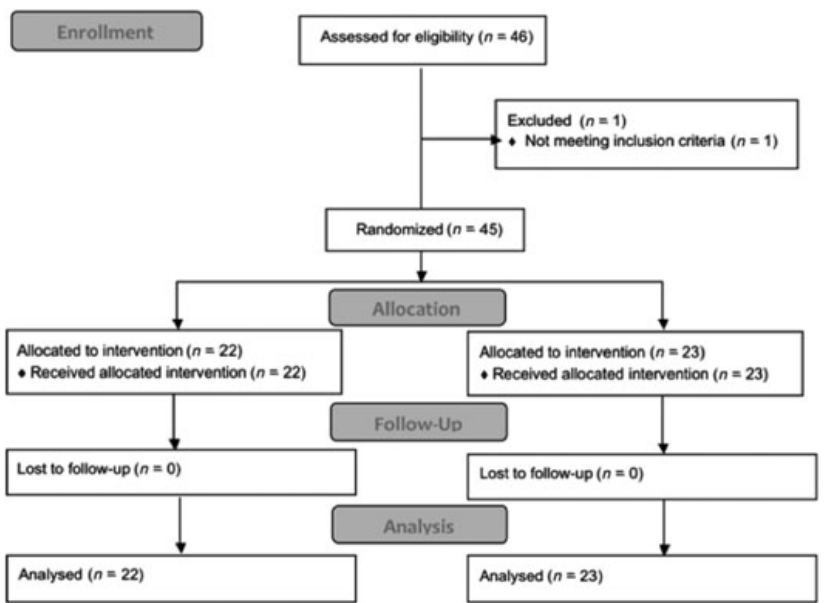

Fig. 1. CONSORT flow chart. graphs taken following placement of the implant supra-structure

- $\mathrm{A} P \mathrm{PD} \geq 5 \mathrm{~mm}$, and with $\mathrm{BOP} /$ suppuration (Lang et al. 2011)

- The selected implants must have angular peri-implant bone defects $(\geq 3 \mathrm{~mm}$ in depth as determined from intra-oral digital radiographs)

\section{Exclusion}

- Uncontrolled diabetes mellitus $(\mathrm{HbAlc}>7)$

- Requiring antibiotic prophylaxis, taking prednisone or other antiinflammatory medications, using antibiotics in the preceding 3 months

- Taking medications known to affect gingival overgrowth

\section{Pre-treatment}

Before entering into the study any periodontal disease around existing teeth had to be treated so that no pockets $>5 \mathrm{~mm}$ were present around any existing tooth. All patients also underwent a preparatory routine treatment phase including mechanical debridement of teeth and implants using hand instruments or ultrasonic devices as designed either for teeth or implants. Subjects were also instructed in oral hygiene measures prior to treatment and 
thereafter as deemed necessary. No surgical intervention for study purpose was performed before the reassurance of good patient motivation and compliance was identified. An update of the medical and dental history was made. Data on the subjects' age, gender, dental status, how long the implant had been in function, and smoking habits were recorded.

\section{Radiographic examination}

Radiographs were obtained of implants in a standardized way using an Eggen holder and long cone equipped dental X-ray unit. Pre- and postoperative radiographs presenting the study implants were digitalized, coded and evaluated using a computer program (OsiriX Imaging software 3.9 for MAC OS 10.6; Osirix Foundation, Geneva, Switzerland). The mesial and distal distances from the implant platform to the bottom of the defect were measured from radiographs taken at baseline and at 12 months. One calibrated examiner (G. R. P.) who was masked to study group allocation assessed all radiographs. Radiographs were studied both as black and white images and by CLUT (colour look-up tables). The most coronal confluent aggregation of bone or bone-like material was used to define the bone level. Black and white images versus CLUT images were switched to select the position of bone levels for the assessments. Single strands or islets of bone or bone like material were not considered.

\section{Clinical measurements and procedures}

One experienced examiner (U. L.) performed all clinical examinations and was unaware of treatment group assignment. Before treatment the 7 following baseline recordings were performed:

- Full set of Intra-oral radiographs (if radiographs not older than 3 months were not available)

- Presence/absence of hyperplasia

The following clinical data were collected at baseline, at 6 , and at 12 months after therapy:
- Full mouth plaque score: Presence of dental plaque along the gingi$\mathrm{val} /$ mucosal margin recorded after use of disclosing dye (Top Dent Lifco Dental AB, Enköping, Sweden) and expressed as a percentage of examined sites within each patient (four sites per tooth and implant)

- Local Plaque Score: Presence of dental plaque along the mucosal margin at four sites of each treated implant recorded after use of disclosing dye and expressed as a percentage of implant sites within each patient

- PD: at the implants (four sites implant) and recorded to the nearest $\mathrm{mm}$ using a plastic probe (Colorview, Hu-Friedy, Chicago, IL)

- BOP: Presence/absence bleeding on probing (BOP) at the treated implant (four sites/implant). Bleeding appearing after measurement of probing depth was expressed as a percentage of examined sites (four sites per implant)

- Suppuration: Presence of pus following probing (four sites implant)

- Mucosal recession: Measured in $\mathrm{mm}$ as the distance from the mucosal margin to the implant shoulder at four sites (mesial, buccal, distal and lingual). Position of the mucosal margin apical to the restoration margin is positive mucosal recession $(\mathrm{MR} ;+)$, position of the mucosal margin coronal to the restoration margin is negative (-) MR.

\section{Surgical treatment}

Following administration of local anaesthetics, a sulcular incision was made around the neck of the implant abutments, and full-thickness flaps were raised at the buccal and lingual surfaces to access the peri-implant defects. The incisions were extended mesially and distally allowing adequate access. All granulomatous tissue was carefully removed with titanium instruments (Deppeler SA, Rolle, Switzerland). The threads were carefully cleaned from mineralized calculus, if apparent, and the implant surface was cleaned with hydrogen peroxide ( $3 \%$ ) for $1 \mathrm{~min}$., followed by profuse rinsing with saline. The baseline assessments of defect characteristics including the loss of implant surrounding bone from the implant platform to the most apical bone defect was measured.

Assignment to test and control group was made using pre-prepared randomization in groups A or B. Cards with group identification were prepared and placed in number coded envelopes as defined by SPSS 18.0 software (IBM SPSS, Armonk, NY, USA). Following surgical entry and debridement of implants the envelope with the code was opened and the subject was treated with bone/bone substitute material as assigned by the code instruction. Once the data set was locked the code was broken.

Depending on the assigned treatment the defect was either filled by $\mathrm{AB}$ that was obtained from the subject using a bone scraper (Safescraper $^{\mathbb{B}}$ TWIST; Biomet3I Inc., Palm Beach, FL, USA), using cortical bone harvested from the mandibular ramus region or Bio-Oss ${ }^{\circledR}$ (particle size $0.25 \mu \mathrm{m}$; Geistlich Pharma, Wolhusen, Switzerland) according to protocol. A resorbable membrane $\left(\right.$ OsseoGuard ${ }^{\circledR}$; Biomet3I Inc., Palm Beach, FL, USA) was used to cover the bone or bone substitute. The flaps were sutured using 4.0 sutures (Ethicon vicryl polyglacin, Johnson \& Johnson, San Angelo, TX, USA) allowing non-submerged wound healing.

Subjects were prescribed postoperative antibiotics (Azithromycin ${ }^{\mathbb{B}}$; Sandoz A/S, Copenhagen Denmark; $2 \times 250 \mathrm{mg}$ day 1 and $1 \times 250 \mathrm{mg}$ days 2-4). During the first 6 weeks after surgery, all subjects rinsed with $0.1 \%$ chlorhexidine (Hexident, Meda AB, Stockholm, Sweden). During the first 3 days all subjects also received an anti-inflammatory and analgesic drug (Ibuprofen $400 \mathrm{mg} \times 3$ days; Ibumetin, $\mathrm{Ny}-$ comed AB Stockholm, Sweden).

Six weeks after surgery the first supportive therapy was given, and the subjects were enrolled in a maintenance programme with visits every third month. At these visits, full mouth plaque scores were obtained. Plaque was disclosed using an erythrosine dye (Top Dent Lifco Dental 
AB, Enköping, Sweden). Re-instruction in oral hygiene procedures was performed as deemed necessary. All existing teeth and implants were cleaned using a rubber cup and a low-abrasive paste. During the follow-up period, none of the subjects was prescribed additional antibiotics.

\section{Successful outcome of treatment}

Two different approaches to define the treatment outcomes as successful were taken and in principle based on current definitions of implant health using PD, BOP and data on suppuration and with no loss of alveolar bone in consideration.

\section{Statistical analysis}

Statistical analysis included descriptive statistics for the clinical and radiographic parameters assessed at the implants a base line and 1-year follow-up. For the peri-implant and radiographic parameters, means and standard deviations were calculated.

The primary outcome measure was the change of bone levels as assessed from intra-oral radiographs. The secondary treatment outcome measure was the changes in mean PDs at treated implants. Implant-based analysis by general linear model multivariate analysis controlling for the number of implants by each subject by weighted least square regression and by Bonferroni adjustment for multiple comparisons was used to assess the effect of therapy on the primary and secondary outcomes. Chisquare test, independent $t$-tests, and multinomial regression analysis was included in the analysis to assess the likelihood of peri-implantitis by implant surface characteristics adjusting for the number of implants assessed per subject were also used. The precision in the assessments of bone levels was studied by intra-class correlation (ICC), and paired $t$-tests. Statistical significance was determined at an alpha level of 0.05 . The IBM SPSS 18.0 statistical software package for MAC computers was used (IBM SPSS, Armonk, NY, USA)

\section{Statistical power analysis}

We assumed a $0.4 \mathrm{~mm}$ probing pocket depth difference by group and with a standard deviation in PD of $0.4 \mathrm{~mm}$, and a normal distribu- tion pattern consistent with variation in the normal population. This would require 20 subjects in each group with $\alpha=0.05$.

\section{Results}

Baseline characteristics for subjects in the two study groups are presented (Table 1).

In the present study, 22 subjects (34 implants) were treated with surgical debridement and the placement of $A B$ obtained from the same study subjects ( $\mathrm{AB}$ ), and 23 subjects (37 implants) were treated with surgical debridement and placement of a bone substitute at study implants (BDX).

In the $\mathrm{AB}$ group, $59.1 \%$ of subjects had a cardiovascular-related disease (high blood pressure, history of stroke or heart attack), one subject had a diagnosis of rheumatoid arthritis, and $36.4 \%$ of the subjects were healthy. In the BDX group, $26 \%$ had a cardiovascular-related disease. One subject reported three significant diseases (rheumatoid arthritis, arthrosis and depression) whereas $62.5 \%$ of the subjects reported that they were healthy. A current smoking habit was reported by $40.9 \%$ and $69.6 \%$ in the $\mathrm{AB}$ and $\mathrm{BDX}$ groups respectively $(p<0.05)$. Periodontitis was the cause of tooth loss resulting in implant placement among $66.7 \%$ of the subjects in the AB group, and in $95.2 \%$ of the subjects in the BDX group $(p<0.05)$.

Repeated measurements of bone levels on radiographs were made from 15 implants and assessed both at the mesial and the distal surfaces using baseline and year one images. The differences bone levels between baseline and year one were calculated and compared between the two sets of measurements. Analysis by paired $t$-test identified a $0.1 \mathrm{~mm}(\mathrm{SD} \pm 0.4)$ bone level change difference between the two sets of measurements $(95 \%$ CI: -0.2 to $0.1, p=0.36$ ). The ICC coefficient was 0.97 (95\% CI: 0.95 to $0.99, p<0.001)$.

Data on the distribution of bone level observations at the time of surgery are presented in Table 2 and the data on clinical and radiographic mean values, SD, and $95 \%$ $\mathrm{CI}$ at the 1 year exam following the surgical procedures are presented in Table 3.

\section{Clinical dierence by study groups at} month 12

At 12 months significant differences between results obtained for implants in the $\mathrm{AB}$ and $\mathrm{BDX}$ groups were found for bone level data $(p<0.001)$, mean BOP $\%(p=0.004)$, and PI \% $(p=0.003)$. Greater clinical improvements were obtained in the $\mathrm{AB}$ group.

\section{Outcomes of intervention (changes} between baseline and month 12)

Adjusted for the number of implants per subject, statistical analysis demonstrated that the differences in bone height levels (radiographic evidence of defect fill) were similar between mesial and distal surfaces but greater in the BDX group $(p<0.001$, and $p<0.05$ respectively; Table 4). Statistical analysis also demonstrated a difference in mean PD reduction between study groups $(p<0.01$; Table 4$)$. In addition, the \% reduction of suppuration was greater in the BDX group $(p<0.01)$. Statistical analysis failed to demonstrate differences in \% BOP and \% PI changes between study groups. A clinical case presenting the use of $\mathrm{AB}$ and 12 months results are illustrated (Fig. 2).

Successful treatment outcome defined by PD $\leq 5 \mathrm{~mm}$, no BOP, and no suppuration (at any implant surface) and gain or no loss of alveolar bone

Using such a definition of successful treatment outcome four implants $(11.1 \%)$ in the $\mathrm{AB}$ group and eight implants $(20.5 \%)$ in the BDX group were successfully treated. Statistical analysis failed to demonstrate a difference in treatment outcome when adjustment was made for the number of study implants in each subjects.

Successful treatment outcome defined by PD $\leq 5 \mathrm{~mm}$, allowing one site with BOP, and no suppuration (at any implant surface) and gain or no loss of alveolar bone

A successful outcome was obtained at 1 year for $13.9 \%$ of implants in the $\mathrm{AB}$ group, and for $38.5 \%$ of implants in the BDX group. This difference was significant $\left(\chi^{2}=5.9\right.$, $p<0.05$ ) with an unadjusted odds 
Table 1. Baseline study conditions

\begin{tabular}{|c|c|c|c|c|c|c|c|c|}
\hline \multirow[t]{2}{*}{ Variables } & \multicolumn{3}{|c|}{ AB group $(n=22)$} & \multicolumn{3}{|c|}{$\begin{array}{l}\text { BDX group } \\
\quad(n=23)\end{array}$} & \multirow[t]{2}{*}{$95 \% \mathrm{CI}$} & \multirow[t]{2}{*}{ Sign. } \\
\hline & $\%$ & Mean & SD & $\%$ & Mean & SD & & \\
\hline Gender (female) & 63.6 & & & 56.5 & & & & NS \\
\hline Subject age & & 70.1 & 6.2 & & 67.0 & 7.5 & & NS \\
\hline Number of estimated pack/years (smokers only) & & 23.2 & 13.4 & & 18.8 & 11.0 & -6.8 to 15.6 & NS \\
\hline Proportion of edentulous subjects & 13.6 & & & 26.1 & & & & NS \\
\hline Number of remaining teeth in dentate subjects & & 13.4 & 7.4 & & 12.9 & 7.8 & -4.6 to 5.7 & NS \\
\hline Number of implants present & & 5.4 & 2.2 & & 6.2 & 2.9 & -0.7 to 2.4 & NS \\
\hline $\begin{array}{l}\text { Number of implants with distance } \geq 2 \mathrm{~mm} \text { from implant platform to } \\
\text { bone level (implants in study) }\end{array}$ & & 3.4 & 1.7 & & 3.6 & 2.2 & -1.0 to 1.4 & NS \\
\hline Number of implants included in the study & & 1.7 & 0.7 & & 2.1 & 1.4 & -0.3 to 1.1 & NS \\
\hline \multicolumn{9}{|l|}{ Type of implant } \\
\hline Implamed & 1 & & & 2 & & & & \\
\hline Nobel biocare & 17 & & & 17 & & & & \\
\hline Straumann & 2 & & & 2 & & & & \\
\hline Ti-Unite & 2 & & & 1 & & & & \\
\hline Unknown & 0 & & & 1 & & & & \\
\hline Proportion of implants in the maxilla & 31.8 & & & 39.1 & & & & NS \\
\hline Attached mucosa (buccal) all implants independent of location & 45.5 & & & 52.2 & & & & NS \\
\hline PD mesial (mm) & & 6.6 & 1.6 & & 6.7 & 1.6 & -0.9 to 1.0 & NS \\
\hline PD buccal (mm) & & 5.3 & 1.5 & & 5.5 & 2.3 & -1.2 to 1.6 & NS \\
\hline PD distal (mm) & & 6.4 & 1.5 & & 6.8 & 2.1 & -0.7 to 1.5 & NS \\
\hline PD lingual/palatal (mm) & & 5.5 & 1.7 & & 5.5 & 2.0 & -1.1 to 1.2 & NS \\
\hline PD mean value (mm) & & 6.0 & 1.3 & & 6.2 & 1.4 & -0.6 to 1.0 & NS \\
\hline BOP mesial & 95.5 & & & 91.3 & & & & NS \\
\hline BOP buccal & 68.2 & & & 73.9 & & & & NS \\
\hline BOP distal & 90.9 & & & 91.3 & & & & NS \\
\hline BOP lingual/palatal & 95.5 & & & 60.9 & & & & $<0.01$ \\
\hline BOP mean BOP \% & & 87.5 & 20.1 & & 79.4 & 28.9 & -6.9 to 23.2 & NS \\
\hline PI mesial & 28.6 & & & 17.4 & & & & NS \\
\hline PI buccal & 19.0 & & & 13.0 & & & & NS \\
\hline PI distal & 19.0 & & & 13.0 & & & & NS \\
\hline PI lingual/palatal & 19.9 & & & 8.7 & & & & NS \\
\hline PI mean \% & & 21.4 & 25.4 & & 13.0 & 23.7 & -6.5 to 23.5 & NS \\
\hline Suppuration mesial & 4.5 & & & 17.4 & & & & NS \\
\hline Suppuration buccal & 27.3 & & & 39.1 & & & & NS \\
\hline Suppuration distal & 13.6 & & & 26.1 & & & & NS \\
\hline Suppuration lingual/palatal & 9.1 & & & 17.4 & & & & NS \\
\hline Suppuration mean \% & & 12.5 & 21.5 & & 25.0 & 32.9 & $-4.3 /$ to 23.4 & NS \\
\hline
\end{tabular}


Table 2. Assessed clinical variables during surgery, and radiographic bone level scores

\begin{tabular}{|c|c|c|c|c|c|c|}
\hline \multirow[t]{2}{*}{ Variables } & \multicolumn{2}{|c|}{$\begin{array}{l}\text { AB group } \\
(n=22)\end{array}$} & \multicolumn{2}{|c|}{$\begin{array}{l}\text { BDX group } \\
\quad(n=23)\end{array}$} & \multirow[t]{2}{*}{$95 \% \mathrm{CI}$} & \multirow[t]{2}{*}{ Sign. } \\
\hline & Mean & SD & Mean & SD & & \\
\hline Number of exposed threads & 7.8 & 3.4 & 6.8 & 3.2 & -0.5 to 2.5 & NS \\
\hline \multicolumn{7}{|c|}{ Defect depth bone crest to defect bottom (mm) } \\
\hline Mesial & 3.7 & 2.1 & 4.0 & 2.4 & -1.4 to 0.7 & NS \\
\hline Buccal & 0.2 & 0.6 & 0.6 & 1.3 & -0.9 to 0.1 & NS \\
\hline Distal & 4.1 & 2.5 & 3.9 & 2.0 & -0.8 to 1.2 & NS \\
\hline Lingual/palatal & 1.9 & 2.0 & 1.2 & 1.8 & -0.1 to 1.7 & NS \\
\hline \multicolumn{7}{|l|}{ Defect depth } \\
\hline Mean value $(\mathrm{mm})$ & 2.5 & 1.3 & 2.6 & 1.5 & -0.7 to 0.6 & NS \\
\hline \multicolumn{7}{|c|}{ Vertical depth [distance: implant platform to defect bottom (mm)] } \\
\hline Mesial & 5.8 & 1.9 & 5.9 & 2.3 & -1.2 to 0.9 & NS \\
\hline Buccal & 5.6 & 2.6 & 5.6 & 2.6 & -1.0 to 1.8 & NS \\
\hline Distal & 6.0 & 2.3 & 5.7 & 2.3 & -1.1 to 0.9 & NS \\
\hline Lingual/palatal & 5.6 & 3.4 & 5.9 & 2.7 & -1.9 to 0.5 & NS \\
\hline $\begin{array}{l}\text { Vertical depth [distance: implant } \\
\text { platform to defect bottom }(\mathrm{mm}) \text { ]: } \\
\text { mean value }\end{array}$ & 5.6 & 2.2 & 5.9 & 2.7 & -1.3 to 0.8 & NS \\
\hline $\begin{array}{l}\text { Radiographic assessment defect } \\
\text { depth [distance: implant platform } \\
\text { to defect bottom: mesial (mm)] }\end{array}$ & 5.9 & 1.8 & 5.2 & 1.8 & -0.2 to 1.5 & NS \\
\hline $\begin{array}{l}\text { Radiographic assessment defect } \\
\text { depth [distance: implant platform } \\
\text { to defect bottom: distal (mm)] }\end{array}$ & 5.8 & 1.6 & 5.3 & 1.8 & -0.2 to 1.3 & NS \\
\hline
\end{tabular}

Table 3. Clinical and radiographic mean values, SD and $95 \% \mathrm{CI}$ at 1 year following implant surgical procedures (adjusted for number of implants per subject in the study)

\begin{tabular}{|c|c|c|c|c|c|c|c|c|}
\hline \multirow[t]{2}{*}{ Variables } & \multicolumn{2}{|c|}{$\begin{array}{l}\text { AB group } \\
(n=22) 36 \\
\text { implants }\end{array}$} & \multicolumn{2}{|c|}{$\begin{array}{c}\text { BDX } \\
\text { group } \\
(n=23) 39 \\
\text { implants }\end{array}$} & \multicolumn{2}{|c|}{$\begin{array}{c}\text { Mean } \\
\text { difference }\end{array}$} & \multirow[t]{2}{*}{$95 \% \mathrm{CI}$} & \multirow[t]{2}{*}{ Sign. } \\
\hline & Mean & SE & Mean & SE & Mean & SE & & \\
\hline $\begin{array}{l}\text { Radiographic assessment } \\
\text { defect depth [distance: } \\
\text { implant platform to } \\
\text { defect bottom: mesial }(\mathrm{mm})]\end{array}$ & 5.8 & 0.3 & 4.0 & 0.3 & 1.8 & 0.4 & 1.0 to 2.6 & 0.000 \\
\hline $\begin{array}{l}\text { Radiographic assessment } \\
\text { defect depth [distance: } \\
\text { implant platform to } \\
\text { defect bottom: distal }(\mathrm{mm}) \text { ] }\end{array}$ & 5.7 & 0.3 & 4.3 & 9.3 & 1.4 & 0.4 & 0.5 to 2.2 & 0.000 \\
\hline Mean defect depth (mm) & 5.8 & 0.3 & 4.2 & 0.3 & 0.8 & 2.4 & 0.8 to 2.4 & 0.000 \\
\hline PD mesial (mm) & 4.0 & 0.3 & 3.5 & 0.2 & 0.5 & 0.3 & -0.2 to 1.1 & 0.18 \\
\hline PD buccal (mm) & 3.2 & 0.2 & 3.0 & 0.2 & 0.2 & 0.3 & -0.4 to 0.9 & 0.49 \\
\hline PD distal $(\mathrm{mm})$ & 3.8 & 0.2 & 3.3 & 0.2 & 0.5 & 0.3 & -0.1 to 1.1 & 0.12 \\
\hline $\mathrm{PD}$ lingual/palatal (mm) & 3.8 & 0.2 & 3.3 & 0.2 & 0.5 & 0.3 & -0.1 to 1.1 & 0.10 \\
\hline PD mean value $(\mathrm{mm})$ & 3.8 & 0.2 & 3.3 & 0.2 & 0.5 & 0.3 & -0.1 to 1.0 & 0.06 \\
\hline Mean BOP \% & 48.4 & 5.4 & 26.7 & 4.7 & 21.7 & 7.1 & 7.4 to 36.0 & 0.004 \\
\hline Mean PI \% & 18.7 & 3.6 & 4.1 & 3.1 & 14.7 & 4.8 & 5.1 to 24.2 & 0.003 \\
\hline Suppuration mean $\%$ & 2.0 & 1.6 & 1.2 & 1.4 & 0.8 & 0.2 & -3.5 to 5.1 & 0.71 \\
\hline
\end{tabular}

ratio of $3.9(95 \% \mathrm{CI}: 1.2$ to 12.2 , $p<0.05)$. When adjusting for the number of implants treated in each subject, the likelihood of a successful treatment outcome allowing one site with BOP was 3.2 (95\% CI: 1.0 to $10.6, p<0.05)$ for the advantage of the BDX group. ity. Limited amounts of defect fill were noticed in both study groups. PD values, BOP and suppuration were reduced in both groups. Baseline defect depth approached on average $2.5 \mathrm{~mm}$ resulting in, on average, a vertical defect fill of $1 \mathrm{~mm}$ at 1 year in the BDX group and less in the AB group. This was unexpected while the defects in both groups were completely filled at the time of surgery.

It appears that smokers have an increased risk of complications following implant therapy (Heitz-Mayfield \& Huynh-Ba 2009, RodriguezArgueta et al. 2011), and this is consistent with regenerative studies in patients with periodontitis (Tonetti et al. 1995). The lesser extent of defect fill in the present study may be explained by differences in smoking status. In the study by Roccuzzo et al. (2011) 17\% of the subjects were smokers compared with $70 \%$ in the present study (BDX group).

In the present study, the use of an autologous bone graft resulted in limited defect fill. This is in contrast to previous reports by Behneke et al. (2000) and Khoury \& Buchmann (2001) reporting considerable defect fill using autologous bone. One explanation to the differences in bone fill obtained in the $\mathrm{AB}$ group in the present study may relate to the fact that bone blocks were stabilized by mini screws by Behneke et al. (2000). Bone blocks may not be displaced easily or as prone to resorption as bone harvested using a bone scraper. In the study by Khoury \& Buchmann (2001) "crater formed defects" were augmented using $\mathrm{AB}$ resulting in an average defect fill of $3.4 \mathrm{~mm}$. The difference in results obtained in the present study compared with the study by Khoury \& Buchmann (2001) may also be explained by the non-submerged healing method used in the present study. Although no comparative human studies exist evaluating submerged versus non-submerged healing, an animal study by Schwarz et al. (2006a,b) demonstrated that submerged healing was superior to non-submerged healing. This has been confirmed in clinical studies Roos-Jansåker et al. (2007a,b). Defect configuration at the time of surgery may also influence the extent of bone fill (Schwarz et al. 2010). 
Table 4. Changes in BOP, PI, suppuration, PD and bone level change (adjusted for the number of implants per subject in the study)

\begin{tabular}{|c|c|c|c|c|c|c|c|c|}
\hline Variables & \multicolumn{2}{|c|}{$\begin{array}{c}\text { AB group } \\
(n=22) 36 \\
\text { implants }\end{array}$} & \multicolumn{2}{|c|}{$\begin{array}{c}\text { BDX group } \\
(n=23) 39 \\
\text { implants }\end{array}$} & \multicolumn{2}{|c|}{ Mean difference } & $95 \% \mathrm{CI}$ & Sign. \\
\hline Mean bone level gain (mm) & 0.2 & 0.3 & 1.1 & 0.3 & 0.8 & 0.4 & 0.1 to 1.7 & 0.05 \\
\hline Mean PD decrease $(\mathrm{mm})$ & 2.0 & 0.2 & 3.1 & 0.2 & 1.1 & 0.3 & 0.5 to 1.7 & 0.01 \\
\hline$\%$ Suppuration mean change (reduction) & 11.5 & 5.2 & 25.2 & 4.3 & 16.3 & 6.5 & 3.4 to 20.2 & 0.01 \\
\hline
\end{tabular}

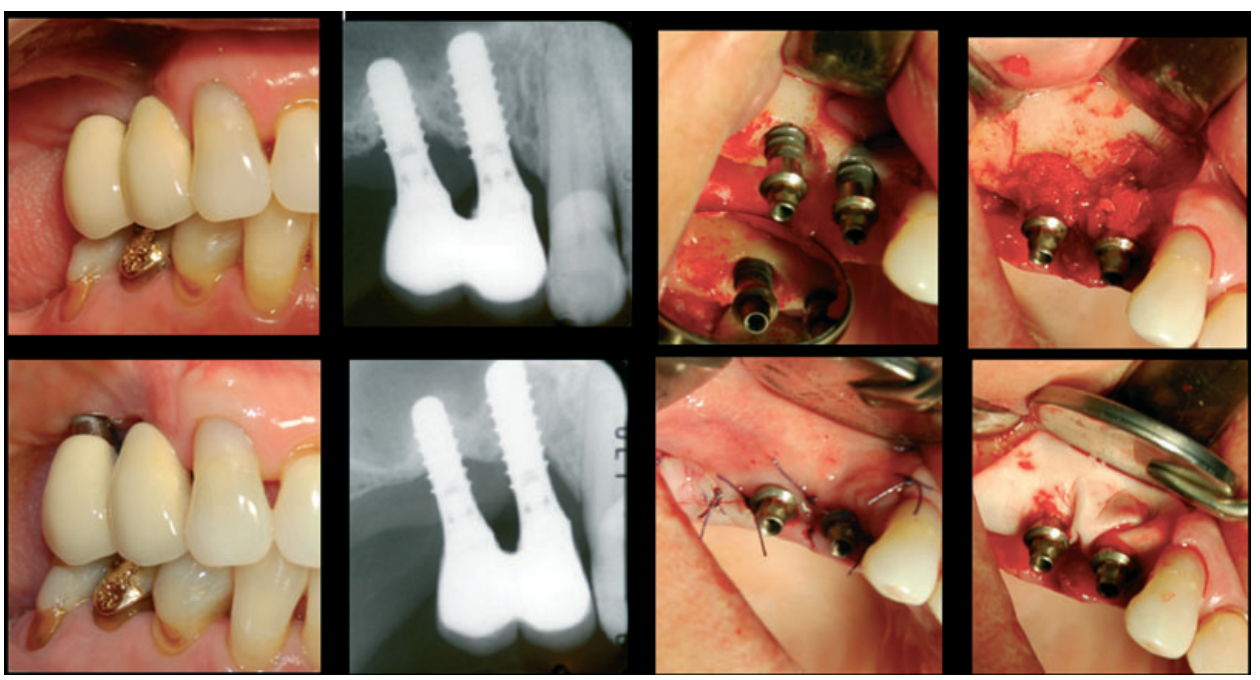

Fig. 2. Panel of radiographic and clinical images at the time of surgery and at 12 months are presented for one case treated with autogenous bone graft.

The placement of bone graft materials composed of a mixture of a xenograft and autologous bone in bone defects $>4 \mathrm{~mm}$ at implants receiving surgical treatment of periimplantitis appears to result in defect fill as assessed radiographically at 1 year varying between 1 and $5 \mathrm{~mm}$ (Wiltfang et al. 2010). The results obtained by Roos-Jansåker et al. (2011) are in the range of the results obtained in the present study for the BDX group. In a recent review of the available literature, the authors concluded that complete fill of the bony defect using guided bone regeneration procedures is not predictable (Sahrmann et al. 2011).

In the present study, we also focused on successful outcomes consistent with implant health as recently defined (Sanz et al. 2012).
The success rate was low but increased to approximately $40 \%$ in the BDX group if BOP at one implant surface was accepted. The high prevalence of BOP was the primary factor why a successful outcome could not be diagnosed.

The rationale for antibiotic prescription was to limit early post-surgical bacterial colonization (Fürst et al. 2007). There is ample evidence that post-surgical prescription and use of antibiotics promote healing and regeneration (Thomas \& Puleo 2011). There are strict medical guidelines when to use pre-operative antibiotic prophylaxis. None of the study subjects met those requirements.

It should be considered that the use of radiographs is limited to describe defect fill and not actually integrated bone fill. Although the reviewer was blinded to study group allocation it would be difficult to blind an experienced examiner not to potentially recognize the material used in the two study groups. Due to the lack of reliable data on the outcomes of regenerative procedures in dental implant research we based our power analysis on limited data and from our previous studies. In the present study a difference in defect fill between $\mathrm{AB}$ and BDX treated implants was found. Thus, we rejected the null hypothesis. The risk for type I error should be considered in relation to the limited success as defined by the criteria for healthy conditions.

In conclusion, the use of a bone xenograft provides more radiographic evidence of defect fill than treatment with $\mathrm{AB}$. The overall success for both 
surgical regenerative procedures was limited. PD reduction, decrease in BOP and presence of suppuration were clinically relevant in both study groups.

\section{Acknowledgements}

We appreciate the support for the study from BIOMET3i Inc., (Palm Beach, FL, USA), the University of Kristianstad, Sweden and from the Uppsala Käkkirurgiska Center and Ms Ulla Lundström RDH (UL) at the Uppsala Käkkirurgiska Center for the clinical measurements. We also appreciate the support for data management by Ms. Johanna Renvert.

\section{References}

Behneke, A., Behneke, N. \& d'Hoedt, B. (2000) Treatment of peri-implantitis defects with autogenous bone grafts: six-month to 3-year results of a prospective study in 17 patients. International Journal of Oral Maxillofacial Implants 15, 125-138.

Charalampakis, G., Rabe, P., Leonhardt, A. \& Dahlén, G. (2011) A follow-up study of periimplantitis cases after treatment. Journal of Clinical Periodontology 38, 864-871.

Esposito, M., Grusovin, M.G. \& Worthington, H V. (2012) Interventions for replacing missing teeth: treatment of peri-implantitis. Cochrane Database of Systematic Reviews 18, CD004970.

Fürst, M.M., Salvi, G.E., Lang, N.P. \& Persson, G.R. (2007) Bacterial colonization immediately after installation on oral titanium implants. Clinical Oral Implants Research 18, 501-518.

Heitz-Mayfield, L.J. \& Huynh-Ba, G. (2009) History of treated periodontitis and smoking as risks for implant therapy. International Journal of Oral Maxillofacial Implants 24(Suppl.), 39-68.

Khoury, F. \& Buchmann, R. (2001) Surgical therapy of peri-implant disease: a 3-year follow-up study of cases treated with 3 different techniques of bone regeneration. Journal of Periodontology 72, 1498-1508.

Lang, N.P., Berglundh, T. \& Working Group 4 of Seventh European Workshop on Periodontology (2011) Periimplant diseases: where are we now? Consensus of the Seventh European Workshop on Periodontology. Journal of Clinical Periodontology 38(Suppl. 11), 178-181.

Persson, G.R., Samuelsson, E., Lindahl, C. \& Renvert, S. (2010) Mechanical non-surgical treatment of peri-implantitis: a single-blinded randomized longitudinal clinical study. II.

\section{Clinical Relevance}

Scientific rationale for the study: Presently, limited evidence exists on the efficacy of surgical treatment of peri-implantitis and the use of autogenous bone grafts whereas some evidence exists for the use of xenografts.
Microbiological results. Journal of Clinical Periodontology 37, 563-573.

Renvert, S., Samuelsson, E., Lindahl, C. \& Persson, G.R. (2009) Mechanical non-surgical treatment of peri-implantitis: a double-blind randomized longitudinal clinical study. I: clinical results. Journal of Clinical Periodontolog 36, 604-609.

Roccuzzo, M., Bonino, F., Bonino, L. \& Dalmasso, P. (2011) Surgical therapy of peri-implantitis lesions by means of a bovine-derive xenograft: comparative results of a prospective study on two different implant surfaces. Journal of Clinical Periodontology 38, 738-745.

Rodriguez-Argueta, O.F., Figueiredo, R., Valmaseda-Castellon, E \& Gay-Escoda, C. (2011) Postoperative complications in smoking patients treated with implants: a retrospective study. Journal of Oral Maxillofacial Surgery 69, 2152-2157.

Romanos, G.E. \& Nentwig, G.H. (2008) Regenerative therapy of deep peri-implant infrabony defects after $\mathrm{CO}_{2}$ laser implant surface decontamination. The International Journal of Periodontics and Restorative Dentistry 28, 245-255.

Romeo, E., Ghisolfi, M., Murgolo, N., Chiapasco, M., Lops, D. \& Vogel, G. (2007) Therapy of peri-implantitis with resective surgery. A 3-year clinical trial on rough screw-shaped oral implants. Part I: clinical outcome. Clinical Oral Implants Research 18, 179-187.

Roos-Jansåker, A-M., Lindahl, C., Persson, G.R \& Renvert, S. (2011) Long-term stability of surgical boneregenerative procedures of periimplantitis lesions in a prospective case-contro study over3 years. Journal of Clinical Periodontology 38, 590-597.

Roos-Jansåker, A-M., Renvert, H., Lindahl, H. \& Renvert, S. (2007a) Submerged healing following surgical treatment of peri-implantitis: a case series. Journal of Clinical Periodontology $\mathbf{3 4}$ 723-727.

Roos-Jansåker, A-M., Renvert, H., Lindahl, H. \& Renvert, S. (2007b) Surgical treatment of periimplantitis using a bone substitute with or without a resorbable membrane: a prospective cohort study. Journal of Clinical Periodontology 34, 625-632.

Sahm, N., Becker, J., Santel, T. \& Schwarz, F (2011) Non-surgical treatment of peri-implantitis using an air-abrasive device or mechanica debridement and local application of chlorhexidine: a prospective, randomized, controlled clinical study, Journal of Clinical Periodontology 38, 872-878.

Sahrmann, P., Attin, T. \& Schmidlin, P.R. (2011) Regenerative treatment of peri-implantitis using bone substitutes and membrane: a systematic review. Clinical Implant and Dental Related Research 13, 46-57.

Sanz, M., Chapple, I. \& on Behalf of Working Group 4 of the Eighth European Workshop on Periodontology (2012) Clinical research on periimplant diseases: consensus report of Working

Principal findings: Less than $40 \%$ of cases were defined as successfully treated, if this was defined as no probing depth $>5 \mathrm{~mm}$, no suppuration, no loss of bone but allowing bleeding on probing at one of four sites around the treated implant, if a bovine bone xenograft was used and
Group 4. Journal of Clinical Periodontology 39 (Suppl.), 202-206.

Schwarz, F., Becker, K., Nuesry, E., Sculean, A. \& Becker, J. (2006b) Clinical and histological healing pattern of peri-implantitis lesions following non-surgical treatment with an Er:YAG laser. Lasers in Surgery and Medicine 38, 663-671.

Schwarz, F., Jepsen, S., Herten, M., Sager, M. Rothamel, D. \& Becker, J. (2006a) Influence of different treatment approaches on non-submerged and submerged healing of ligature induced peri-implantitis lesions: an experimental study in dogs. Journal of Clinical Periodontology 33, 584-595.

Schwarz, F., Sahm, N., Bieling, K. \& Becker, J. (2009) Surgical regenerative treatment of periimplantitis lesions using a nanocrystalline hydroxyapatite or a natural bone mineral in combination with a collagen membrane: a fouryear clinical follow-up report. Journal of Clinical Periodontology 36, 807-814.

Schwarz, F., Sahm, N., Iglhaut, G. \& Becker, J (2011) Impact of the method of surface debridement and decontamination on the clinical outcome following combined surgical therapy of peri-implantitis: a randomized controlled clinical study. Journal of Clinical Periodontology 38, 276-284.

Schwarz, F., Sahm, N., Schwarz, K. \& Becker, J. (2010) Impact of defect configuration on the clinical outcome following surgical regenerative therapy of peri-implantitis. Journal of Clinical Periodontology 37, 449-455.

Serino, G. \& Turri, A. (2011) Outcome of surgical treatment of peri-implantitis: results from a 2-year prospective clinical study in humans. Clinical Oral Implants Research 22, 1214-1220.

Thomas, M.V. \& Puleo, D.A. (2011) Infection, inflammation, and bone regeneration: a paradoxical relationship. Journal of Dental Research 90, 1052-1061

Tonetti, M.S., Pini-Prato, G. \& Cortellini, P. (1995) Effect of cigarette smoking on periodontal healing following GTR in infrabony defects. A preliminary retrospective study. Journal of Clinical Periodontology 22, 229-234.

Wiltfang, J., Zernial, O., Behrens, E., Schlegel, A., Warnke, P.H. \& Becker, S.T. (2010) Regenerative treatment of peri-implantitis bone defects with a combination of autologous bone and a demineralized xenogenic bone graft: a series of 36 defects. Clinical Implant Dentistry and Related Research doi: 10.1111/j.17088208.2009.00264.x.

\section{Address:}

S. Renvert

Kristianstad University

29188 Kristianstad

Sweden

E-mail: stefan.renvert@hkr.se

even fewer successful cases for autogenous bone.

Practical implications: Based on the present study results, the use of autogenous bone or a bovinederived xenograft has limited effects in the treatment of peri-implantitis. 
II 



\section{CLINICAL ORAL IMPLANTS RESEARCH}

\section{Stefan Renvert \\ Ahmad Aghazadeh \\ Hadar Hallström \\ Gösta Rutger Persson}

\section{Factors related to peri-implantitis - a retrospective study}

Authors' affiliations:

Stefan Renvert, Gösta Rutger Persson, Department of Oral Sciences, Kristianstad University, Kristianstad, Sweden Stefan Renvert, School of Dental Sciences, Trinity College, Dublin, Ireland

Stefan Renvert, Blekinge Institute of Technology, Karlskrona, Sweden

Ahmad Aghazadeh, Uppsala Käkkirurgiska

Ahmad Aghazadeh, Uppsala
Centrum, Uppsala, Sweden

Hadar Hallström, Department of Periodontology, Maxillofacial Unit, Hospital of Halland, Halmstad, Sweden

Gösta Rutger Persson, Departments of Periodontics and Oral Medicine, University of Washington, Seattle, WA, USA

Gösta Rutger Persson, Department of

Periodontology, University of Bern, Bern, Switzerland

\section{Corresponding author:}

Stefan Renvert

Department of Oral Sciences

Kristianstad University

SE-29188 Kristianstad, Sweden

Tel.: +46 44204090

Fax: +46 44128590

e-mail: stefan.renvert@hkr.se

Key words: peri-implantitis, periodontitis, risk assessment, smoking, systemic disease

\section{Abstract}

Objectives: Retrospectively, we assessed the likelihood that peri-implantitis was associated with a history of systemic disease, periodontitis, and smoking habits.

Methods: Data on probing pocket depth (PPD), bleeding on probing (BOP), and radiographic bone levels were obtained from individuals with dental implants. Peri-implantitis was defined as described by Sanz \& Chapple 2012. Control individuals had healthy conditions or peri-implant mucositis. Information on past history of periodontitis, systemic diseases, and on smoking habits was obtained.

Results: One hundred and seventy-two individuals had peri-implantitis (mean age: 68.2 years, $S D \pm 8.7$ ), and 98 individuals (mean age: 44.7 years, $S D \pm 15.9$ ) had implant health/peri-implant mucositis. The mean difference in bone level at implants between groups was $3.5 \mathrm{~mm}$ (SE mean $\pm 0.4,95 \% \mathrm{Cl}: 2.8,4.3, P<0.001$ ). A history of cardiovascular disease was found in $27.3 \%$ of individuals with peri-implantitis and in $3.0 \%$ of individuals in the implant health/peri-implant mucositis group. When adjusting for age, smoking, and gender, odds ratio (OR) of having periimplantitis and a history of cardiovascular disease was 8.7 (95\% Cl: $1.9,40.3 P<0.006)$, and odds ratio of having a history of periodontitis was $4.5(95 \% \mathrm{Cl} 2.1,9.7, P<0.001)$. Smoking or gender did not significantly contribute to the outcome.

Conclusions: In relation to a diagnosis of peri-implantitis, a high likelihood of comorbidity was expressed by a history of periodontitis and a history of cardiovascular disease.

The 7th and the 8th European Workshops on Periodontology have provided the curren guidelines for the definition of peri-implantitis (Lang \& Berglundh 2011; Sanz \& Chapple 2012). Thus, dental implants with periimplantitis must have evidence of $\geq 2-\mathrm{mm}$ bone loss from the expected marginal bone at implant installation and with concurrent bleeding on probing (BOP) and/or suppuration. Implants with a distance $<2.0 \mathrm{~mm}$ between bone level and implant platform level or other reference point and with no BOP or suppuration represent healthy conditions. If bleeding and/or suppuration can be identified at such implants, the diagnosis is peri-implant mucositis (Renvert et al. 2008, Lang \& Berglundh 2011).

Several studies have identified a high prevalence of peri-implantitis (i.e. Fransson et al 2005; Roos-Jansåker et al. 2006; Koldsland et al. 2010; Simonis et al. 2010; Rinke et al 2011). Data on 103 individuals with dental implants in function $\geq 8.5$ years have shown that $37 \%$ of the individuals presented with peri-implantitis in $37 \%$ having a high likelihood of active periodontitis or being edentulous and $\geq 65$ years of age (Marrone et al. 2012). In contrast, a study comprising 303 individuals with implants in function over 10 years demonstrated that the prevalence of peri-implantitis was only $1.8 \%$ (Buser et al. 2012). Another study including 36 non-smoking individuals over $\geq 10$ years has reported a subject-based prevalence rate of peri-implantitis in $9.1 \%$ of cases (Frisch et al. in press).

A relationship between severe chronic periodontitis and peri-implantitis has been identified (Aloufi et al. 2009). Recent data also suggest that peri-implantitis is a polymicrobial anaerobic infection (Charalampakis et al. 2012). Infectious susceptibility is most likely an important factor in peri-implantitis. Thus, it seems logical that a past history of periodontitis is linked to an increased risk of periimplantitis. Individuals older than 65 years, having active periodontitis, or being edentulous also appear to have high odds of developing peri-implantitis (Marrone et al. 2012). 
Several studies have suggested that smoking habits are associated with an elevated risk of peri-implantitis (Ferreira et al. 2006; RoosJansåker et al. 2006; Levin et al. 2008 , Carcuac \& Jansson 2011; Rodriguez-Argueta et al. 2011). A smoking habit in combination with poor compliance and poor oral hygiene appears to enhance the risk of peri-implantitis Rinke et al. 2011). Other data have, however suggested that smoking is not associated with peri-implantitis, whereas male gender and a history of periodontitis are risk indicators for peri-implantitis (Koldsland et al. 2011).

The clinical success of the implant is dependent on a perfect oral hygiene (Schroede et al. 1981). This may, however, be difficult to achieve by many individuals with denta implants. The absence of preventive maintenance has also been associated with a high incidence of peri-implantitis (Costa et al 2012; Koldsland et al. 2011). It has also been reported that maintenance of periodontal health rather than a previous history of periodontitis is the critical determinant of an increased risk of peri-implantitis /Cho-Yan Lee et al. 2012). The value of supportive main tenance care, particularly in subjects affected by periodontitis, in order to control re-infection and limit biological complications has been demonstrated (Roccuzzo et al. 2010).

There is limited information on the association between peri-implantitis and common systemic diseases. Some literature review reports have suggested that individuals with diabetes mellitus are at risk of peri-implantitis. There are, however, no studies that can confirm this perception, which seems to be driven by studies on the association between periodontitis and diabetes mellitus. One shortterm study including older individuals has failed to show that systemic conditions including cardiovascular diseases were associated with dental implant complications (Lee et al 2010). Another recent report has shown a significant comorbidity in individuals with car diovascular diseases and evidence of implants and with a high prevalence of moderate plaque, $\mathrm{BOP}$, and the presence of bacteria associated with periodontitis (Lachmann et al. in press).

The objectives of the present retrospective study were to assess the risk of having a diagnosis of periodontitis, a history of systemic disease, and a smoking habit in relation to peri-implantitis.

\section{Methods}

The Regional Ethics Review Board at Lund University, Sweden, approved the protocols for the studies performed at three clinical centers (LU 182-01, LU 183-01, Dnr 550/2006, Dnr 89/2007, Dnr 615/2007, Dnr 233/2007). All enrolled subjects signed written approved consent. The present retrospective clinical study was based on material and data col lected between 2007 and 2011 at the University of Kristianstad, Sweden (Center 1), at the Specialty Clinic for Periodontology, Region Halland, Halmstad, Sweden (Center 2), and at the Uppsala Käkkirurgiska Centrum, Uppsala Sweden (Center 3) (Renvert et al. 2007, 2009 2011; Hallström et al. 2012; Aghazadeh et al 2012 and yet unpublished data by the authors). The present study reports on baseline conditions obtained at the initial examination of consecutively enrolled individuals with either healthy/peri-implant mucositis implant conditions or peri-implantitis. Individuals $\geq 18$ years of age, who had not received sys temic or local antibiotics three months before enrollment, or otherwise received treatment for peri-implantitis during 6 months preced ing the examination, were included in the present retrospective analysis.

\section{Analysis of radiographs to assess alveolar bone} levels

One examiner (GRP) measured the distances between the most apical implant to bone contact level and implant platform level (IPL) for all sets of radiographs. The radiographs were taken with bite blocks to facilitate perpendicular alignment. The distance equal to three implant threads (known for each implant system in the analysis) was measured and used for the calibration of images. Bone level distances were measured with the OsiriX 3.9.1, 32-bit DICOM viewer opensource software (Pixmeo Sarl, Geneva, Switzerland) for Mac OS X version 10.6.7 computers. The images were studied in black and white and by CLUT (Color Look Up Tables) color-enhanced images to facilitate assess ments and confirm bone levels. The average bone level distances of mesial and distal aspects of each implant correcting for image magnification were calculated. The interex aminer precision (intraclass correlation) by independent assessments of distances was studied by repeated measurements of bone levels from 38 radiographs randomly selected from radiographs representing study implants. The repeated measurements were made with a time interval of at least one week between assessments.

\section{Definition of peri-implantitis}

Peri-implantitis was defined as an osseointegrated implant with loss of bone $\geq 2.0 \mathrm{~mm}$ assessed from the implant platform level (IPL) to the most apical level of bone to implant contact as defined by digital intraoral $(26 \times 37 \mathrm{~mm})$ radiographs. In addition, BOP, or suppuration from at least one surface area of the implant, and probing pocket depth $(\mathrm{PPD}) \geq 4 \mathrm{~mm}$ must be present. The PPD measurements were made with a standardized probing force of $0.2 \mathrm{~N}$ with the same probe design (Hawe Click-Probe, Hawe Neos Dental, Switzerland). The same probe design was used at all three study centers. BOP and the presence of suppuration were assessed within $60 \mathrm{~s}$ after measurements of PPDs.

\section{Healthy implants and implants with peri-} implant mucositis

Implants with healthy conditions were defined as those with no bleeding, or only bleeding at one surface assuming a point of bleeding as a consequence of trauma from probing, no suppuration, and bone loss $<2.0 \mathrm{~mm}$. Peri-implant mucositis was defined for implants with bone loss $<2.0 \mathrm{~mm}$ but with clinical evidence of overt BOP, tissue edema, and/or suppuration. Due to the fact that intra-oral radiographs form the time point when implants were placed could not be retrieved, we accepted bone remodeling $<2 \mathrm{~mm}$ from implant platform level to bone level as recommended by the 8th European Workshop on Periodontology (Sanz \& Chapple 2012). Individuals with implant health and those with evidence of peri-implant mucositis were merged to the non-periimplantitis group and as a different category than implants with evidence of progressive bone loss $(>2 \mathrm{~mm})$.

\section{Information on dental and medical history}

To the extent possible, dental records were used to confirm subject statement about past history of periodontitis. In dentate individuals, the examiner diagnosed current periodontal status and then confirmed the diagnosis. In non-dentate patients, the patient's answers to the question why their teeth had been lost were used to discriminate between periodontitis and non-periodontitis patients. Study participants also provided information about current and past smoking habits and medical conditions. If the individual had quit smoking more than 10 years ago, a no smoking status was assigned. In regard to medical conditions, subject-based information and medication lists were used to define the presence or absence of a history of disease. For cardiovascular diseases, a history of disease was assigned regardless of disease severity and included acute coronary syndrome, stroke, 
aneurysm, heart arrhythmia, ischemia, heart valve disease, atherosclerosis, and high blood pressure with medication.

\section{Statistical analysis}

Kolmogorov-Smirnov one-sample tests were performed to assess whether the data presented with a normal distribution patterns or not. The statistical methods included descriptive statistics, intraclass correlation analysis, independent $t$-test, Mann-Whitney $U$-tests, Pearson $\chi^{2}$ tests, Mantel-Haenszel unadjusted odds ratio, and assessments of odds ratios by bivariate logistic regression analysis adjusting for covariates. Significance was declared at $P<0.001$. The PASW/SPSS 21.0 statistical software package (IBM/SPSS, Amorak, NY, USA) for MAC computer was used for the analysis.

\section{Results}

\section{Differences by repeat measurements of bone} levels from intra-oral radiographs

The mean differences between repeated measurements of bone levels at implants (implant platform level to the most apical point of implant to bone connection were $0.1 \mathrm{~mm}$ (SD $\pm 0.2,95 \% \mathrm{CI}:-0.03$ to $1.4, P=0.24)$ at the mesial and $0.1 \mathrm{~mm}$ (SD $\pm 0.2,95 \% \mathrm{CI}:-0.05$ to $1.1, P=0.30$ ) at the distal surfaces. This corresponded to in traclass correlation coefficients (ICC) of 0.94 (95\% CI: $0.8,1.0, P<0.001)$ and $0.92(95 \%$ CI: $0.8,1.0, P<0.001)$, respectively.

\section{Implant characteristics}

Implants with healthy conditions included $76.6 \%$ Brånemark and $23.4 \%$ Astra Tech implants. Implants with peri-implantitis included: Brånemark, Nobel Biocare denta implants $(74.1 \%)$ (Nobel Biocare Services AG, Kloten, Switzerland), Astra Tech implant system $(13.7 \%$ ) (Astra Tech $\mathrm{AB}$ Mölndal, Sweden), Straumann implants (7.4\%) (Institute Straumann AG, Basel, Swit zerland), ImplaMed implants $(2.8 \%)$ (Sterngold-ImplaMed $^{\mathrm{TM}}$, Attleboro, MA, USA), and non-identifiable dental implant types $(0.4 \%)$.

\section{Individual based factors}

Among the 172 individuals with peri-implantitis, 86 individuals $(50.0 \%)$ were from center 1,40 individuals $(23.3 \%)$ from center 2 , and 46 individuals $(26.7 \%)$ from center 3. A majority of these individuals (118 of 172 , $68.6 \%$ ) were women. Among the 98 individuals with healthy implant conditions/periimplant mucositis, 58 individuals $(59.2 \%$ were from center 1 and 40 individuals
$(40.8 \%)$ were from center 2. A majority of them $(55$ of $98,56.1 \%)$ were men. Subject based characteristics are presented (Table 1). Clinical data, radiographs, and review of available dental records and medical/dental history suggested that none of the individuals with periodontitis could be identified with a history of aggressive periodontitis.

Clinical conditions at implants with periimplantitis or implants diagnosed as having healthy conditions or peri-implant mucositis Analyses by Kolmogorov-Smirnov one-sam ple test failed to identify a normal distribution patterns for all variables studied with the exception of the variable for the age of the individuals and the distance between implant platform level and bone level. The mean PPD values at implants with peri-implantitis or implant healthy conditions/peri-implant mucositis were $5.5 \mathrm{~mm} \quad(\mathrm{SD} \pm 0.8)$ and $4.2 \mathrm{~mm}(\mathrm{SD} \pm 1.1)$, respectively, with a mean difference of $1.2 \mathrm{~mm}$ (SE $\pm 0.2 \mathrm{~mm}, 95 \% \mathrm{CI}$ $3.1,3.9, P<0.001), P$-value $=0.001 \quad($ MannWhitney $U$-test). The mean distance between implant platform and bone levels at implants with peri-implantitis or implant healthy conditions/peri-implant mucositis was $5.0 \mathrm{~mm}$ $(\mathrm{SD} \pm 1.7)$ and $1.5 \mathrm{~mm}(\mathrm{SD} \pm 0.4)$, respec tively, with a mean difference of $3.5 \mathrm{~mm}$ (SE $\pm 0.2,95 \%$ CI: 3.1, 3.8, $P<0.001$ ). The

mean proportions of study implants with sites presenting with plaque at study implants with peri-implantitis or healthy implant/periimplant mucositis conditions were $39.3 \%$ and $29.1 \%$, respectively $(P<0.001)$ (independent t-test). The mean full-mouth (teeth and implants) proportions of sites with BOP at implants in individuals with peri-implantitis or healthy implant/peri-implant mucositis conditions were $47.8 \%$ and $37.1 \%$, respectively $(P<0.001$, Mann-Whitney $U$-test $)$. The mean full-mouth (teeth and implants) proportions of sites with the presence of plaque in individuals with peri-implantitis and in individuals with implant health/peri-implant mucositis were $43.3 \%$ and $47.2 \%$, respectively (NS) (Mann-Whitney $U$-test).

Analysis of implant bone levels in individuals with peri-implantitis or healthy implant conditions/peri-implant mucositis in regard to a history of periodontitis and/or smoking

Data on the analysis on the impact of periodontitis and/or smoking between individuals with peri-implantitis or healthy implant /periimplant mucositis are presented for bone levels (Table 2). Regardless of whether the individuals were grouped based on the four possible combinations of a history of smoking or periodontitis, the individuals with periimplantitis presented with greater distances

Table 1. Study group characteristics by implant conditions (Bold markings for group with significantly higher scores)

\begin{tabular}{|c|c|c|c|}
\hline Variable & Peri-implantitis & $\begin{array}{l}\text { Implant health/peri-implant } \\
\text { mucositis }\end{array}$ & $P$-value \\
\hline Female gender $(\%)^{*}$ & $118 / 172(68.8)$ & $43 / 98(43.9)$ & 0.001 \\
\hline Subject mean age and $S \mathrm{C} \uparrow$ & $68.2(S D \pm 8.7)$ & $44.7(S D \pm 15.9)$ & 0.001 \\
\hline Current or past smoking habit (\%) & 78/167 (46.7)§ & $32 / 98(32.7$ & 0.001 \\
\hline $\begin{array}{l}\text { Number of years with implant } \\
\text { in function }\end{array}$ & $11.8(\mathrm{SD} \pm 3.3)$ & $7.0(S D \pm 3.0)$ & 0.001 \\
\hline History of periodontitis (\%)* & 119/172 (69.2) & 18/98 (18.4) & 0.001 \\
\hline $\begin{array}{l}\text { History of periodontitis and } \\
\text { current smoking }(\%)^{*}\end{array}$ & $70 / 164(42.7)$ & $6 / 98(6.1)$ & 0.001 \\
\hline $\begin{array}{l}\text { History of smoking but not } \\
\text { periodontitis }(\%)^{*}\end{array}$ & 22/164 (13.4)ף & $26 / 98(26.5)$ & 0.001 \\
\hline $\begin{array}{l}\text { History of periodontitis but no } \\
\text { smoking habit }(\%)^{*}\end{array}$ & $42 / 164(25.6) \uparrow$ & $12 / 98(12.2)$ & 0.001 \\
\hline $\begin{array}{l}\text { Neither a history of periodontitis } \\
\text { nor smoking }(\%)^{*}\end{array}$ & 24/164 (14.6)ף & $54 / 98(55.1)$ & 0.001 \\
\hline $\begin{array}{l}\text { History of cardiovascular } \\
\text { diseases }(\%)^{*}\end{array}$ & $47 / 172(27.3)$ & $3 / 98(3.0)$ & 0.001 \\
\hline $\begin{array}{l}\text { History of rheumatoid } \\
\text { arthritis }(\%)^{*}\end{array}$ & $11 / 172(6.5)$ & $1 / 98(1.0)$ & 0.01 \\
\hline $\begin{array}{l}\text { History of diabetes mellitus } \\
\text { type II }(\%)^{*}\end{array}$ & $10 / 172(5.9)$ & $1 / 98(1.0)$ & 0.05 \\
\hline History of osteoporosis (\%)* & $4 / 172(2.4)$ & $1 / 98(1.0)$ & 0.40 \\
\hline History of lung disease (\%)* & 9/172 (5.3) & $2 / 98(2.0)$ & 0.16 \\
\hline Diagnosis of cancer $(\%)^{*}$ & $7 / 172(84.2)$ & $2 / 98(2.0)$ & 0.28 \\
\hline Diagnosis of depression (\%)* & $1 / 172(0.6)$ & $2 / 98(2.0)$ & 0.30 \\
\hline \multicolumn{4}{|c|}{$\begin{array}{l}\text { *Analysis by Pearson } \chi^{2} \text { tests. } \\
\text { †Analysis by independent } t \text {-test. } \\
\text { †Confirmed information was missing for } 5 \text { subjects. } \\
\text { §Confirmed information was missing for } 5 \text { subjects. } \\
\text { ๆConfirmed information was missing for } 8 \text { subjects. }\end{array}$} \\
\hline
\end{tabular}


Table 2. Subject-based bone level data (distance between implant platform level and bone level) defined by implant status in subjects with (i) neither a history of periodontitis nor a history of periodontitis but no history of smoking, and (iv) a history of both periodontitis and smoking

\begin{tabular}{|c|c|c|c|c|c|c|}
\hline & $\begin{array}{l}\text { Peri- } \\
\text { implantitis } \\
(\mathrm{mm})\end{array}$ & $\begin{array}{l}\text { Implant health/ } \\
\text { peri-implant } \\
\text { mucositis }(\mathrm{mm})\end{array}$ & $\begin{array}{l}\text { Mean, } \\
\text { Difference } \\
(\mathrm{mm})\end{array}$ & $\begin{array}{l}\text { SE } \\
\text { difference }\end{array}$ & $95 \% \mathrm{Cl}$ & $P$-value \\
\hline $\begin{array}{l}\text { (i) Mean bone level } \\
\text { and SD no } \\
\text { periodontitis/no } \\
\text { smoking }\end{array}$ & $5.1 \pm 1.5$ & $1.6 \pm 0.3$ & 3.5 & \pm 0.4 & $2.8,4.3$ & 0.001 \\
\hline $\begin{array}{l}\text { (ii) Mean bone level } \\
\text { and SD } \\
\text { periodontitis/no } \\
\text { smoking }\end{array}$ & $5.1 \pm 1.8$ & $1.6 \pm 0.3$ & 3.6 & \pm 0.4 & $2.8,4.3$ & 0.001 \\
\hline $\begin{array}{l}\text { (iii) Mean bone level } \\
\text { and SD } \\
\text { No periodontitis } \\
\text { /smoking }\end{array}$ & $5.7 \pm 1.7$ & $0.7 \pm 1.3$ & 5.1 & \pm 0.7 & $0.6,10.6$ & 0.001 \\
\hline $\begin{array}{l}\text { (iv) Mean bone level } \\
\text { and SD } \\
\text { periodontitis } \\
\text { /smoking }\end{array}$ & $5.4 \pm 1.8$ & $1.1 \pm 0.1$ & 4.4 & \pm 0.2 & $4.0,4.8$ & 0.001 \\
\hline
\end{tabular}

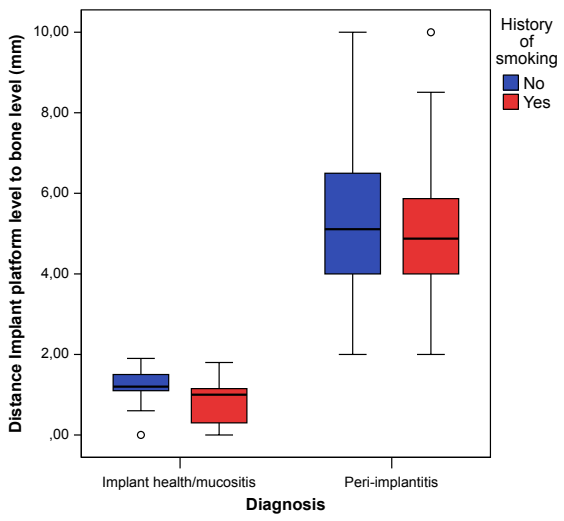

Fig. 1. Box plot diagram illustrating radiographic evidence of the distance between implant platform level and bone level in $\mathrm{mm}$ at implants with a diagnosis of implant health/mucositis or peri-implantitis in relation to a history of smoking or not. $1^{\circ}=$ outlier values $)$.

between implant platform level and bone leve $(P<0.001)$. The greatest difference in bone levels, with a mean difference of $5.1 \mathrm{~mm}$, was found between individuals with peri-implantitis and healthy/mucositis for the combination of a history of smoking but without a history of periodontitis. The extent of implant bone levels in individuals with implants diagnosed with peri-implantitis or not and in relation to a history of periodontitis or a history of smoking is illustrated in box plot diagrams (Figs 1 and 2). The extent of implant bone levels in individuals with a history of cardiovascular disease or a history of periodontitis in relation confounding factors, a history of periodontitis and a history of cardiovascular disease were significantly associated with a risk of peri-implantitis with age as a contributory factor. Neither smoking nor gender had a significant impact on the risk association (Table 4).

\section{Discussion}

The study identified that individuals with a diagnosis of peri-implantitis had PPD values at study implants that were significantly higher than what were found in individuals with study implant defined as healthy or with a diagnosis of peri-implant mucositis. In addition, the distance between IPL and bone level and the extent of BOP was greater in individuals with peri-implantitis. This was anticipated as part of the diagnostic and the enrollment criteria. It confirmed, however, that in regard to implant conditions, the two study groups were distinctively different. Although the length of time that the study implants had been in function was longer for individuals diagnosed with peri-implantitis, this was not a clinically significant factor to explain the differences between study groups.

As anticipated, older individuals had more systemic diseases, and the older individuals also had a higher prevalence of peri-implantitis. Due to the fact that many systemic diseases are chronic and more common in older individuals, we included age as a common covariate in all models of the data analysis. For some of the diseases, either none of the individuals or only one of them in the implant health/peri-implant mucositis group reported a systemic condition (i.e. rheumatoid arthritis). This restricted the usefulness of the risk analysis for these conditions. Nevertheless, it should be recognized that for other diseases as well as for the overall presence of disease, the group of individuals with peri-implantitis included a high number of individuals with cardiovascular disease or periodontitis. The present study identified that a history of cardiovascular disease and a history of periodontitis could be associated with peri-implantitis and with age as a contributory factor.

There are extensive data on the risk association between a diagnosis of periodontitis and a diagnosis of cardiovascular disease (Persson \& Persson 2008; Buhlin et al. 2009, 2011; Renvert et al. 2010; Romagna et al. 2012). There are data to suggest that mortality by cardiovascular disease among 60 - to 70-year-old men is elevated if the men had severe periodontitis (Linden et al. 2012). An

525 | Clin. Oral Impl. Res. 25, 2014 / 522-529 


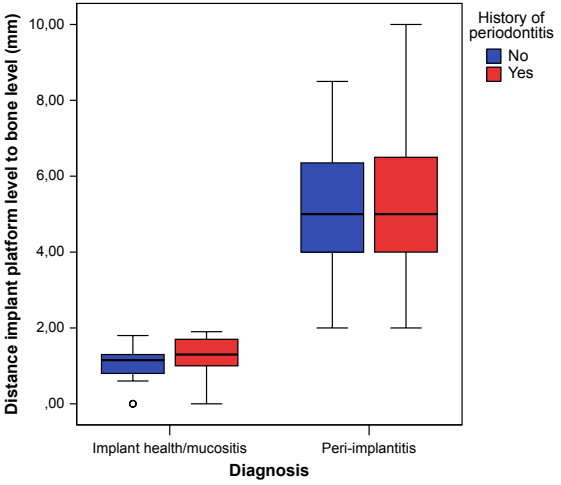

Fig. 2. Box plot diagram illustrating radiographic evidence of the distance between implant platform level and bone level in mm at implants with a diagnosis of implant health/mucositis or peri-implantitis in relation to a history of periodontitis or not. $\left(^{\circ}=\right.$ outlier values $)$.

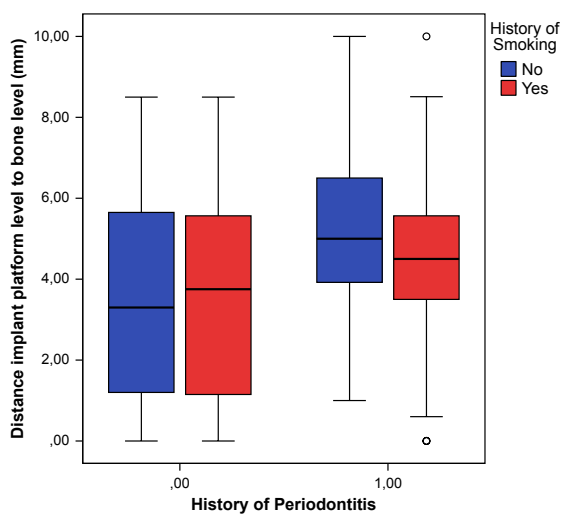

Fig. 3. Box plot diagram illustrating radiographic evidence of the distance between implant platform level and bon level in mm at implants with a diagnosis of periodontitis or not in relation to a history of smoking or not $1^{\circ}=$ outlier values).

association between periodontitis and elevated blood pressure has also been reported (Buhlin et al. 2011).

Tooth loss has been linked to cardiovascular disease (Elter et al. 2004) and to a risk of mortality (Watt et al. 2012). In a recent metaanalysis, it was questioned whether the number of replaced teeth affects mortality (Polzer et al. 2012). The present study demonstrated that individuals who had established periimplantitis had a high likelihood of also having cardiovascular disease.

The present study failed to identify that diabetes mellitus, osteoporosis, lung diseases,

526 | Clin. Oral Impl. Res. 25, 2014 / 522-529 demonstrate a significant odds ratio between plantitis group $(P=0.09)$, the study a history of diabetes mellitus type II and periimplantitis. Likewise, the study failed to demonstrate a significant likelihood that individuals with rheumatoid arthritis would have peri-implantitis. The positive impact of anti-inflammatory treatment in individuals with rheumatoid arthritis should not be ruled out as a confounding factor (Persson 2012). The sample size with $>75$ individuals in each group and the distribution of individuals in each group were sufficient for the assessments of cardiovascular diseases, diabetes mellitus, and rheumatoid arthritis, but not for osteoporosis, lung disease, depression, or cancer diseases. This was primarily an effect of disease distribution in the two study groups.

Several studies have identified an association between pre-existing periodontitis and a risk of peri-implantitis (i.e. Karoussis et al. 2003; Koldsland et al. 2011, Marrone et al. 2012). Residual pockets following periodontal treatment have been shown to be a risk of the development of peri-implantitis (Cho-Yan Lee et al. 2012; Pjetursson et al. 2012). Patients on maintenance care developing re-infections are also at greater risk of peri-implantitis and implant loss than periodontally stable patients (Pjetursson et al. 2012). Studies have also shown that patients treated for generalized aggressive periodontitis are more susceptible to mucositis and peri-implantitis, with lower implant survival and success rates (Swierkot et al. 2012). In the present study, none of the subjects had been diagnosed with generalized aggressive periodontitis.

Microbiological studies have shown that subject factors are explanatory to bacterial load at both tooth and implant sites (Agerbaek et al. 2006). A complex microbiota including several bacteria associated with periodontitis have been identified in individuals with peri-implantitis (Renvert et al. 2007; Persson et al. 2006, 2010, 2011; Shibli et al. 2008; Charalampakis et al. 2012; Hallström et al. 2012). Thus, the presence of bacteria associated with periodontitis can commonly be found in peri-implantitis. In addition, data suggest that other pathogens not commonly found in periodontitis can be associated with infections at dental implants (i.e. Persson et al. 2010, 2011; Faveri et al. 2011; Charalampakis et al. 2012; Hallström et al. 2012). Bacteria commonly found in both periodontitis and peri-implantitis can also be identified in subgingival samples of patients with myocardial infarction (Renvert et al. 2006). Thus, an infectious axis between a history of periodontitis with peri-implantitis and cardiovascular disease is plausible. 


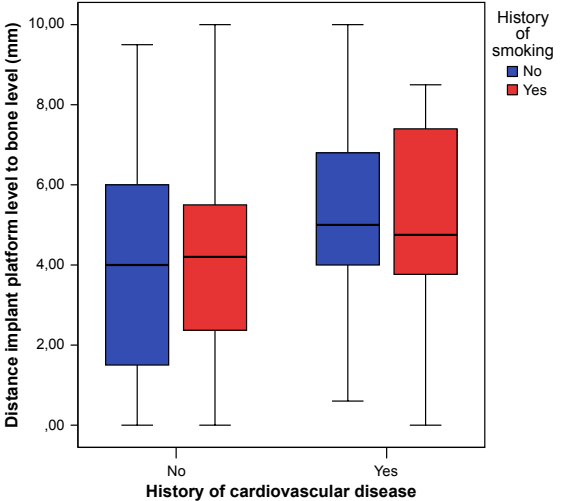

Fig. 4. Box plot diagram illustrating mean distances between the implant platform (IPL) to bone level (bone loss) as assessed from intra-oral radiographs in individuals with a diagnosis of periodontitis or no diagnosis of periodontitis in relation to a history of cardiovascular disease or no history of cardiovascular disease.

Table 3. Results of risk assessments based on unadjusted and adjusted odds and likelihood ratios for subject-based implant status in relation to study condition

\begin{tabular}{llll}
\hline \multicolumn{4}{l}{ Mantel-Haenszel unadjusted odds ratio } \\
\hline Variable & OR & $95 \% \mathrm{Cl}$ & $P$-value \\
\hline Cardiovascular & 11.9 & $36,39.4$ & 0.001 \\
$\quad$ disease & & & \\
Periodontitis & 10.8 & 5.820 .0 & 0.001 \\
Diabetes & 6.1 & $0.8,48.1$ & 0.09 \\
$\quad$ mellitus & & & \\
$\quad$ type II & & & \\
Rheumatoid & 6.5 & $0.9,52.8$ & 0.07 \\
$\quad$ arthritis & & & \\
$\quad$ Lung disease & 2.7 & $0.6,12.7$ & 0.21 \\
Osteoporosis & 2.3 & $0.3,21.2$ & 0.21 \\
$\quad$ Cancer & 2.1 & $0.4,10.4$ & 0.35 \\
$\quad$ Depression & 0.3 & $0.0,3.2$ & 0.31 \\
$\quad$ Smoking & 2.5 & $1.4,4.2$ & 0.001 \\
$\quad$ Gender & 2.8 & $1.7,4.7$ & 0.001 \\
\hline
\end{tabular}

A history of smoking habits has been associated with an elevated risk of periodontitis (Heitz-Mayfield \& Huynh-Ba 2009; Hugoson \& Rolandsson 2011; Goodson et al. 2012 Mdala et al. 2012) and of peri-implantitis (Ferreira et al. 2006; Roos-Jansåker et al. 2006; Levin et al. 2008; Carcuac \& Jansson 2011; Rinke et al. 2011; Rodriguez-Argueta et al 2011). The studies by Koldsland et al. (2010 2011), and Marrone et al. (2012) failed to identify smoking as a significant risk factor in peri-implantitis. It should be noticed that in the present study, a significantly higher
Table 4. Assessment of the odds that a history of periodontitis or cardiovascular disease could be associated with a risk of peri-implantitis (binary logistic regression forward Wald analysis with age of individuals, gender, and smoking entered at step 1 of the analysis)

\begin{tabular}{rrrr} 
OR & $95 \% \mathrm{Cl}$ & $P$-value \\
\hline
\end{tabular}

\begin{tabular}{lllll}
\hline Periodontitis & 4.5 & $2.1,9.7$ & 0.001
\end{tabular}

$\begin{array}{llll}\text { Cardiovascular disease } & 8.7 & 1.9,40.3 & 0.006\end{array}$

Entered on step 1

Age

$11,1,4.2 \quad 0.001$

Variable not in equation

Gender

Smoking

0.20

0.32

proportion of individuals in the implant health/peri-implant mucositis group were smokers. Thus, the present study demonstrated a higher likelihood that individuals with healthy implants/peri-implant mucositis had a smoking habit as compared to those in the peri-implantitis group.

One of the limitations of the present study is defined by its retrospective cross-sectional nature, and this must be considered when the validity of the results is evaluated. Another limitation is that implants with different surfaces are included. Both machined and moderately rough surface implants were included. However, two recent reports were unable to find differences in peri-implantitis prevalence as an effect of surface structure (Zetterqvist et al. 2010; Renvert et al. 2012). The use of

information on general health based on information provided by study individuals has been criticized in many studies. Nevertheless, such information is used as part of standard of care procedures in dentistry. The chances of false-negative information are difficult to estimate, and this would apply similarly to both study groups. The complexity of prospective studies to assess factors associated with periimplantitis may make it very difficult to design such studies considering the impact of standard of care procedures and to assess the likelihood of comorbidity of diseases. The present study represents a rather large cohort of subjects adding validity to the present findings and in spite of the retrospective nature of the study.

The role of supportive maintenance care must be stressed as this has been identified as a key factor in reducing the risk of implant complications (Roccuzzo et al. 2010). In the present retrospective study, it was not possible to address the impact of the individualized supportive maintenance care each individual had received. We can only assume that standard of care protocols was followed as the concept of maintenance care is well accepted among clinicians (Lang \& Nyman 1994).

In conclusion, the study identified a high level of probability of comorbidity expressed as a history of periodontitis and as a history of cardiovascular disease in relation to a diag nosis of peri-implantitis. The risk of periimplantitis increases with age.

Acknowledgements: We appreciate the work by Ms. Christel Lindahl in regard to data management and coordination of studies.

\section{Source of funding}

The University of Kristianstad, Sweden, and the Public Dental Health Service, Region Halland, funded the study.

\section{Conflict of interest}

None of the authors have a conflict of interest. The authors meet the International Committee of Medical Journal Editors (ICMJE) requirements for authorship.

implant and tooth sites in subjects on supportive periodontal therapy. I. Impact of clinical vari ables, gender and smoking. Clinical Oral Implants Research 17: 18-24. 
Aghazadeh, A., Persson, G.R. \& Renvert, S. (2012) A single-center randomized controlled clinical trial on the adjunct treatment of intra-bony defects with autogenous bone or a xenograft: results after 12 months. Journal of Clinical Peri odontology 39: 666-673.

Aloufi, F., Bissada, N., Ficara, A., Faddoul, F. \& Al-Zahrani, M.S. (2009) Clinical assessment of peri-implant tissues in patients with varying severity of chronic periodontitis. Clinical Implant and Dentistry Related Research 11: 37-40.

Buhlin, K., Hultin, M., Norderyd, O., Persson, L. Pockley, A.G., Rabe, P., Klinge, B. \& Gustafsson, A. (2009) Risk factors for atherosclerosis in case with severe periodontitis. Journal of Clinical Periodontology 36: 541-549.

Buhlin, K., Mäntylä, P., Paju, S., Peltola, J.S. Nieminen, M.S., Sinisalo, J. \& Pussinen, P.J. (2011) Periodontitis is associated with angiographically verified coronary artery disease. Journal of Clinical Periodontology 38: 1007-1114.

Buser, D., Janner, S.F., Wittneben, J.G., Brägger, U. Ramseier, C.A. \& Salvi, G.E. (2012). 10-year survival and success rates of 511 titanium implant with a sandblasted and acid-etched surface: a retrospective study in 303 partially edentulous patients. Clinical Implant and Dentistry Related Research 14: 839-851.

Carcuac, O. \& Jansson, L. (2011) Peri-implantitis in a specialist clinic of periodontology. Clinical fea tures and risk indicators. Swedish Dental Journal 34: 53-61.

Charalampakis, G., Leonhardt, A., Rabe, P. \& Dahlén, G. (2012) Clinical and microbiological characteristics of peri-implantitis cases: a retrospective multicentre study. Clinical Oral Implants Research 23: 1045-1054.

Cho-Yan Lee, J., Mattheos, N., Nixon, K.C. \& Ivanovski, S. (2012) Residual periodontal pocket are a risk indicator for peri-implantitis in patient treated for periodontitis. Clinical Oral Implants Research 23: 325-333.

Costa, F.O., Takenaka-Martinez, S., Cota, L.O. Ferreira, S.D., Silva, G.L. \& Costa, J.E. (2012) Peri-implant disease in subjects with an without preventive maintenance: a 5-year follow-up. Journal of Clinical Periodontology 39: $173-181$

Elter, J.R., Champagne, C.M., Offenbacher, S. \& Beck, J.D. (2004) Relationship of periodontal disease and tooth loss to prevalence of coronary hear disease. Journal of Periodontology 75: 782-790.

Faveri, M., Gonçalves, L.F., Feres, M., Figueiredo, L.C., Gouveia, L.A., Shibli, J.A. \& Mayer, M.P (2011) Prevalence and microbiological diversity of Archaea in peri-implantitis subjects by $16 \mathrm{~S}$ ribosomal RNA clonal analysis. Journal of Periodon tal Research 46: 338-344.

Ferreira, S.D., Silva, G.L., Cortelli, J.R., Costa, J.E. \& Costa, F.O. (2006) Prevalence and risk variables for peri-implant disease in Brazilian subjects. Journal of Clinical Periodontology 33: 929-935.

Fransson, C., Lekholm, U., Jemt, T. \& Berglundh, T. (2005) Prevalence of subjects with progressive bone loss at implants. Clinical Oral Implants Research 16: 440-446.

Frisch, E., Ziebolz, D. \& Rinke, S. (in press) Long term results of implant-supported over-denture retained by double crowns: a practice-based retrospective study after minimally 10 years followup. Clinical Oral Implants Research doi: 10 1111/j.1600-0501.2012.02568.x

Goodson, J.M., Haffajee, A.D., Socransky, S.S. Kent, R., Teles, R., Hasturk, H., Bogren, A., Van Dyke, T., Wennstrom, J. \& Lindhe, J. (2012) Control of periodontal infections: a randomize controlled trial I. The primary outcome attach ment gain and pocket depth reduction at treated sites. Journal of Clinical Periodontology 39: 526-536.

Hallström, H., Persson, G.R., Lindgren, S., Olofsson, M. \& Renvert, S. (2012) Systemic antibiotic and debridement of peri-implant mucositis. A randomized clinical trial. Journal of Clinical Peri odontology 39: 574-581.

Heitz-Mayfield, L.J. \& Huynh-Ba, G. (2009) History of treated periodontitis and smoking as risks for implant therapy. International Journal of Oral Maxillofacial Implants 24(Suppl.): 39-68.

Hugoson, A. \& Rolandsson, M. (2011) Periodontal disease in relation to smoking and the use of Swedish snus: epidemiological studies coverin 20 years (1983-2003). Journal of Clinical Peri odontology 38: 809-816

Karoussis, I.K., Salvi, G.E., Heitz-Mayfield, L.J., Brägger, U. Hämmerle, C.H. \& Lang, N.P. (2003) Long-term implant prognosis in patients with an without a history of chronic periodontitis: a 10 year prospective cohort study of the ITI Dental Implant System. Clinical Oral Implants Research 14: 329-339.

Koldsland, O.C., Scheie, A.A. \& Aas, A.M. (2011) The association between selected risk indicator and severity of peri-implantitis using mixed model analyses. Journal of Clinical Periodontol ogy 38: 285-292.

Koldsland, O.C., Scheie, A.A. \& Aass, A.M. (2010) Prevalence of peri-implantitis related to severity of the disease with different degrees of bone loss. Journal of Periodontology 81: 231-238.

Lachmann, S., Stehberger, A., Axmann, D. \& Weber, H. (in press) The peri-implant health in patients attending an annual recall program. A clinical and microbiological study in 74 patients from the Tübingen Implant Registry. Clinical Oral Implants Research doi: 10.1111/j.1600-0501 2012.02573.x

Lang, N.P., Berglundh, T. \& Working Group 4 of Seventh European Workshop on Periodontology (2011) Periimplant diseases: where are we now? Consensus of the Seventh European Workshop on Periodontology. Journal of Clinical Periodontol ogy 38(Suppl. 11): 178-181.

Lang, N.P. \& Nyman, S.R. (1994) Supportive main tenance care for patients with implants and advanced restorative therapy. Periodontology 2000 4: 119-126.

Lee, H.J., Kim, Y.K., Park, J.Y., Kim, S.G., Kim, M.J. \& Yun, P.Y. (2010) Short-term clinical retrospective study of implants in geriatric patients older than 70 years. Oral Surgery, Oral Medicine, Oral Pathology, Oral Radiology, and Endodontol ogy 110: 442-446.

Levin, L., Hertzberg, R., Har-Nes, S. \& Schwartz Arad, D. (2008) Long-term marginal bone loss around single dental implants affected by curren and past smoking habits. Implant Dentistry 17: $422-429$

Linden, G.J., Linden, K., Yarnell, J., Evans, A., Kee, F. \& Patterson, C.C. (2012) All-cause mortality and periodontitis in 60-70-year-old men: a prospective cohort study. Journal of Clinical Peri odontology 39: 940-946.

Marrone, A., Lasserre, J., Bercy, P. \& Brecx, M.C (2012) Prevalence and risk factors for periimplant disease in Belgian adults. Clinical Oral Implants Research. doi:10.1111/j.1600-0501.2012. 02476.x

Mdala, I., Haffajee, A.D., Socransky, S.S., de Blasio B.F., Thoresen, M., Olsen, I. \& Goodson, J.M. (2012) Multilevel analysis of clinical parameters in chronic periodontitis after root planing/scaling surgery, and systemic and local antibiotics: 2-year results. Journal of Oral Microbiology 4: doi:10. 3402/jom.v4i0.17535.

Persson, G.R. (2012) Rheumatoid arthritis and periodontitis - inflammatory and infectious connections. Review of the literature. Journal of Oral Microbiology 4: doi:10.3402/jom.v4i0.11829.

Persson, G.R. \& Persson, R. E. (2008) Cardiovascular disease and periodontitis: an update on the associations and risk. Journal of Clinical Periodontology 35 (8 Suppl): 362-379.

Persson, G.R., Roos-Jansåker, A.M., Lindahl, C. \& Renvert, S. (2011) Microbiologic results after nonsurgical erbium-doped: yttrium, aluminum, and garnet laser or air-abrasive treatment of peri-implantitis: a randomized clinical trial. Journal of Periodontology 82: 1267-1278.

Persson, G.R., Salvi, G.E., Heitz-Mayfield, L.J. \& Lang, N.P. (2006) Antimicrobial therapy using local drug delivery system (Arestin) in the treatment of peri-implantitis. I. microbiological outcomes. Clinical Oral Implants Research 17: 386-393.

Persson, G.R., Samuelsson, E., Lindahl, C. \& Renvert, S. (2010) Mechanical non-surgical treatmen of peri-implantitis: a single-blinded randomized longitudinal clinical study. II. Microbiological results. Journal of Clinical Periodontology 37: 563-573.

Pjetursson, B.E., Helbling, C., Weber, H.P., Matuliene, G., Salvi, G.E., Brägger, U., Schmidlin, K., Zwahlen, M. \& Lang, N.P. (2012) Peri-implantitis susceptibility as it relates to periodontal therapy and supportive care. Clinical Oral Implants Research 23: 888-894.

Polzer, I., Schwahn, C., Völzke, H., Mundt, T. \& Biffar, R. (2012) The association of tooth loss with all-cause and circulatory mortality. Is there a benefit of replaced teeth? A systematic review and meta-analysis. Clinical Oral Investigations 16: 333-351.

Renvert, S., Lindahl, C. \& Persson, G.R. (2012) The incidence of peri-implantitis for two different implant systems over a period of thirteen years. Journal of Clinical Periodontology 39: 1191-1197. Renvert, S., Lindahl, C., Roos Jansåker, A.M. \& Persson, G.R. (2011) Treatment of peri-implantitis using an Er:YAG laser or an air-abrasive device: a randomized clinical trial. Journal of Clinical Periodontology 38: 65-73.

Renvert, S., Ohlsson, O., Pettersson, T. \& Persson, G.R. (2010) Periodontitis: a future risk of acute 
coronary syndrome? A follow-up study over 3 years. Journal of Periodontology 81: 992-1000.

Renvert, S., Pettersson, T., Ohlsson, O. \& Persson, G.R. (2006) Bacterial profile and burden of periodontal infection in subjects with a diagnosis of acute coronary syndrome. Journal of Periodontol. ogy 77: 1110-1119.

Renvert, S., Roos-Jansåker, A.M. \& Claffey, N. (2008) Non-surgical treatment of peri-implan mucositis and peri-implantitis: a literature review. Journal of Clinical Periodontology 35/8 Suppl): 305-315.

Renvert, S., Roos-Jansåker, A.M., Lindahl, C., Renvert, H. \& Persson, G.R. (2007) Infection at titanium implants with or without a clinical diagnosis of inflammation. Clinical Oral Implants Research 18: 509-516.

Renvert, S., Samuelsson, E., Lindahl, C. \& Persson, G.R. (2009) Mechanical non-surgical treatment of peri-implantitis: a double-blind randomized longitudinal clinical study. I: clinical results. Journal of Clinical Periodontology 36: 604-609.

Rinke, S., Ohl, S., Ziebolz, D., Lange, K. \& Eick holz, P. (2011) Prevalence of periimplant disease in partially edentulous patients: a practice-based cross-sectional study. Clinical Oral Implants Research 22: 826-833.

Roccuzzo, M., De Angelis, N., Bonino, L. \& Aglietta, M. (2010) Ten-year results of a three-arm prospective cohort study on implants in periodontally com promised patients. Part 1: implant loss and radiographic bone loss. Clinical Oral Implants Research 21: 490-496.

Rodriguez-Argueta, O.F., Figueiredo, R., Valmaseda-Castellon, E. \& Gay-Escoda, C. (2011) Postoperative complications in smoking patients treated with implants: a retrospective study. Journal of Oral Maxillofacial Surgery 69: 2152 2157.

Romagna, C., Dufour, L., Troisgros, O., Lorgis, L., Richard, C., Buffet, P., Soulat, G., Casillas, J.M. Rioufol, G., Touzery, C., Zeller, M., Laurent, Y \& Cottin, Y. (2012) Periodontal disease: a new factor associated with the presence of multiple complex coronary lesions. Tournal of Clinical Periodontology 39: 38-44.

Roos-Jansåker, A.M., Lindahl, C., Renvert, H. \& Renvert, S. (2006) Nine- to fourteen-year follow up of implant treatment. Part II: presence of peri implant lesions. Journal of Clinical Periodontology 33: 290-295.

Sanz, M. \& Chapple, I.L. (2012) Clinical research on peri-implant diseases: consensus report of Working Group 4. Journal of Clinical Periodontology 39(Suppl. 12): 202-220

Schroeder, A., van der Zypen, E., Stich, H. \& Sutter, F. (1981) The reactions of bone, connective tissue, and epithelium to endosteal implants with titanium-sprayed surfaces. Journal of Maxillofacial Surgery 9: 15-25.

Shibli, J.A., Melo, L., Ferrari, D.S., Figueiredo, L.C. Faveri, M. \& Feres, M. (2008) Composition of supra- and subgingival biofilm of subjects with healthy and diseased implants. Clinical Oral Implants Research 19: 975-982.

Simonis, P., Dufour, T. \& Tenenbaum, H. (2010) Long-term implant survival and success: a 10-16 year follow-up of non-submerged dental implants. Clinical Oral Implants Research 21: 772-777.

Swierkot, K., Lottholz, P., Flores-de-Jacoby, L. \& Mengel, R. (2012) Mucositis, peri-implantitis, implant success, and survival of implants in patients with treated generalized aggressive periodontitis: 3- to 16-year results of a prospective long-term cohort study. Journal of Periodontology 83: 1213-1225.

Watt, R.G., Tsakos, G., de Oliveira, C. \& Hamer M. (2012) Tooth loss and cardiovascular disease mortality risk-results from the Scottish Health Survey. PLoS One 7: e30797.

Zetterqvist, L., Feldman, S., Rotter, B., Vincenzi, G.,Wennström, J.L., Chierico, A., Stach, R.M. \& Kenealy, J.N. (2010) A prospective, multicenter, randomized-controlled 5-year study of hybrid and fully etched implants for the incidence of periimplantitis. Journal of Periodontology $\mathbf{8 1}$ 493-501 
III 



\title{
Impact of bone defect morphology on the outcome of reconstructive treatment of peri-implantitis
}

\author{
Ahmad Aghazadeh', Rutger G. Persson ${ }^{2,3,4}$ and Stefan Renvert ${ }^{2,5,6,7^{*}}$ (D)
}

\begin{abstract}
Objectives: To assess if (I) the alveolar bone defect configuration at dental implants diagnosed with peri-implantitis is related to clinical parameters at the time of surgical intervention and if (II) the outcome of surgical intervention of peri-implantitis is dependent on defect configuration at the time of treatment.

Materials and methods: In a prospective study, 45 individuals and 74 dental implants with $\geq 2$ bone wall defects were treated with either an autogenous bone transplant or an exogenous bone augmentation material. Defect fill was assessed at 1 year.

Results: At baseline, no significant study group differences were identified. Most study implants $(70.7 \%, n=53)$ had been placed in the maxilla. Few implants were placed in molar regions. The mesial and distal crestal width at surgery was greater at 4-wall defects than at 2-wall defects $(p=0.001)$. Probing depths were also greater at 4-wall defects than at 2 -wall defects $(p=0.01)$. Defect fill was correlated to initial defect depth $(p<0.001)$. Defect fill at 4wall defects was significant $(p<0.05)$.

Conclusions: (I) The buccal-lingual width of the alveolar bone crest was explanatory to defect configuration, (II) 4wall defects demonstrated more defect fill, and (III) deeper defects resulted in more defect fill.
\end{abstract}

Keywords: Peri-implantitis, Bone grafting, Reconstruction, Regeneration, Bone defect, Radiograph

\section{Introduction}

Peri-implantitis is a complication following replacement of teeth using dental implants. In a recent meta-analysis, the authors identified that peri-implantitis is a common disease with an estimated weighted mean prevalence of $43 \%$ [1]. According to the existing definition of periimplantitis, the condition is always associated with bone loss exceeding the loss of bone resulting from remodelling [2]. In many cases, the loss of bone in periimplantitis is related to the presence of intraosseous defects.

\footnotetext{
* Correspondence: Stefan.renvert@hkr.se

${ }^{2}$ Faculty of Health Sciences, Kristianstad University, SE-291 88 Kristianstad, Sweden

${ }^{5}$ Blekinge Institute of Technology, SE-371 79 Karlskrona, Sweden Full list of author information is available at the end of the article
}

Definitions of the topography of alveolar bone lesions associated with bone defects at dental implants have been presented [3-5]. The defect morphology has been reported to influence the healing potential following reconstructive therapy of peri-implantitis [3]. From a clinical perspective, the decision to perform resective or reconstructive procedures may be affected by defect configuration. Resective surgery may be used for the elimination of peri-implant lesions, whereas reconstructive therapies may be applied to obtain defect fill $[5,6]$. Reconstructive surgical treatment of peri-implantitis may be enhanced by using deproteinized bovine material or an enamel matrix derivate [7]. In a recent meta-analysis, the authors concluded that although the evidence was limited, the use of grafting material and barrier membranes may contribute to a better reduction of probing depth and more evidence of defect fill [8]. 
In the treatment of peri-implantitis defects, the outcome of surgical intervention has been reported to be related to defect configuration, suggesting that circumferential defects will more likely result in defect fill [3]. In a recent clinical study evaluating a reconstructive treatment of peri-implantitis defects using an enamel matrix derivate, the number of remaining bone walls in the peri-implant defect was one of the factors reported to be associated with successful healing [9]. In another recent publication, it was concluded that there is a lack of evidence of whether or not the resolution of the periimplant disease is associated with the defect configuration [10].

While conventional radiographs can only assess bone levels at mesial and distal aspects of teeth and implants, intraoral radiography may not be accurate in defining bone defect morphology [11]. Also, due to dental implant opacity and shape, it is not possible to accurately assess bone defect depths at mid-buccal or mid-lingual aspects [12]. The best opportunity to determine defect configuration at dental implants is at the time of surgical intervention. The anatomy of the peri-implantitis defects may depend on factors such as the alveolar bone configuration, the distance from the implant to the adjacent tooth/implant, anterior-posterior location of the implant, and the presence or absence of keratinized mucosa.

The objectives of the present study were to assess if (I) the alveolar bone defect configuration at dental implants diagnosed with peri-implantitis is related to clinical parameters at the time of surgical intervention and if (II) the outcome of surgical intervention of peri-implantitis is dependent on defect configuration at the time of treatment.

\section{Materials and methods Study design}

Data from a single-blinded prospective longitudinal human randomized clinical trial [13] was used to evaluate the association between defect configuration and clinical evidence of healing. The study randomization process has been described previously [13].

\section{Study population}

The Institutional Review Board at Lund, Sweden, approved the study (id nr: 89: 2007). All study participants signed informed consent. Thirty-nine consenting individuals with 74 dental implants with a diagnosis of peri-implantitis demonstrating $\geq 2$ bone wall lesions at the surgical intervention were enrolled in the present study between 2007 and 2010 at the Uppsala Käkkirurgiska Centrum, Sweden.

\section{Inclusion criteria}

(I) A minimum of one osseointegrated implant with $\geq$ $2 \mathrm{~mm}$ alveolar bone loss defined by comparing intra-oral radiographs at the time of screening for this study with bone loss assessed from radiographs taken at the placement of the supra-structure

(II) Probing pocket depth (PPD) $\geq 5 \mathrm{~mm}$, with bleeding on probing (BOP) and or suppuration

(III)The selected implant must have an angular periimplant bone defect ( $\geq 3 \mathrm{~mm}$ in depth as determined from intra-oral digital radiographs)

(IV)Only cases with clinical evidence of 2-, 3-, or 4-wall defects at the time of surgical intervention were included

\section{Exclusion criteria}

(I) Not properly controlled diabetes mellitus (HbA1c > 7)

(II) Requiring antibiotic prophylaxis

(III)Taking prednisone or other anti-inflammatory medications

(IV)Using antibiotics in the preceding 3 months

(V) Taking medicine known to affect gingival overgrowth

\section{Implant included in the study by the manufacturer}

The distributions of implants included were the following: Brånemark, Nobel Biocare dental implants (74.1\%) (Nobel Biocare Services AG, Kloten, Switzerland), Astra Tech implant system (13.7\%) (Astra Tech AB, Mölndal, Sweden), Straumann implants (7.4\%) (Institute Straumann AG, Basel, Switzerland), ImplaMed implants (2.8\%) (Sterngold-ImplaMed ${ }^{\mathrm{Tx}}$, Attleboro, MA, USA), and non-identifiable dental implant types (0.4\%).

\section{Pre-treatment}

An update of the medical and dental histories was made. Before entering the study, participants with periodontitis were treated such that no pockets $>5 \mathrm{~mm}$ were present at the time of surgical intervention. The study participants also underwent a preparatory routine treatment phase, including mechanical debridement of teeth and implants. Hand instruments, and/or ultrasonic devices as designed either for teeth or dental implants were used. Before treatment, all study participants were instructed in oral hygiene measures. The oral hygiene instructions were reinforced at the recall visits as deemed necessary. No surgical intervention for study purpose was performed before the re-assurance of good patient motivation and compliance had been established.

\section{Radiographic examination}

Standardized intra-oral radiographs of implants were obtained using an Eggen holder and long cone equipped dental X-ray unit. Pre- and postoperative radiographs presenting the study implants were digitalized, coded, 
and evaluated using a computer program (OsiriX Imaging software 3.9 for MAC OS 10.6, Osirix Foundation, Geneva, Switzerland). The distance equal to three implant threads (known for each implant system in the analysis) was measured and used for the calibration of images. The mesial and distal bone level distances were measured from the implant platform to the most apical point of contact to implant. Radiographs were taken at baseline and 12 months. One calibrated examiner (GRP) who was unaware of the study group/procedures assessed the radiographs. Radiographs were studied both as black and white images and by using the CLUT (colour lookup tables) option. The most coronal confluent aggregation of bone or bone-like material was used to define the coronal bone level. Black and white images versus CLUT images were switched on and off to select the position of bone levels for the assessments. Single strands or islets of bone/radiopaque material were not considered.

\section{Clinical measurements and procedures}

One experienced examiner (UL) performed all clinical examinations. The examiner was unaware of treatment group allocation.

Before treatment, the following baseline recordings were performed:

- Full set of intraoral radiographs (at 1 year only exposures for the implants in the study)

- Presence/absence of peri-implant soft tissue hyperplasia

The following clinical data were collected at baseline and 12 months after therapy:

- Full mouth plaque score: Presence of dental plaque along the gingival/mucosal margin recorded after use of disclosing dye (Top Dent Lifco Dental AB, Enköping, Sweden) and expressed as a percentage of examined sites within each patient (four sites per tooth and implant)

- Local plaque score: Presence of dental plaque along the mucosal margin at four locations of each treated implant recorded after the use of disclosing dye and expressed as a percentage of implant sites within each patient

- PPD: at the implants (4 sites/implant) and recorded to the nearest millimetre using a plastic probe (Colorview, Hu-Friedy, Chicago Il, USA)

- BOP: Presence/absence bleeding on probing at the treated implant (4 sites/implant). Bleeding appearing after measurement of probing depth was expressed as a percentage of examined sites (4 sites per implant)

- Suppuration: Presence of pus following probing (4 sites/implant)

- Mucosal recession (MR): Measured in millimetre as the distance from the mucosal margin to the implant shoulder at four sites (mesial, buccal, distal, and lingual). Position of the mucosal margin apical to the restoration margin is a positive mucosal recession (+); location of the mucosal margin coronal to the restoration margin is negative (-) mucosal recession

\section{Surgical treatment}

Following the administration of local anaesthetics, a sulcular incision was made around the neck of the implant abutments, and full-thickness flaps were raised at the buccal and lingual surfaces to access peri-implant defects. After removing all granulomatous tissues and carefully cleaning the implants from mineralized calculus, the implant surfaces were cleaned with hydrogen peroxide $(3 \%)$ for $1 \mathrm{~min}$, followed by profuse rinsing with saline. Assessments of defect characteristics, including the extent of bone loss/vertical defects from the implant platform to the most apical bone defect, were made. The extent of bone loss/vertical defects from the implant platform to the most apical bone defect and the distance from the implant platform to the most coronal part of the bone was measured (in millimetre) at the mesial, buccal, distal, and lingual surfaces around the implant. The number of bone walls was assessed. These measurements were used to calculate the defect depth and to classify the defect as a 2, 3, or 4 wall defect.

The distance from the affected implant to a neighbouring tooth or implant was measured (in millimetre) as well as the width of the alveolar crest mesially and distally of the affected implant. Depending on the assigned treatment, the defect was then either filled by autogenous bone $(\mathrm{AB})$ obtained from the ramus region using a bone scraper (Safescraper ${ }^{\circ}$ TWIST; Biomet3i Inc., Palm Beach, FL, USA) or bovine-derived xenograft (BDX) (Geistlich Pharma, Wolhusen, Switzerland). A resorbable membrane (OsseoGuard ${ }^{\circ}$; Biomet3i Inc., Palm Beach, FL, USA) was used to cover the bone or bone substitute. The flaps were sutured using 4.0 sutures (Ethicon vicryl polyglactin, Johnson \& Johnson, San Angelo, TX, USA) allowing non-submerged wound healing.

\section{Post-operative therapy}

Postoperative antibiotics (Azithromycin ${ }^{\circ}$; Sandoz A/S, Copenhagen Denmark; $2 \times 250 \mathrm{mg}$ day 1 and $1 \times 250 \mathrm{mg}$ days $2-4$ ) were prescribed to all study participants. During the first 6 weeks after surgery, all study participants 
rinsed with $0.1 \%$ chlorhexidine (Hexident, Meda $\mathrm{AB}$, Stockholm, Sweden). During the first 3 days, they also received anti-inflammatory and analgesic medications (Ibuprofen $400 \mathrm{mg} \times 3$ days; Ibumetin, Nycomed AB Stockholm, Sweden).

\section{Definition of bone walls}

Defects were defined at the time of surgical intervention as ;(1) 2-wall defects with one of the following affected bone wall combinations a mesial-buccal, buccal-distal, mesiallingual, distal-lingual, or a mesial and a distal defect; (2) three-wall defects requiring one surface without a bone wall, but with vertical angulated bone loss towards three implant surfaces; and (3) four-wall defect includes vertical angulated defects towards the implant at all four surfaces. The fourwall defect can also be described as a saucer-like defect.

\section{Statistical analysis}

Statistical analysis included descriptive statistics for the clinical and radiographic parameters assessed at the implants a baseline and 1-year follow-up. For the periimplant and radiographic parameters, means, and standard deviations were calculated. Comparisons were made with either paired or independent $t$ tests (equal variance not assumed) and by one-way ANOVA (including Bonferroni post hoc tests). The data regarding defect depth and bone fill were assessed with Pearson's correlation. Statistical significance was determined at an alpha level of 0.05 . The IBM SPSS 25 statistical software package for MAC computers was used (IBM SPSS, Armonk, NY, USA).

\section{Results}

A total of 74 dental implants with a diagnosis of periimplantitis with bone lesions involving two or more bone walls were included. The implants were distributed among 45 study individuals. None of the patients had had radiotherapy or was on bisphosphonates. During the 1-year follow-up, no implants were lost, no emergency treatment was performed on implants, and no antibiotics or antiinflammatory medications were prescribed beyond what was part of the study protocol. At the end of year one, no loss to follow-up by study participant had occurred.

The mean age of the study individuals was 68.8 years $(\mathrm{SD} \pm 6.9)$ not significant between treatment groups ( $\mathrm{AB}$ versus BDX). Statistical analyses failed to demonstrate baseline treatment group differences regarding the distribution of defect configuration, PPD at implants, distances to adjacent teeth/implants, defect depth at mesial and distal aspects (assessed clinically as well as from radiographs), or if attached/non-attached mucosa was found clinically or not. Adjusted for the number of implants per subject, statistical analysis demonstrated that the differences in bone height levels (radiographic evidence of defect fill) were similar between mesial and distal surfaces but greater in the BDX group $(p<0.001$ and $p<0.05$, respectively).

Many of the implants,70.7\% $(n=53)$, had been placed in the maxilla. The distribution of location and defect types for implants with 2-, 3-, or 4-wall bone defects are presented (Table 1). Data on clinical assessments performed immediately before and during surgical procedures are presented for defects located in the maxilla or the mandible (Table 2). No differences in clinical findings were found between maxillary or mandibular defect characteristics, or location, apart from mesial and distal probing depths at 2-wall defects that were deeper at maxillary locations $(p<0.05)$.

\section{Analyses of duplicate radiographic measurements}

Repeated measurements of bone levels on radiographs were made from 15 implants and assessed both at the mesial and the distal surfaces using baseline and year one images. The differences in bone levels between baseline and year one were studied and compared between the two sets of measurements. Analysis by paired $t$ test identified a $0.1-\mathrm{mm}$ (SD \pm 0.4 ) bone level change difference between the two sets of measurements ( $95 \%$ CI 0.2 to $0.1, p=0.36$ ). The ICC coefficient was 0.97 (95\% CI 0.95 to $0.99, p<0.001)$.

\section{Analyses of clinical assessments concerning defect} configuration (one-way ANOVA post hoc Bonferroni)

The mesial and distal crestal width was significantly greater at 4-wall defects than at two wall defects (mean diff 1.8 $\mathrm{mm}, \mathrm{SE} \pm 0.4,95 \%$ CI $0.7,2.8, p<0.001$ ). No differences were found between 2- and 3-wall defects or between 3and 4-wall defects. The relationships between crestal width and defect characteristics are illustrated (Fig. 1).

Statistical analyses failed to demonstrate plaque score differences, bleeding score differences, or differences in suppuration by defect configuration. Statistical analyses also were unable to show differences for the distances to both the mesial and the distal aspects of implant fixtures in relation to adjacent tooth/or another implant. There were no differences in the presence of attached buccal mucosa by defect type.

Probing pocket depths at all implants varied between 4 and $11 \mathrm{~mm}$. At 2-, 3-, and 4-wall defects, PPD values $\geq$ $6 \mathrm{~mm}$ were found at $65.4 \%, 66.7 \%$, and $100 \%$ of implants, respectively. Analyses by one-way ANOVA (Bonferroni post hoc tests) identified that mesial and distal PPD values at 4 -wall defects were deeper than at 2-wall defects $(p=0.01$ and $p=0.03$, respectively). No differences were found between any of the comparisons of baseline PPD values made between 3- and 4-wall defects. The clinical assessments identified that defect depth was more significant at 4-wall defects both at buccal and lingual aspects than at 2-wall defects (mean diff $1.5 \mathrm{~mm}, \mathrm{SE}$ $\pm 0.3,95 \%$ CI $0.8,2.3, p<0.001$ and mean diff $1.8 \mathrm{~mm}$, $\mathrm{SE} \pm 0.5,95 \%$ CI $0.7,3.7, p=0.002$ ). Clinical assessments of the defects are illustrated (Fig. 2). 
Table 1 Distribution of implants by location and type of defect

\begin{tabular}{|c|c|c|c|c|c|c|c|}
\hline & \multicolumn{3}{|l|}{ Maxilla } & \multicolumn{3}{|l|}{ Mandible } & \multirow{2}{*}{$\begin{array}{l}\text { Total } \\
\text { numbers }\end{array}$} \\
\hline & 2-wall defects & 3-wall defects & 4-wall defects & 2-wall defects & 3-wall defects & 4-wall defects & \\
\hline Anterior region & 17 & 6 & 3 & 3 & 4 & 0 & 33 \\
\hline Premolar region & 10 & 10 & 5 & 5 & 1 & 3 & 34 \\
\hline Molar region & 0 & 2 & 0 & 1 & 2 & 2 & 7 \\
\hline Total numbers & 27 & 18 & 8 & 9 & 7 & 5 & 74 \\
\hline
\end{tabular}

Clinical changes: bleeding on probing (per cent change), plaque scores (per cent), suppuration, or by treatment ( $A B$ vs $B D X)$ in relation to defect configuration

The mean proportion of implant sites with suppuration at year one was $3.0 \%$ and therefore not further assessed. Analyses by one-way ANOVA failed to demonstrate differences in changes of the proportions of implants with $\mathrm{BOP}$ or presence of plaque by defect classification.
Analyses by independent $T$ tests also were unable to show differences in the proportions of changes in BOP or presence of plaque by treatment modality.

\section{Radiographic and clinical assessments of defect depth}

Analysis by paired samples $t$ test (equal variance not assumed failed to identify differences of bone defect depth when mesial (mean diff $0.2 \mathrm{~mm}$ ( $\mathrm{SD} \pm 1.8,95 \% \mathrm{CI}-$

Table 2 Distribution of clinical measurements before and during surgical procedures (mean values and standard deviation) for defects at implants in the maxilla or mandible

\begin{tabular}{|c|c|c|c|c|c|c|}
\hline & \multicolumn{3}{|l|}{ Maxilla } & \multicolumn{3}{|l|}{ Mandible } \\
\hline & 2-wall defects & 3-wall defects & 4-wall defects & 2-wall defects & 3-wall defects & 4-wall defects \\
\hline \multicolumn{7}{|l|}{ Probing depth (mm) } \\
\hline Mesial & $6.1 \pm 1.6$ & $7.0 \pm 1.6$ & $7.5 \pm 1.4$ & $5.7 \pm 0.7$ & $6.3 \pm 0.8$ & $8.3 \pm 1.2$ \\
\hline Buccal & $6.3 \pm 1.8$ & $5.8 \pm 1.5$ & $5.6 \pm 1.5$ & $5.6 \pm 1.8$ & $5.2 \pm 1.3$ & $5.5 \pm 1.0$ \\
\hline Distal & $6.6 \pm 6.6$ & $6.6 \pm 1.5$ & $7.4 \pm 1.3$ & $5.9 \pm 1.4$ & $6.6 \pm 1.0$ & $8.2 \pm 7.4$ \\
\hline Palatal/Lingual & $5.9 \pm 1.6$ & $5.9 \pm 1.1$ & $6.0 \pm 1.1$ & $4.4 \pm 1.3$ & $5.0 \pm 1.2$ & $7.4 \pm 2.1$ \\
\hline Overall mean & $6.2 \pm 1.2$ & $6.3 \pm 1.1$ & $6.7 \pm 0.5$ & $5.4 \pm 1.1$ & $5.7 \pm 0.8$ & $7.6 \pm 1.2$ \\
\hline \multicolumn{7}{|l|}{ Plaque score } \\
\hline 1 surface & $61.5 \%$ & $58.8 \%$ & $87.5 \%$ & $30.0 \%$ & $28.6 \%$ & $20.0 \%$ \\
\hline 2 surfaces & $19.2 \%$ & $23.5 \%$ & $12.5 \%$ & $30.0 \%$ & $28.6 \%$ & $80.0 \%$ \\
\hline 3 surfaces & $11.5 \%$ & $17.6 \%$ & $0.0 \%$ & $20.0 \%$ & $42.9 \%$ & $0.0 \%$ \\
\hline 4 surfaces & $7.7 \%$ & $0.0 \%$ & $0.0 \%$ & $20.0 \%$ & $0.0 \%$ & $0.0 \%$ \\
\hline \multicolumn{7}{|l|}{$\mathrm{BOP}$} \\
\hline Mesial & $84.6 \%$ & $88.2 \%$ & $100.0 \%$ & $100.0 \%$ & $100.0 \%$ & $100.0 \%$ \\
\hline Buccal & $74.1 \%$ & $83.3 \%$ & $87.5 \%$ & $70.0 \%$ & $71.4 \%$ & $100.0 \%$ \\
\hline Distal & $84.6 \%$ & $94.1 \%$ & $100.0 \%$ & $88.9 \%$ & $100.0 \%$ & $100.0 \%$ \\
\hline Palatal/lingual & $70.4 \%$ & $77.8 \%$ & $100.0 \%$ & $100.0 \%$ & $100.0 \%$ & $100.0 \%$ \\
\hline \multicolumn{7}{|l|}{ Suppuration } \\
\hline Mesial & $18.5 \%$ & $5.6 \%$ & $25.0 \%$ & $0.0 \%$ & $14.3 \%$ & $0.0 \%$ \\
\hline Buccal & $44.4 \%$ & $22.2 \%$ & $37.5 \%$ & $10.0 \%$ & $57.1 \%$ & $0.0 \%$ \\
\hline Distal & $30.8 \%$ & $11.1 \%$ & $12.5 \%$ & $10.0 \%$ & $14.3 \%$ & $0.0 \%$ \\
\hline Palatal/lingual & $26.9 \%$ & $0.0 \%$ & $12.5 \%$ & $0.0 \%$ & $0.0 \%$ & $0.0 \%$ \\
\hline Mucosa buccal not attached & $29.5 \%$ & $33.3 \%$ & $50.0 \%$ & $70.0 \%$ & $85.7 \%$ & $20.0 \%$ \\
\hline Mesial crestal width (mm) & $3.4 \pm 1.2$ & $3.9 \pm 1.3$ & $5.3 \pm 1.2$ & $4.7 \pm 1.2$ & $5.6 \pm 0.8$ & $6.0 \pm 0.0$ \\
\hline Distal crestal width (mm) & $3.4 \pm 1.2$ & $4.3 \pm 1.2$ & $6.3 \pm 1.2$ & $5.1 \pm 1.0$ & $5.6 \pm 0.8$ & $5.8 \pm 0.5$ \\
\hline Overall mean crestal width (mm) & $3.5 \pm 1.3$ & $4.1 \pm 1.2$ & $5.8 \pm 1.1$ & $4.9 \pm 1.0$ & $5.6 \pm 0.8$ & $5.9 \pm 0.2$ \\
\hline Distance to fixture mesial (mm) & $5.7 \pm 2.7$ & $5.6 \pm 2.3$ & $5.6 \pm 2.3$ & $5.1 \pm 1.9$ & $7.1 \pm 3.5$ & $5.4 \pm 1.7$ \\
\hline Distance to fixture distal (mm) & $5.0 \pm 2.1$ & $4.4 \pm 1.6$ & $4.6 \pm 2.1$ & $5.9 \pm 3.6$ & $6.8 \pm 4.1$ & $8.0 \pm 3.5$ \\
\hline
\end{tabular}




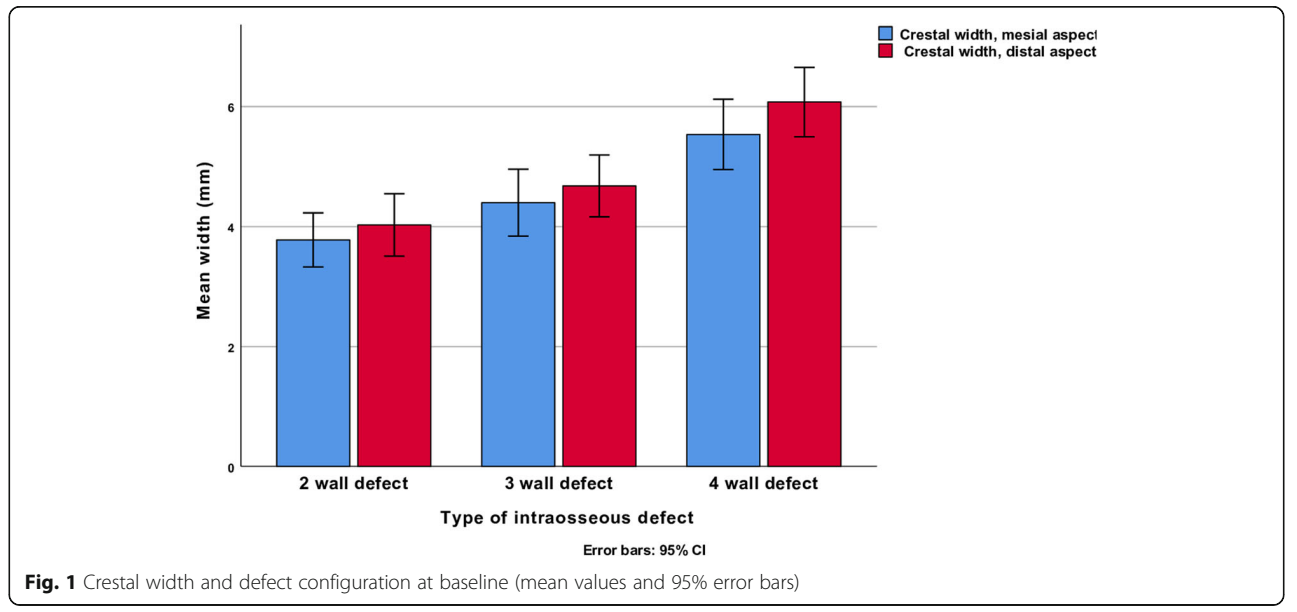

$0.2,0.6, p=0.34$ ), distal (mean diff $0.2 \mathrm{~mm}(\mathrm{SD} \pm 1.7$, $95 \% \mathrm{CI}-0.2,0.6, p=0.34)$, clinical, and radiographic assessments were studied (Fig. 3).

\section{Radiographic evidence of defect fill in relation to} bleeding on probing (per cent change), plaque scores (per cent), suppuration, or by treatment ( $A B$ vs $B D X$ ) in relation to defect configuration

Analyses by Pearson's correlation failed to demonstrate that changes in defect fill were correlated with changes in BOP, changes in plaque scores, or changes in PPD.
Clinical and radiographic changes at 2-, 3-, and 4-wall defects between baseline and year one and by treatment (Table 3)

When all cases with 2-wall defects were included (groups merged), analyses by paired samples $t$ test (equal variance not assumed) failed to demonstrated changes over time for plaque level changes, PPD changes, or radiographic evidence of defect fill. When all cases with 3-wall defects were included (groups merged), analyses by paired samples $t$ test identified improvements in BOP scores $(p<0.001)$ and probing depths (mean diff $1.5, \mathrm{SE}$

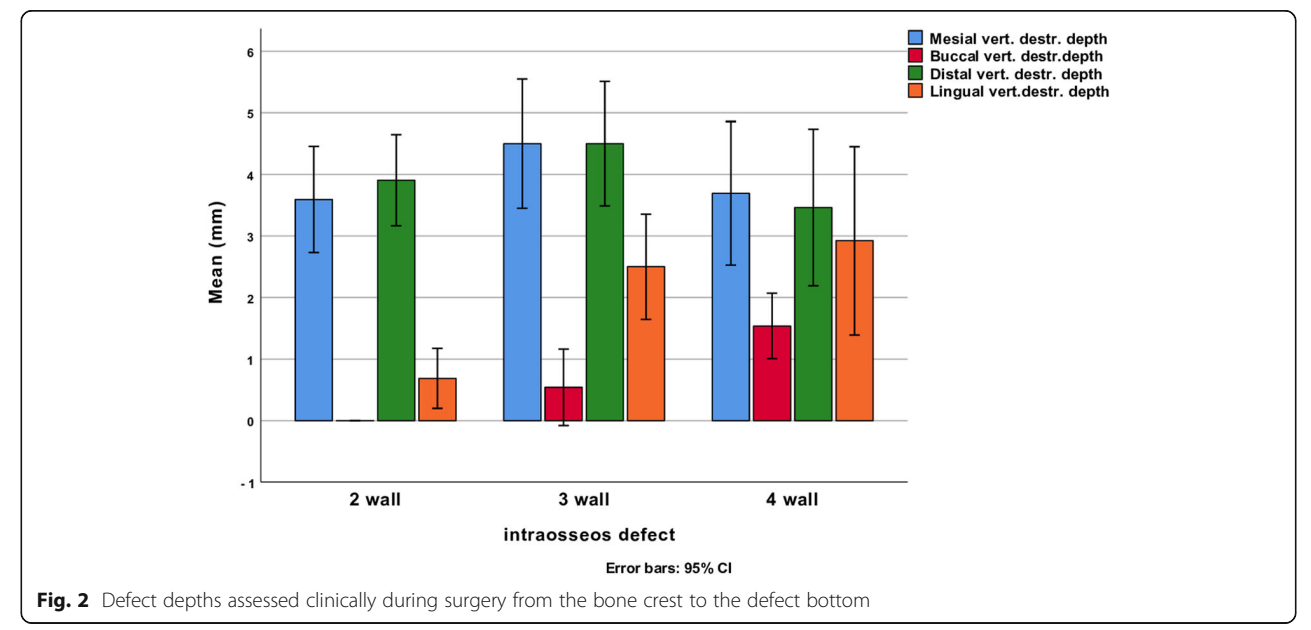




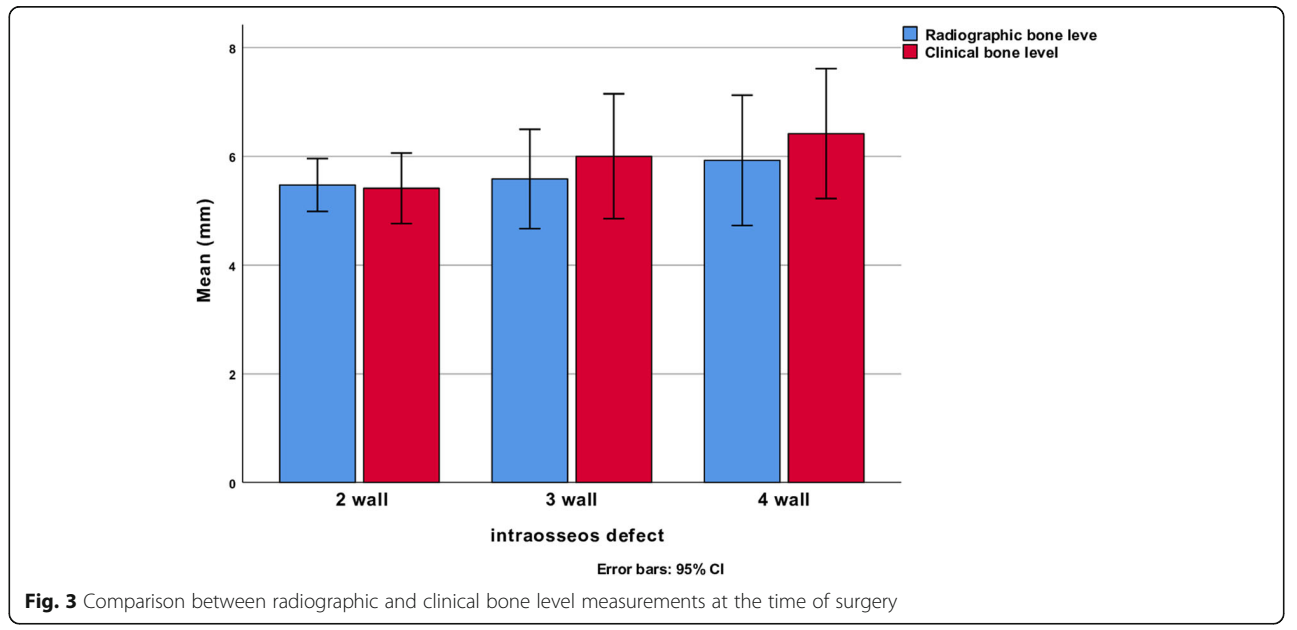

$\pm 0.3,95 \%$ CI 1.5, 2.8, $p<0.001)$. The analyses failed to demonstrate differences in plaque scores or evidence of defect changes between baseline and year 1. At 4-wall defects (groups merged), the analysis identified radiographic evidence of defect fill (mean diff $1.2 \mathrm{~mm}, \pm \mathrm{SE}$ $0.5,95 \%$ CI $0.1,2.4, p=0.05)$. Over time, probing depth reductions (mean diff $2.4, \mathrm{SE} \pm 0.5,95 \%$ CI $1.3,3.5, p<$ 0.001 ) and BOP \% reductions were significant (mean diff $34.6, \mathrm{SE} \pm 10.0,95 \%$ CI $12.8,56.5, p<0.01$ ). No differences in plaque scores could be verified. The distributions of defect fill (millimetre), probing depth change (millimetre), change in BOP (\%), and plaque index change (\%) between baseline and year one by defect type and treatment are presented in Fig. $4 a-d$.

\section{Impact of defect depth at mesial and distal lesions}

Analyses by Pearson's correlation between baseline implant defect depth and the extent of radiographic evidence of defect fill were significantly related at both mesial (corr. coeff $0.32, p=0.02$ ) and distal aspects (corr. coeff $0.46, p=0.001$ ). More defect fill was found at deeper defects.

\section{Discussion}

In a previous patient-based report on 1-year treatment results following the use of two different augmentation materials [13], no attempt was made to relate the influence of site characteristics to the presence of varying defect characteristics and no effort was made to describe defect characteristics to the reconstruction of the defects. Over the years, it has been debated on what type of defect that would benefit most from a reconstructive treatment. In the present report, the focus was to evaluate the possible influence of defect configuration (2-, 3-, or 4-bone wall lesions) on the treatment outcome 1 year after surgical intervention. The present study identified

Table 3 Changes in clinical conditions between baseline and year one by defect configuration and treatment. Independent $t$ tests (equal variance not assumed)) failed to demonstrate study group differences in clinical results regardless of defect configuration

\begin{tabular}{|c|c|c|c|c|c|c|c|c|c|}
\hline \multirow[t]{2}{*}{ Variable } & \multirow[t]{2}{*}{ Treatment } & \multicolumn{2}{|c|}{ 2-wall defects } & \multirow[t]{2}{*}{ Treatment } & \multicolumn{2}{|c|}{ 3-wall defects } & \multirow[t]{2}{*}{ Treatment } & \multicolumn{2}{|c|}{ 4-wall defects } \\
\hline & & Mean & SD & & Mean & SD & & Mean & SD \\
\hline \multirow[t]{2}{*}{ Defect fill mean (improvement) (mm)) } & $\mathrm{AB}(n=16)$ & 0.4 & 1.5 & $\mathrm{AB}(n=14)$ & 0.1 & 1.9 & $\mathrm{AB}(n=5)$ & 1.7 & 0.8 \\
\hline & $\operatorname{BDX}(n=19)$ & 1.2 & 1.1 & $\operatorname{BDX}(n=10)$ & 1.4 & 1.8 & $\operatorname{BDX}(n=7)$ & 0.9 & 2.3 \\
\hline \multirow[t]{2}{*}{ PPD mean change (reduction) (mm) } & $\mathrm{AB}(n=16)$ & 1.8 & 1.4 & $\mathrm{AB}(n=15)$ & 1.9 & 1.7 & $\mathrm{AB}(n=6)$ & 2.7 & 1.0 \\
\hline & $\operatorname{BDX}(n=19)$ & 2.5 & 1.6 & $\operatorname{BDX}(n=10)$ & 2.6 & 1.1 & $\mathrm{BD}(n=7)$ & 3.3 & 0.9 \\
\hline \multirow[t]{2}{*}{ BOP \% mean change (reduction) } & $\mathrm{AB}(n=16)$ & 43.8 & 35.9 & $\mathrm{AB}(n=14)$ & 25.0 & 27.7 & $\mathrm{AB}(n=16)$ & 33.3 & 43.8 \\
\hline & $\operatorname{BDX}(n=19)$ & 34.2 & 48.0 & $\operatorname{BDX}(n=10)$ & 52.5 & 39.9 & $\mathrm{BD}(n=19)$ & 67.9 & 23.8 \\
\hline \multirow[t]{2}{*}{ Plaque score $\%$ mean change (reduction) } & $\mathrm{AB}(n=15)$ & 10.0 & 26.4 & $\mathrm{ABX}(n=14)$ & 3.6 & 39.4 & $\mathrm{AB}(n=15)$ & 8.5 & 12.9 \\
\hline & $\operatorname{BDX}(n=20)$ & 11.3 & 27.4 & $\operatorname{BDX}(n=10)$ & 12.5 & 25.0 & $\mathrm{BD}(n=20)$ & 0.0 & 14.4 \\
\hline
\end{tabular}




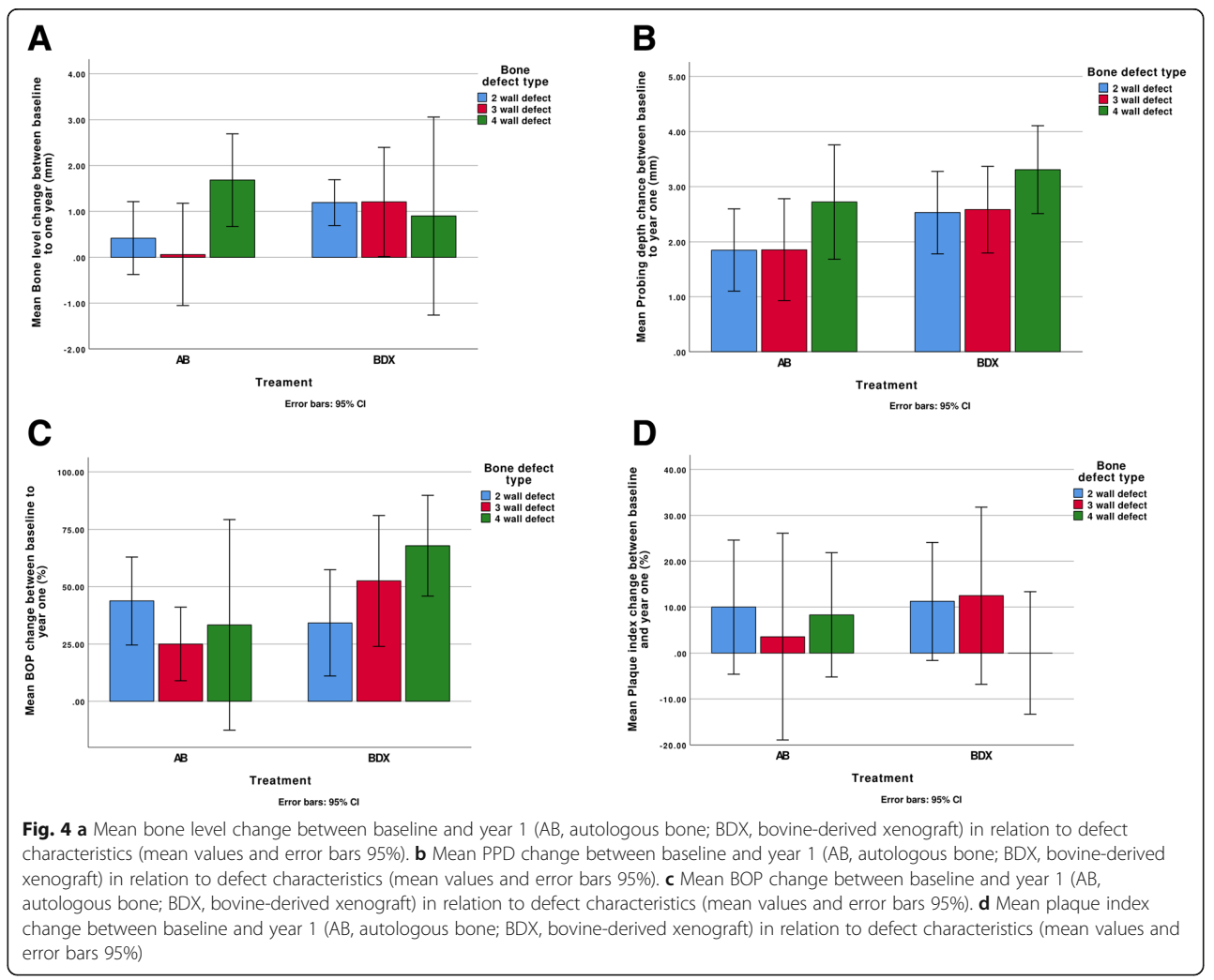

that 4-wall lesions could be reconstructed with better results. Furthermore, the analyses revealed that apart from the buccolingual crest width, no other factor was explanatory to defect configuration. Defects with 4 wall characteristics were associated with broader buccolingual crestal width. The present study also demonstrated a good correlation between radiographic and clinical measurements of bone loss at dental implants.

Recently published data suggest that 3-wall bone defect lesions are the most common type of defects in peri-implantitis, followed by defects with buccal dehiscence [5]. In the present study, 2-wall defects were found more prevalent than other defects. The distribution of peri-implantitis defects may vary depending on anatomical differences depending on the location of the actual implant. The fact that anatomical differences may be related to implant location further highlighted by the differences between the present study and what has been reported elsewhere $[3,14]$. The majority $(50 \%)$ of the defects in the present study were identified as 2-wall defects as compared to $10,2 \%$ in a previous report [14] Recently, however, it was reported that buccal dehiscence defects with semi-circular bone resorption to the middle of the implant body were present in more than a third of the cases (35.7\%) [15] which also contrasts the data reported earlier [14]. The results of the present study identified that the width of the alveolar ridge was a factor influencing the number of bony walls in a defect presenting with peri-implantitis.

In the study by Schwarz et al. [14], most of the implants were placed in the posterior region of the oral cavity. Thus, the differences in findings between the results reported in the present study and previous reports $[3,14,15]$ may be explained by the fact that most of the implants with peri-implantitis in the present study were located in the anterior and premolar regions. It has also been reported in the periodontal literature that bone defect configuration at teeth with periodontitis appears to differ between anterior and posterior positions [16]. 
The explanation to the implant location may be related to the fact that the Swedish Dental Insurance System did not always cover the placement of implants in the posterior region. Thus, the present study cannot correctly address the question if one type of peri-implantitis defect is more common than any other kind of defect. In general, neither other studies nor the present study included a diverse large study population. Therefore, the question of the prevalence of defect type remains to be further addressed.

The lack of keratinized buccal mucosa in the present study reached $50 \%$ at 4 -wall defects. Other types of defects were without presence of keratinized tissues less prevalent. It has previously been reported that overall, $50 \%$ of defects were associated with no keratinized tissues at buccal aspects [5]. Both studies failed to identify that presence or absence of keratinized tissues was explanatory to defect characteristics.

The present study, including mesial and distal defect depths $\geq 3 \mathrm{~mm}$ at implants assessed during the surgical intervention in cases with peri-implantitis, demonstrated that more defect fill, as evaluated from radiographs, was found at defects that were deeper at the time of surgical intervention. The results from the present study are consistent with the periodontal literature suggesting that deep intraosseous defects have a better healing potential than shallow pockets [17-20]. Furthermore, defect fill was higher at 4-wall lesions than at 2- and 3-wall lesions. These findings are consistent with a previous report [3]. It should, however, be noted that a resorbable membrane was also used in the present study. It is possible that the comparable good reconstructive results observed at 2- and 3-wall defects may have been influenced by the capacity of the membrane to keep the bone augmentation material in place.

The shortcomings from the present study are related to the number of implants included and to that relatively few implants were available from molar regions. Most of the implants were placed in the maxilla. Additionally, two different regenerative materials were used. Notwithstanding these limitations, the present study identified that deep defects had the best reconstructive potential.

\section{Conclusions}

Four-wall defects demonstrated more defect fill 1 year after treatment. Deeper defects resulted in more defect fill. The buccal-lingual width of the alveolar bone was explanatory to defect configuration.

\section{Abbreviations}

PPD: Probing pocket depth; BOP: Bleeding on probing; HbA1c: Haemoglobin a1c; GRP: G. Rutger Persson; CLUT: Colour look-up tables; UL: Ulla Lindström; MR: Mucosal recession; AB: Autogenous bone; BDX : Bovine-derived xenograft; ANOVA: Analysis of variance; ICC: Intraclass correlation; SD: Standard deviation

\section{Acknowledgements}

We appreciate the clinical work by Ms Ulla Lundström (UL) RDH at Uppsala Oral Surgery Centre, Sweden. We also appreciate the support from Biomet 3 I, Inc. Palm Beach Florida, USA, and Kristianstad University, Kristianstad, Sweden.

Authors' contributions

All authors were involved in planning the project. Prof. Persson evaluated the radiographs. Dr Aghazadeh performed and managed the data collected. All authors analysed the data. Dr Aghazadeh led the writing. Prof. Renvert and Prof. Persson participated in the final manuscript production. All authors reviewed and accepted the final manuscript.

\section{Funding}

This manuscript was partially supported by funds from Biomet3i, Palm Beach, USA, and University of Kristianstad, Sweden.

\section{Availability of data and materials}

Contact the corresponding author

\section{thics approval and consent to participate}

The Institutional Review Board at Lund, Sweden, approved the study (id nr: 89: 2007). All study participants signed an informed consent

\section{Consent for publication}

N/A.

\section{Competing interests}

Prof. Rutger Persson and Dr Ahmad Aghazadeh declare no conflict of interest. Prof. Stefan Renvert states research grants and fees from Geistlich Pharma outside the present work

\section{Author details}

${ }^{1}$ Tand \& Implantat Specialistkliniken, Solna, Sweden. ${ }^{2}$ Faculty of Health Sciences, Kristianstad University, SE-291 88 Kristianstad, Sweden. ${ }^{3}$ Department of Periodontics, University of Washington, Seattle, WA, USA. ${ }^{4}$ Department of Oral Medicine, University of Washington, Seattle, WA, USA. ${ }^{5}$ Blekinge Institute of Technology, SE-371 79 Karlskrona, Sweden. ${ }^{6}$ School of Dental Science, Trinity College, Dublin, Ireland. 'Faculty of Dentistry, The University of Hong Kong, Hong Kong, SAR, China.

Received: 5 February 2020 Accepted: 24 April 2020 Published online: 17 June 2020

\section{References}

1. Derks J, Tomasi C. Peri-implant health and disease. A systematic review of current epidemiology. J Clin Periodontol. 2015;42(Suppl 16):S158-71.

2. Berglundh T, Armitage G, Araujo MG, Avila-Ortiz G, Blanco J, Camargo PM, Chen S, Cochran D, Derks J, Figuero E, Hämmerle CHF, Heitz-Mayfield LA, Huynh-Ba G, lacono V, Koo KT, Lambert F, Mc Cauley L, Quirynen M, Renvert S, Salvi GE, Schwarz F, Tarnow D, Tomasi C, Wang HL, Zitzmann N. Periimplant diseases and conditions: consensus report of workgroup 4 of the 2017 World Workshop on the classification of periodontal and peri-implant diseases and conditions. J Clin Periodontol. 2018:45(Suppl 20):S286-91.

3. Schwarz F, Sahm N, Schwarz K, Becker J. Impact of defect configuration on the clinical outcome following surgical regenerative therapy of periimplantitis. J Clin Periodontol. 2010;37:449-55.

4. Renvert S, Giovannoli J-L. Treatments. In: Peri-implantitis. Paris: Quintessence International; 2012. p. 132-87.

5. Monje A, Pons R, Insua A, Nart J, Wang HL, Schwarz F. Morphology and severity of peri-implantitis bone defects. Clin Impl Dent Rel Res. 2019;21: $635-43$.

6. Smeets $R$, Henningsen $A$, Jung $O$, Heiland M, Hammächer C, Stein JM. Definition, etiology, prevention and treatment of peri-implantitis--a review. Head Face Med. 2014:3(10):34

7. Mercado F, Hamlet S, Ivanovski S. Regenerative surgical therapy for periimplantitis using deproteinized bovine bone mineral with 10\% collagen, enamel matrix derivative and doxycycline-a prospective 3-year cohort study. Clin Oral Implants Res. 2018:29:583-91. 
8. Chan $H L$, Lin GH, Suarez F, MacEachern M, Wang HL. Surgical management of peri-implantitis: a systematic review and meta-analysis of treatment outcomes. J Periodontol. 2014;85:1027-41.

9 Isehed C, Holmlund A, Renvert S, Svenson B, Johansson I, Lundberg P. Effectiveness of enamel matrix derivative on the clinical and microbiological outcomes following surgical regenerative treatment of peri-implantitis. A randomized controlled trial. J Clin Periodontol. 2016:43:863-73.

10. Roccuzzo M, Gaudioso L, Lungo M, Dalmasso P. Surgical therapy of single periimplantitisintrabony defects, by means of deproteinized bovine bone mineral with 10\% collagen. J Clin Periodontol. 2016;43:311-8.

11. Christiaens V, De Bruyn H, De Vree H, Lamoral S, Jacobs R, Cosyn J. A controlled study on the accuracy and precision of intraoral radiography in assessing interproximal bone defect morphology around teeth and implants. Eur J Oral Implantol. 2018;11:361-7.

12. Ritter $L$, Elger $M C$, Rothamel $D$, Fienitz $T$, Zinser $M, S c h$ warz F, Zöller JE. Accuracy of peri-implant bone evaluation using cone beam $C T$, digital intraoral radiographs and histology. Dentomaxillofac Radiol. 2014;43:20130088.

13. Aghazadeh A, Persson GR, Renvert S. A single-centre randomized controlled clinical trial on the adjunct treatment of intra-bony defects with autogenous bone or a xenograft: results after 12 months. J Clin Periodontol. 2012:39:666-73.

14. Schwarz F, Herten M, Sager M, Bieling K, Sculean A, Becker J. Comparison of naturally occurring and ligature-induced peri-implantitis bone defects in humans and dogs. Clin Oral Implants Res. 2007;18:161-70.

15. Roccuzzo M, Pittoni D, Roccuzzo A, Charrier L, Dalmasso P. Surgical treatment of peri-implantitis intrabony lesions by means of deproteinized bovine bone mineral with 10\% collagen: 7-year-results. Clin Oral Implant Res. 2017:28:1577-83.

16. Wu SK, Yeh HC, Chan CP. The prevalence and distribution of bone defects in patients with moderate to advanced periodontitis. Chang Gung Med J. 2001;24:423-30.

17. Polson AM, Heijl LC. Osseous repair in infrabony periodontal defects. J Clin Periodontol. 1978:5:13-23.

18. Falk H, Laurell L, Ravald N, Teiwik A, Persson R. Guided tissue regeneration therapy of 203 consecutively treated intrabony defects using a bioabsorbable matrix barrier. Clinical and radiographic findings. $J$ Periodontol. 1997;68:571-81

19. Cortellini P, Carnevale G, Sanz M, Tonetti MS. Treatment of deep and shallow intrabony defects. A multi-center randomized controlled clinica trial. J Clin Periodontol. 1998;25:981-7.

20. Eickholz P, Hausmann E. Accuracy of radiographic assessment of interproximal bone loss in intrabony defects using linear measurements. Eur J Oral Sci. 2000:108.70-3.

\section{Publisher's Note}

Springer Nature remains neutral with regard to jurisdictional claims in published maps and institutional affiliations.

\section{Submit your manuscript to a SpringerOpen ${ }^{\circ}$ journal and benefit from:}

Convenient online submission

- Rigorous peer review

- Open access: articles freely available online

- High visibility within the field

- Retaining the copyright to your article 


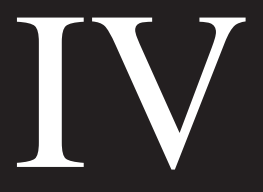



Long-term stability of treatment results obtained following reconstructive treatment of peri-implant defects - Results after five years.

Ahmad Aghazadeh ${ }^{1}$

G. Rutger Persson ${ }^{2,3}$,

Andreas Stavropoulos ${ }^{4,5}$

Stefan Renvert $2,6,7,8$

${ }^{1}$ Tand \& Implantat Specialistkliniken, Solna, Sweden

${ }^{2}$ Department of Oral Sciences, Kristianstad University, Kristianstad, Sweden

${ }^{3}$ Departments of Periodontics and Oral Medicine, University of Washington, Seattle, WA. USA

${ }^{4}$ Department of Periodontology, Malmö University, Malmö, Sweden

${ }^{5}$ Division of Regenerative Dental Medicine and Periodontology, CUMD, University of Geneva, Geneva, Switzerland

${ }^{6}$ Blekinge Institute of Technology, Karlskrona, Sweden

${ }^{7}$ Faculty of Dentistry, The University of Hong Kong, Hong Kong SAR, China

${ }^{8}$ School of Dental Sciences, Trinity College, Dublin, Ireland

Corresponding author:

Stefan Renvert,

Oral Health Sciences,

Kristianstad University,

Kristianstad 291 88, Sweden.

Email: stefan.renvert@hkr.se

Keywords: peri-implantitis, bone augmentation, reconstructive surgery

Running title: Reconstructive treatment of peri-implantitis

Number of words in the abstract: 230

Number of words in manuscript: 3728

Number of figures: 4

Number of tables: 5 


\section{Abstract}

Objectives: To assess the long-term efficacy of reconstructive treatment of peri-implantitis intraosseous defects using either autogenous bone graft $(A B)$ combined with a resorbable membrane or a bovine-derived xenograft (BDX) combined with a resorbable membrane. Material and Methods: Peri-implant intraosseous $\geq 2$ bone walls defects were treated with reconstructive surgery using either $\mathrm{AB}$ or $\mathrm{BDX}$ in combination with a collagen membrane. Maintenance was provided every three months for five years. Achieving a successful treatment outcome (= no bone loss, no probing pocket depth (PPD) $>5 \mathrm{~mm}$, no suppuration, maximum one implant surface with evidence of bleeding on probing (BOP) allowed) was considered as the primary outcome.

Results: In the $A B$ group, 11 implants were lost to follow-up; 16 patients and 25 implants remained at year 5 . In the BDX group at year 5, all 23 patients with 37 implants remained. BOP and PPD were reduced between baseline and year $5(p<0.001)$. A successful treatment outcome was observed in $16 \%$ of implants in the $A B$ group and $43 \%$ of implants in the BDX group. There was a $3.1(95 \% \mathrm{Cl} 1.2,8.4, \mathrm{p}<0.02)$ likelihood of achieving a better result for implant treatment in the BDX group.

Conclusions: Reconstructive surgical treatment of peri-implant intraosseous defects can result in successful clinical outcomes, maintainable over at least five years. Use of BDX has a higher likelihood of resulting in successful clinical outcomes than the use of autogenous bone. 


\section{Introduction}

Peri-implantitis is a clinical complication of implant therapy. In a recent systematic review and meta-analysis, the estimated weighted mean prevalence of peri-implantitis on patientlevel was 22\% (Cl: 14-30\%) (Derks \& Tomasi, 2015). Due to significant heterogeneity in case definitions, peri-implantitis prevalence in the included individual studies varied between $1 \%$ and $47 \%$. Treatment of peri-implantitis is complex, and non-surgical treatment modalities may not result in healthy conditions ( Renvert, Roos-Jansaker, Claffey, 2008). In clinical practice, surgery is used to expose and debride the involved part of the implant surface. Short-term clinical improvements following reconstructive therapy using different bone augmentation materials have been reported ( Roos-Jansaker, Renvert, Lindahl, Renvert,. 2007, Aghazadeh, Person, Renvert., 2012, Jepsen et al., 2016, Carcuac et al., 2016, Roccuzzo, Gaudioso, Lungo, Dalmasso., 2016, La Monaca et al., 2018, Renvert, RoosJansåker, Persson., 2018, Clem \& Gunsolley., 2019). Reconstructive surgical treatment of peri-implantitis defects using a graft material alone (Mercado, Hamlet, Ivanovski, 2018), or mixed with antibiotics (Nart, de Tapia, Pujol, Pascual, Valles, 2018), or combined with a barrier membrane (Chan, Lin, Suarez, MacEachern, Wang, 2014) may result in significantly better clinical improvements. In contrast, a recent study demonstrated that surgical treatment of peri-implantitis with adjunct use of bone-grafting did not improve the healing response in terms of the number of cases with disease resolution or average BOP and PPD reductions (Ramanauskaite, Becker, Juodzbalys, Schwarz.2018).

Regular supportive care is essential to retain and secure the results following treatment of peri-implantitis (Serino, Turri, Lang,. 2015, Heitz-Mayfield et al. 2018, Roccuzzo, Layton, Roccuzzo, Heitz-Mayfield,. 2018). In a recent retrospective study, patients receiving 
supportive implant therapy (SIT) had a lower incidence of peri-implantitis than patients without regular maintenance. Individuals without SIT exhibited a 4.3-fold increased risk for peri-implantitis over seven years (Frisch, Vach, Ratka-Krueger, 2020). Stability of clinical improvements following surgical treatments of peri-implantitis has been demonstrated in studies with varying supportive care intervals (Schwarz, Sahm, Bieling, Becker. ,2009, Rocuzzu et al. 2017, Schwarz, Derks, Monje, Wang HL,. 2018). For example, stable conditions were reported over a 5-year follow-up of cases following reconstructive surgical therapy (Roos-Jansåker et al. 2014); in this study, the patients were recalled on a 3-month basis and had a mean plaque index score of approximately $15 \%$ during the entire 5 -year follow-up period. Reconstructive surgery of peri-implantitis defects is a complicated procedure. The scientific evidence regarding long-term treatment outcomes following different treatment modalities is limited. The present study aimed to assess the long-term efficacy of reconstructive treatment of peri-implantitis intraosseous defects using either autogenous bone graft or a bovine-derived xenograft in combination with a resorbable membrane.

\section{Materials and Methods}

\section{Study design}

The study was a single-blinded human prospective randomised longitudinal clinical trial on reconstructive surgical treatment of peri-implantitis, with a 5-year follow-up period. 


\section{Study population}

The Regional Ethics Committee in Lund, Sweden approved the study (ID nr108/2007). All participating individuals signed informed consent. The CONSORT guidelines for clinical trials were followed. The study flow chart is presented (Figure 1).

The present study reports on the long-term outcomes of a study population of 45 patients including a total of 75 implants with a diagnosis of peri-implantitis, surgically treated between 2007 and 2011 at a specialist centre in Uppsala, Sweden (Uppsala Käkkirurgiska Centrum). Peri-implant defects were, following thorough debridement and chemical cleaning of the implant surfaces with $3 \%$ hydrogen peroxide, grafted with either autogenous bone graft (AB), or with a bovine-derived xenograft (BDX) (Bio-Oss ${ }^{\circledR}$ Geistlich Pharma, Wolhusen, Switzerland). All treated implants were covered with a collagen membrane (OsseoGuard ${ }^{\circledR}$, Biomet3I Inc., Palm Beach, FL., USA), and surgical flaps were repositioned and sutured. The 1-year results have previously been reported (Aghazadeh et al. 2012). The patients were enrolled in a 3-month maintenance program and followed for five years. Inclusion criteria

(I) $\geq 1$ osseointegrated implant with radiographic evidence of bone loss $\geq 2 \mathrm{~mm}$, when comparing radiographs taken at the time of screening with radiographs taken at the time of placement of the implant supra-structure

(II) Probing pocket depth $\geq 5 \mathrm{~mm}$ combined with BOP/suppuration on probing

(III) Angular peri-implant bone defect ( $\geq 3 \mathrm{~mm}$ in depth as determined from intra-oral digital radiographs) 


\section{Exclusion criteria}

(I) uncontrolled diabetes mellitus ( $\mathrm{HbA} 1 \mathrm{c}>46 \mathrm{mmol} / \mathrm{mol})$

(II) requiring antibiotic prophylaxis

(III) taking prednisone or other anti-inflammatory medications

(IV) using antibiotics in the preceding three months

(V) taking medications known to affect gingival growth

\section{Pre-treatment procedures}

The participants' medical and dental history was updated. Before enrolment, the study participants received periodontal therapy eliminating periodontal pockets of $>5 \mathrm{~mm}$ at existing teeth and ensuring that the participants' oral hygiene was under control.

\section{Radiographic analysis}

Standardised intra-oral radiographs were obtained using an Eggen holder and long cone equipped dental X-ray unit. Pre- and postoperative radiographs presenting the study implants were digitalised, coded and evaluated using a computer program (OsiriX Imaging software 3.9 for MAC OS 10.6, Osirix Foundation, Geneva, Switzerland). The mesial and distal distances from the implant platform to the bottom of the defect were measured on radiographs taken at baseline, 12 , and 60 months. One calibrated examiner (GRP) who was masked to study allocation assessed all radiographs. The most coronal confluent aggregation of bone or bone-like material was used to define the marginal bone level. Single strands or islets of bone or bone-like material were not considered. Radiographs/measurements were calibrated based on the known distance between implant threads (Figure 2). 


\section{Clinical measurements and procedures}

At baseline a complete set of intraoral radiographs (unless recent radiographs taken within the last three months were available)

One experienced examiner (U.L.), unaware of treatment group assignment, performed all clinical examinations.

The following clinical data were registered at baseline, 12, and 60 months after therapy:

- Full mouth plaque score (PI), as presence/absence of plaque along the gingival/mucosal margin after use of disclosing dye (Top Dent, Lifco Dental AB, Enköping, Sweden) and expressed as percentage of examined sites ( 4 sites/tooth and 4 sites/implant) with evidence of staining.

- Local plaque score, as presence/absence of plaque along the mucosal margin of each treated implant (4 sites/implant) after using the disclosing dye and expressed as percentage of implant sites with evidence of staining in each patient.

- Probing pocket depth (PPD) at the implants (4 sites/implant) and recorded to the nearest $1 \mathrm{~mm}$ using a plastic periodontal probe (Colorview, Hu-Friedy, Chicago II, USA)

- Bleeding on probing (BOP) was recorded as presence /absence of bleeding within $30 \mathrm{~s}$ following probing at teeth and implants expressed as a percentage of examined sites.

- Local BOP at the implant (4 sites/implant) recorded as presence/absence of BOP.

- Suppuration (SUP), as presence/absence of pus following probing (4 sites/implant)

- Mucosal recession (MR), at implants (4 sites/implant) recorded to the nearest $\mathrm{mm}$. The position of the mucosal margin apical to the restoration margin was considered a positive recession (+), and the position of the mucosal margin coronal to the restoration margin as a negative recession (-). 


\section{Surgical treatment}

All implant-supported reconstructions were removed before surgical interventions.

Following the administration of local anesthetics, by means of an intrasulcular incision, a mucoperiosteal flap was raised. Granulomatous tissues were removed using titanium curettes (Deppeler SA, Rolle, Switzerland). The implant surfaces were first debrided and then chemically cleaned with a gauze soaked in $3 \%$ hydrogen peroxide, followed by thorough rinsing with saline.

The assignment to a treatment group was made using pre-prepared randomisation in groups $A B$ or BDX. Cards with group identification were prepared and placed in number-coded envelopes as defined by SPSS 18.0 software (IBM SPSS, Armonk, NY, USA). The envelope with the code was opened only after surgical entry and debridement of the implants. Depending on the assignment, the defect was either filled with cortical AB obtained with a bone scraper (Safescraper ${ }^{\circledR}$ TWIST; Biomet3I Inc., Palm Beach, FL, USA) from the mandibular ramus region or with BDX (Bio-Oss ${ }^{\circledR}$ particle size $0.25-\mathrm{Imm}$; Geistlich Pharma, Wolhusen, Switzerland). A resorbable membrane (OsseoGuard ${ }^{\circledR}$, Biomet3I Inc., Palm Beach, FL, USA) was used to cover the AB or BDX. The flaps were sutured using 4.0 sutures (Ethicon vicryl polyglactin, Johnson \& Johnson, San Angelo, TX, USA). All study participants were given antibiotics postoperatively (Azithromycin $250 \mathrm{mg} \times 2$ during day 1, and then one tablet daily for a further four days). During the first three days, they also received an anti-inflammatory and analgesic drug (Ibuprofen 400 mg x 3 days) (Ibumetin, Nycomed AB Stockholm, Sweden). During the first six weeks after surgery, the participants also rinsed daily with $0.1 \%$ chlorhexidine (Hexident, Meda AB, Stockholm, Sweden). 
Six weeks after surgery, the first supportive therapy was given. All participants were placed on a maintenance program with visits every third month. Plaque at implants was disclosed using an erythrosine dye (Top Dent Lifco Dental AB, Enköping, Sweden). Reinstructions in oral hygiene procedures were performed as deemed necessary. All existing teeth and implants were cleaned using a rubber cup and a low-abrasive paste. If BOP was detected, the area was re-instrumented with curettes (Deppeler SA, Rolle, Switzerland).

\section{Statistics}

Statistical analysis included descriptive statistics for the clinical and radiographic parameters assessed at the implants at baseline, at 1 and 5 years. For the peri-implant and radiographic parameters, means and standard deviations were calculated. The primary outcome measure was successful treatment, defined as no further radiographic evidence of bone loss between screening (BL) and year 5, no presence of suppuration at any aspect of the implant, no clinical finding of PPD $>5 \mathrm{~mm}$ at any of four sites per implant; only one implant surface with BOP was allowed.

Statistical analyses were performed with independent t-tests (equal variance not assumed) and paired t-tests, One-way ANOVA, Chi-square (Pearson), and Mantel Haenszel likelihood ratio. Backwards conditional binary logistic regression analyses were performed to identify any association of gender, patient age, plaque scores at implants at baseline and 5 years, smoking, defect type, or treatment assignment with treatment outcome. The precision in the assessments was investigated using intra-class correlation (ICC) and paired t-tests. Statistical significance was determined at an alpha level of 0.05 . The IBM SPSS 27.0 statistical software package for MAC computers was used (IBM, SPSS, Armonk, NY, USA). 


\section{Results}

A summary of characteristics of the remaining study individuals and dental implants in the present study are presented in Fig 1, flowchart. Baseline study group conditions are presented as patient-based data (Table 1). In the AB group, 22 individuals with 36 dental implants with intraosseous defects classified as having $\geq 2$ defect walls were included. At year 5, 16 individuals and 25 implants remained for the final analyses. Eleven implants had been lost to follow-up. In the BDX group, all 23 individuals with 37 dental implants with $\geq 2$ wall defects remained year 5 . One implant had been lost due to implant fracture, and one radiograph was deemed impossible to assess, leaving 37 implants with a complete data set. At baseline, no difference in clinical measurements between study groups was identified.

The mean age of study participants remaining at year 5 were $76.2 \pm 6.7$ (SD) years (range: 62$85)$ and $67.6 \pm 7.3(S D)$ years (range: $52-78)$ for the AB and BDX groups, respectively $(p<$ 0.001). Additional study group conditions including data from study participants who completed the study are presented in Table 2.

\section{Analyses of duplicate radiographic measurements}

Repeated measurements of bone levels on radiographs were made of 15 implants and assessed both at the mesial and the distal surfaces. The ICC coefficient was 0.97 (95\% Cl 0.95 to $0.99, p<0.001$ ).

Changes in full mouth plaque and bleeding scores over time

Changes in full mouth plaque and bleeding scores for the study participants in the $A B$ and BDX groups are illustrated in Fig 3. The improvements were maintained over the remaining study period. 
Clinical and radiographic changes between baseline, 1 , and 5 years for the $A B$ group The summary of findings is presented in Table 3. The reduction in BOP and PPD between baseline and year 1 and between baseline and year 5 were significant (pairwise t-tests; $p<0.001)$. No significant improvements occurred for plaque scores or for bone level changes over time.

Clinical and radiographic changes between baseline, 1, and 5 years for the BDX group A summary of the findings is presented in Table 4 . A total of 37 implants presented with all variables for analysis. The results from pairwise t-test analyses identified that the improvements (reductions) at implants of BOP, PPD bone defect depth (assessed radiographically) were significant between baseline and year 1 and between baseline and year $5(p<0.001)$. In contrast, plaque level scores improved only between baseline and year 1 with no difference between baseline and year 5 .

\section{Clinical and radiographic changes between study groups}

The summary of the findings is presented in Table 5 . The results from independent t-tests identified that the changes in BOP and PI over time did not differ between study groups. However, the PPD reductions were greater in the AB group (approximately $0.5 \mathrm{~mm}$ difference at both 1 and 5 years). Bone defect fill was greater in the BDX group at 1 and 5 years. In the BDX group at both 1 and 5 years, 3/37 (8.1\%) of the implants had experienced an increasing defect depth assessed radiographically. In the AB group at year 1, 9/25 (36\%) had experienced increasing defect depth $\geq 1 \mathrm{~mm}$. At year 5, 17/25 (68\%) had experienced a loss of radiographically assessed bone of $\geq 1 \mathrm{~mm}$. Percentage changes in plaque and BOP scores between baseline and year 5 are presented in a boxplot diagram (Figure 3). Changes 
in PPD $(\mathrm{mm})$ and radiographic evidence of bone level changes $(\mathrm{mm})$ between baseline and year 5 are presented in a boxplot diagram (Figure 4).

\section{Successful treatment outcome after five years}

A successful treatment outcome was observed in $4 / 25(16.0 \%)$ implants in the $A B$ group, and in $16 / 37$ (43\%) of the implants in the BDX group $\left(\chi^{2}=5.4, p<0.021\right)$, and with a likelihood ratio of a better result in the $\mathrm{BDX}$ group $=3.1,(95 \% \mathrm{Cl} 1.2,8.4, \mathrm{p}<0.02)$.

Radiographic evidence of bone defect fill at 2-, 3-, and 4-wall defects in the BDX group. Analysis using One-way ANOVA (including post-hoc Bonferroni) identified a difference in bone defect fill between 3- and 4-wall defects at year 1 (mean diff: $2.1 \mathrm{~mm}, \mathrm{SE} 0.8, p<0.05$ ). After five years, no differences were found by defect configuration at baseline.

\section{Patient-based data}

In the $A B$ group, $43.7 \%$ of the individuals had more than one study implant included. In the BDX groups, $47.8 \%$ of the individuals had more than one study implant included. The change in radiographic bone levels demonstrated an average loss of bone of $0.9 \mathrm{~mm}$ (SD: \pm 1.8 ) between $\mathrm{BL}$ and year 5 in the $\mathrm{AB}$ group, whereas in the BDX group, an average improvement of $1.5 \mathrm{~mm}$ (SD: \pm 1.9 ) was identified (mean diff: 2.4 SE diff: $0.6,95 \% \mathrm{Cl}: 1.1,3.7, \mathrm{p}<0.01$ ) (equal variance not assumed). In the $A B$ group, two of the individuals demonstrated radiographic evidence of relevant clinical improvement with a mean defect fill of $\geq 1.0 \mathrm{~mm}$. In the BDX group, 11 individuals demonstrated such an average gain of defect fill. 


\section{Discussion}

There are few long-term follow-up studies on reconstructive surgical treatment of cases with peri-implantitis. The present study assessed the outcome of reconstructive surgical treatment of peri-implantitis-related bone defects using either AB or BDX in patients who were enrolled in a maintenance care program with maintenance visits every third month for five years following initial therapy. A successful treatment outcome was obtained in $16 \%$ of the cases treated with $A B$ and $43 \%$ in the cases treated with BDX. These findings are in agreement with previously published studies (Roos-Jansåker et al. 2014, Roccuzzo, Pittoni, Roccuzzo, Charrier, Dalmasso,. 2017, Heitz- Mayfield et al. 2018).

Several publications have highlighted the importance of maintenance visits to prevent/reduce the incidence of peri-implantitis (Roos-Jansåker, Lindahl, Persson, Renvert., 2011, Roccuzzo, De Angelis, Bonino, Aglietta., 2010, Rinke, Ohl Ziebolz, Lange, Eickholz., 2011, Costa et al. 2012, Pjetursson et al. 2012, Serino et al. 2015, Monje et al. 2016, Monje A, Wang HL, Nart J., 2017, Hu, Lang, Ong, Lim, Tan,. 2020). Frequent maintenance may be critical for the maintenance of the initially obtained treatment results. In the present study, and similar to Roos-Jansåker, Persson, Lindahl, Renvert,. (2014), all patients attended a 3month maintenance program. Both studies indicate that it is possible to maintain initially obtained treatment results over five years. Similarly, Serino et al. (2015) also demonstrated that the peri-implant conditions obtained following peri-implant surgery could be maintained as stable for most patients and implants for five years if a high standard of oral hygiene could be maintained using a 6-month recall system. In a recent 10-year follow-up study, $84 \%$ of available healthy treated implants maintained healthy peri-implant conditions, and $67 \%$ of implants treated for peri-implantitis maintained stable peri-implant conditions (despite the presence of pockets and BoP/Sup) (Serino, Wada, Mameno, 
Renvert,. 2021). It should, however, be emphasised that plaque scores during the 10-year maintenance period remained below $20 \%$ for all patients. Thus, it appears that the patient's ability and willingness to obtain good oral hygiene is crucial for maintaining long-term periimplant health.

In the present study, plaque levels decreased from baseline to year 5 in the $A B$ and BDX groups. In the AB group, one implant was lost due to disease progression, whereas in the BDX group, one implant fractured and was removed. Furthermore, 11 implants were lost to follow-up in the AB group, whereas no implants were lost to follow-up in the BDX group. Forty per cent of the remaining implants in the $A B$ group and $8 \%$ of remaining implants in the BDX group presented with bone loss $\geq 1 \mathrm{~mm}$ at 5 years. These results are better than those reported in another recent long-term follow-up study after resective peri-implantitis surgery, in which 49 of the initial 179 (27.4\%) implants were lost to follow-up (Carcuac et al., 2020). Fifty-seven of the remaining 130 implants (44\%) were diagnosed with progression of peri-implantitis. Twenty-seven of the 130 remaining implants were removed, 13 implants were surgically re-treated, and an additional 17 presented with bone loss of $>1 \mathrm{~mm}$ (Carcuac et al., 2020). In the study by Carcuac et al. (2020), the patients had been monitored every three months during the first three years and then annually. It is possible that the prolonged maintenance schedule partly explains the difference in recurrence of disease between the present study and the study by Carcuac et al. (2020). However, the differences in disease recurrence could also be related to treatment choice (resective versus reconstructive) or the disease severity at baseline. In a recent publication evaluating the results of resective treatment of peri-implantitis, Ravidá et al. (2020) demonstrated that the probability of implant failure was influenced by the extent of the marginal bone loss. Furthermore, the analyses also indicated that clinical improvements in BOP, PPD, and suppuration were 
influenced by the number of supportive peri-implant therapy visits $(P<0.01)$ (Ravidá et al. 2020). Among the individuals remaining in the 5-year follow-up study by Roos-Jansåker et al. (2014), no implants were lost. Only one implant was identified with loss of additional bone $\geq 1.2 \mathrm{~mm}$ combined with BOP. During the whole follow-up period, the patients had excellent oral hygiene and plaque scores were reduced from approximately $50 \%$ at baseline to approximately $15 \%$ from three months to study endpoint in all patients (Roos-Jansåker et al. 2014). The evidence from Roos-Jansåker et al. (2014), Heitz-Mayfield et al. (2018), and the present study highlight that it is possible to maintain good treatment outcomes following peri-implantitis therapy for at least five years.

In the present study, pocket depths were reduced to a similar extent in both groups. The reduction of PPD in the BDX group may be related to defect fill whereas the reduction of PPD in the $A B$ group may result from soft tissue retraction. In the BDX group a mean defect fill of $1.8 \mathrm{~mm}$ was observed at 5 years.

One of the shortcomings of the present study is that several study individuals in the $A B$ treatment group were lost to follow-up, whereas none was lost to follow-up in the BDX group. The review of case history, age, gender, and other clinical factors could not explain why these cases were lost to follow-up. Whether implants in those lost cases were associated with further bone loss with or without implant loss, could not be further investigated. It should be acknowledged that analyses of bone level changes assessed from radiographs of sites grafted with radio-opaque materials (as in the case of DBX) cannot be a substitute for re-entry surgical procedures and measurements. It should, therefore, be emphasised that the present results are based on radiographic evidence regarding the extent of defect fill or loss and are only indicating the possibility of reconstruction of alveolar 
bone in 2-, 3-, or 4-wall defects. The assessment methods used in the present study cannot define if the defect fill is of functional value or not.

In conclusion, reconstructive surgical treatment of peri-implant defects can lead to successful clinical outcomes, maintainable over at least five years. Use of BDX results in more predictable outcomes than use of autogenous bone. 


\section{Legends}

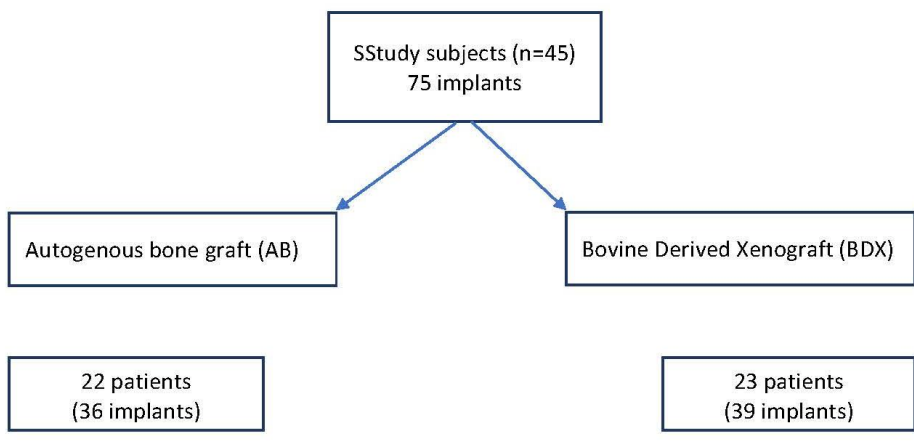

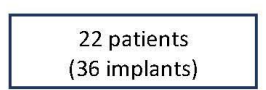
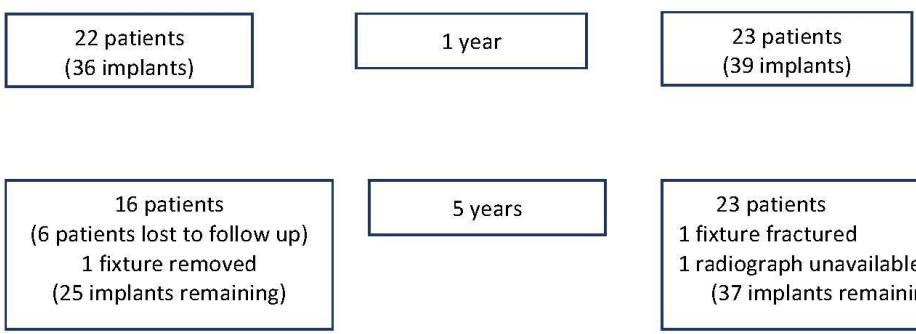

5 years

23 patients

1 fixture fractured

1 radiograph unavailable (37 implants remaining)

\section{Figure 1}

\section{Study flow chart}




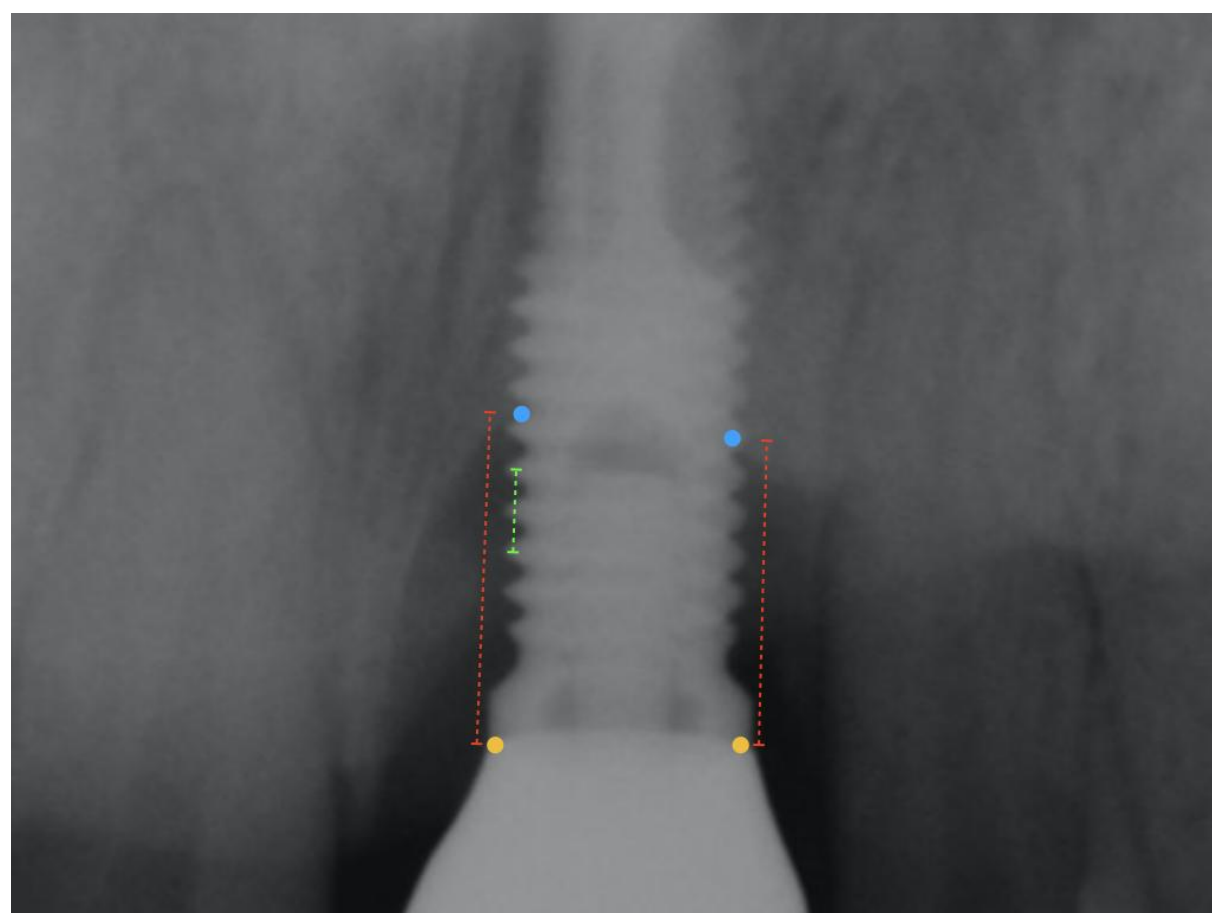

\section{Figure 2}

Illustration of the measurements on radiographs. The yellow points represent the implantabutment junction, and the blue points the most coronal bone-to-implant contact. The red dotted lines represent the distance from the implant platform to the bottom of the defect. The green dotted line represents the distance between three threads, used for calibration purposes. 


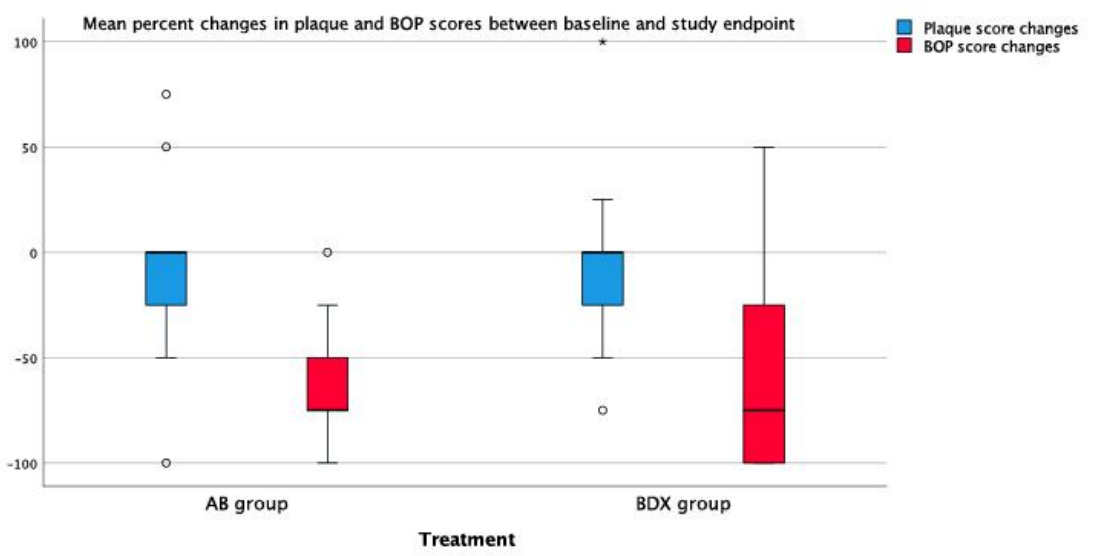

\section{Figure 3}

Boxplot diagram illustrating the mean percentage changes in plaque and BOP scores at study implants in the $A B$ and BDX groups. The $25^{\text {th }}$ and $75^{\text {th }}$ percentiles are presented by the lower and upper levels of the box with the inter-quartile range between the $25^{\text {th }}$ and $75^{\text {th }}$ percentiles. The middle line is the $50^{\text {th }}$ percentile. Outliers are represented by " 0 ". The whiskers represent the 1.5 interquartile range below and above the $25^{\text {th }}$ and $75^{\text {th }}$ percentiles 


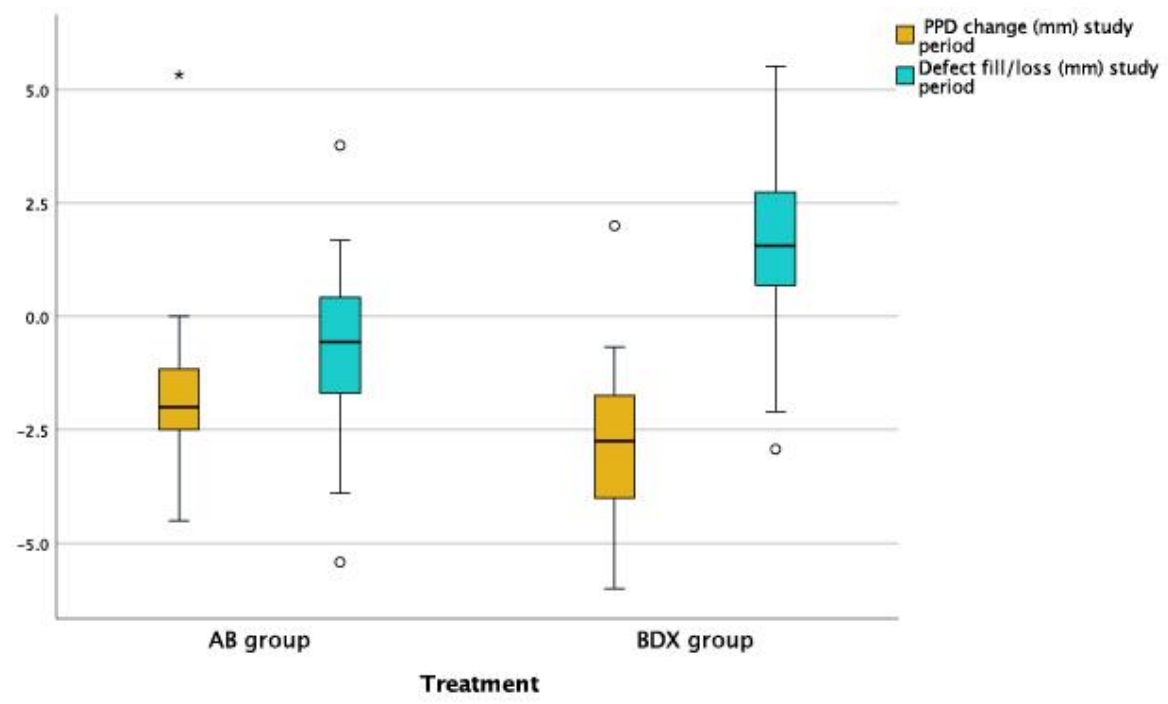

Figure 4

A decrease in PPD $(\mathrm{mm})$ suggests a clinical improvement. An increase in the extent of bone fill as defined from intra-oral radiographs illustrates an improvement. The $25^{\text {th }}$ and $75^{\text {th }}$ percentiles are presented by the lower and upper levels of the box with the inter-quartile range between the $25^{\text {th }}$ and $75^{\text {th }}$ percentiles. The middle line is the $50^{\text {th }}$ percentile. Outliers are represented by "o". The whiskers represent the 1.5 interquartile range below and above the $25^{\text {th }}$ and $75^{\text {th }}$ percentiles. 
Table 1. Baseline study conditions patient data.

\begin{tabular}{|c|c|c|c|c|c|c|c|c|}
\hline \multirow[t]{2}{*}{ Variables } & \multicolumn{3}{|c|}{ AB group $(n=22)$} & \multicolumn{3}{|c|}{ BDX group $(n=23)$} & \multirow[t]{2}{*}{$95 \% \mathrm{CI}$} & \multirow[t]{2}{*}{ Sign. } \\
\hline & $\%$ & Mean & S.D. & $\%$ & Mean & S.D. & & \\
\hline Gender (female) & 63.6 & & & 56.5 & & & & NS \\
\hline Subject age & & 70.1 & 6.2 & & 67.0 & 7.5 & & NS \\
\hline Number of estimated packs/years (smokers only) & & 23.2 & 13.4 & & 18.8 & 11.0 & -6.8 to 15.6 & NS \\
\hline Proportion of edentulous subjects & 13.6 & & & 26.1 & & & & NS \\
\hline Number of remaining teeth in dentate subjects & & 13.4 & 7.4 & & 12.9 & 7.8 & -4.6 to 5.7 & NS \\
\hline Number of implants present & & 5.4 & 2.2 & & 6.2 & 2.9 & -0.7 to 2.4 & NS \\
\hline $\begin{array}{l}\text { Number of implants with distance } \geq 2 \mathrm{~mm} \text { from } \\
\text { implant platform to bone level (implants in study) }\end{array}$ & & 3.4 & 1.7 & & 3.6 & 2.2 & -1.0 to 1.4 & NS \\
\hline Number of implants included in the study & & 1.7 & 0.7 & & 2.1 & 1.4 & -0.3 to 1.1 & NS \\
\hline $\begin{array}{ll}\text { Type of implant } & \text { Implamed } \\
& \text { Nobel Biocare } \\
& \text { Straumann } \\
& \text { Ti-Unite } \\
& \text { Unknown } \\
\end{array}$ & $\begin{array}{r}1 \\
17 \\
2 \\
2 \\
0 \\
\end{array}$ & & & $\begin{array}{c}2 \\
17 \\
2 \\
1 \\
1\end{array}$ & & & & \\
\hline
\end{tabular}


Table 2.Study participant characteristics by study group including those participants who completed the study

\begin{tabular}{|l|l|l|}
\hline Study groups & AB group & BDX group \\
\hline Gender & & \\
Female /male & $60 \% / 40 \%$ & $57 \% / 43 \%$ \\
\hline Smoking (current) & $37.3 \%$ & $39.3 \%$ \\
\hline Implant location & & \\
Incisor/cuspid & $48.0 \%$ & $46.0 \%$ \\
Premolar & $40,0 \%$ & $48.6 \%$ \\
Molar & $12.0 \%$ & $5.4 \%$ \\
Maxillary/mandibular & $60.0 \% / 40.0 \%$ & $86.5 \% / 13.5 \%$ \\
& & \\
\hline Defect configuration & & \\
2-wall & $43.8 \%$ & $56.5 \%$ \\
3-wall & $43.8 \%$ & $30.4 \%$ \\
4-wall & $12.5 \%$ & $13.0 \%$ \\
\hline Health status: & & \\
No reported medical history & $68.8 \%$ & $91.3 \%$ \\
Cardiovascular disease & $6.3 \%$ & $4.3 \%$ \\
High blood pressure & $12.5 \%$ & $0.0 \%$ \\
Diabetes mellitus & $0.0 \%$ & $0.0 \%$ \\
Arthrosis & $6.3 \%$ & $4.3 \%$ \\
Rheumatoid arthritis & $6.3 \%$ & $0.0 \%$ \\
Osteoporosis & $0.0 \%$ & $0.0 \%$ \\
Depression & $0.0 \%$ & $0.0 \%$ \\
\hline
\end{tabular}


Table 3. Results from t-tests (pairwise comparison) in the AB study group ( $\mathrm{n}=25$ ) including all cases that completed the study. Pairwise t-test comparisons between baseline and year 1 and between baseline and year 5 (two-tailed significance), positive values indicating improvements over time.

\begin{tabular}{|c|c|c|c|c|}
\hline \multicolumn{5}{|c|}{ AB group $(n=25)$} \\
\hline \multicolumn{5}{|c|}{ Bleeding on probing (\%) } \\
\hline Time & $\begin{array}{c}\text { Mean } \\
\text { change } \\
\text { (reduction) }\end{array}$ & SE diff & $95 \% \mathrm{CI}$ & Sign. \\
\hline BL to year 1 & 47.0 & 6.5 & $33.5, \quad 60.4$ & 0.001 \\
\hline BL to year 5 & 59.0 & 56.9 & 71.3 & 0.001 \\
\hline \multicolumn{5}{|c|}{ Plaque score $(\%)$} \\
\hline Time & $\begin{array}{c}\text { Mean } \\
\text { change } \\
\text { (reduction) }\end{array}$ & SE diff & $95 \% \mathrm{CI}$ & Sign. \\
\hline BL to year 1 & 14.0 & 7.4 & $-1.2, \quad 29.3$ & 0.07 (NS.) \\
\hline BL to year 5 & 7.0 & 8.0 & $-9.5, \quad 23.5$ & 0.39 (NS.) \\
\hline \multicolumn{5}{|c|}{ Probing pocket depth (mm) } \\
\hline Time & $\begin{array}{c}\text { Mean } \\
\text { change } \\
\text { (reduction) }\end{array}$ & SE diff & $95 \% \mathrm{CI}$ & Sign. \\
\hline BL to year 1 & 1.9 & 0.3 & $1.3, \quad-2.5$ & 0.001 \\
\hline BL to year 5 & 1.8 & 1.8 & $0.9, \quad 2.5$ & 0.001 \\
\hline \multicolumn{5}{|c|}{ Radiographic evidence of bone defect depth change (mm) } \\
\hline Time & $\begin{array}{l}\text { Mean bone } \\
\text { level change }\end{array}$ & SE diff & $95 \% \mathrm{CI}$ & Sign. \\
\hline BL to year 1 & 0.1 & 0.3 & -0.6 & NS. \\
\hline BL to year 5 & -0.7 & 0.4 & $\begin{array}{ll}-1.4, & 0.2\end{array}$ & NS. \\
\hline
\end{tabular}


Table 4. Results from t-tests (pairwise comparison) in the BDX study group, including all cases $(\mathrm{N}=37)$ that completed the study. Pairwise t-test comparisons between baseline and year 1 and between baseline and year 5 (two-tailed significance), positive values indicating improvements over time.

\begin{tabular}{|c|c|c|c|c|}
\hline \multicolumn{5}{|c|}{ BDX group $n=37$} \\
\hline \multicolumn{5}{|c|}{ Bleeding on probing (\%) } \\
\hline Time & Mean change & SE diff & $95 \% \mathrm{CI}$ & Sign. Diff. \\
\hline BL to year 1 & 47.3 & 5.6 & $35.9, \quad 58.7$ & 0.001 \\
\hline BL to year 5 & 56.8 & 7.2 & $42.3, \quad 71.3$ & 0.001 \\
\hline \multicolumn{5}{|c|}{ Plaque score $(\%)$} \\
\hline Time & $\begin{array}{c}\text { Mean change } \\
\text { (reduction) }\end{array}$ & SE diff & $95 \% \mathrm{CI}$ & Sign. Diff. \\
\hline BL to year 1 & 10.8 & 4.1 & $2.4, \quad 19.2$ & 0.01 \\
\hline BL to year 5 & 8.8 & 5.1 & $-1.5,198.0$ & 0.09 (NS) \\
\hline \multicolumn{5}{|c|}{ Probing pocket depth $(\mathrm{mm})$} \\
\hline Time & $\begin{array}{c}\text { Mean change } \\
\text { (reduction) }\end{array}$ & SE diff & $95 \% \mathrm{CI}$ & Sign. Diff. \\
\hline BL to year 1 & 2.9 & 0.2 & $2.4, \quad 3.4$ & 0.001 \\
\hline BL to year 5 & 2.8 & 0.3 & $2.3, \quad 3.4$ & 0.001 \\
\hline \multicolumn{5}{|c|}{ Radiographic evidence of bone defect depth change (mm) } \\
\hline Time & $\begin{array}{c}\text { Mean bone level } \\
\text { change }\end{array}$ & SE diff & $95 \% \mathrm{CI}$ & Sign. Diff. \\
\hline BL to year 1 & 1.2 & 0.3 & $0.7, \quad 1.8$ & 0.001 \\
\hline BL to year 5 & 1.8 & 0.3 & $1.0, \quad 2.2$ & 0.001 \\
\hline
\end{tabular}




\section{Table 5.}

Changes between study groups for the following variables: bleeding on probing (\%), plaque scores $(\%)$, probing pocket depth $(\mathrm{mm})$, and radiographic evidence in bone defect levels. The results from the statistical analyses are reported based on independent t-tests, equal variances not assumed. A negative mean difference denotes that the different variables' result was more favourable in the $\mathrm{AB}$ group.

\begin{tabular}{|c|c|c|c|c|}
\hline \multicolumn{5}{|c|}{ Bleeding on probing $(\%)$} \\
\hline $\begin{array}{c}\text { Change between baseline and time } \\
\text { points between } \mathrm{BDX} \text { and } \mathrm{AB} \\
\text { groups }\end{array}$ & Mean diff & SE diff & $95 \% \mathrm{Cl}$ & Sign. Diff. \\
\hline One year & 0.2 & 4.34 & $-8.8, \quad 8.5$ & 0.97 (NS.) \\
\hline Five years & 1.1 & 5.5 & $-8.8, \quad 4.6$ & 0.81 (NS.) \\
\hline \multicolumn{5}{|c|}{ Plaque score $(\%)$} \\
\hline $\begin{array}{c}\text { Change between baseline and time } \\
\text { points between BDX and AB } \\
\text { groups }\end{array}$ & Mean diff & SE diff & $95 \% \mathrm{Cl}$ & Sign. Diff. \\
\hline One year & 1.6 & 4.2 & $\begin{array}{ll}-6.3 & 10.1 \\
\end{array}$ & 0.81 (NS.) \\
\hline Five years & 0.9 & 9.0 & $-10.4,4.7$ & 0.69 (NS.) \\
\hline \multicolumn{5}{|c|}{ Probing pocket depth (mm) } \\
\hline $\begin{array}{c}\text { Change between baseline and time } \\
\text { points between } \mathrm{BDX} \text { and } \mathrm{AB} \\
\text { groups }\end{array}$ & Mean diff & SE diff & $95 \% \mathrm{Cl}$ & Sign. Diff. \\
\hline One year & -0.5 & 0.3 & $-0.9 \quad 4.7$ & 0.01 \\
\hline Five years & -0.6 & 0.2 & $-1.0,-0.01$ & 0.05 \\
\hline \multicolumn{5}{|c|}{ Radiographic evidence of bone defect depth change (mm) } \\
\hline $\begin{array}{c}\text { Change between baseline and time } \\
\text { points between BDX and AB } \\
\text { groups }\end{array}$ & Mean diff & SE diff & $95 \% \mathrm{Cl}$ & Sign. Diff. \\
\hline One year & 1.1 & 0.4 & $-0.3,-0.2$ & 0.01 \\
\hline Five years & 2.3 & 0.5 & -1.2 & 0.001 \\
\hline
\end{tabular}




\section{Acknowledgements}

We appreciate the support for the study from the University of Kristianstad, Sweden and the Uppsala Käkkirurgiska Center, and from Ms. Ulla Lundström RDH (UL) for the clinical measurements.

\section{Author contributions}

Ahmad Aghazadeh: Performed the surgeries, planned and was responsible for the follow-up, collected and analysed data and drafted the manuscript.

Rutger Persson: Analysed data and critically revised the manuscript.

Andreas Stavropoulos: Critically revised the manuscript.

Stefan Renvert: Conceived the idea, analysed the data and critically revised the manuscript. All authors gave final approval and agreed to be accountable for all aspects of the work.

\section{Orchid}

Stefan Renvert https://orcid.org/0000-0003-0992-2362

Andreas Stavropoulos https://orcid.org/0000-0001-8161-3754

Rutger Persson https://orcid.org/0000-0002-7976-3849

\section{Founding}

This paper was self-funded by the authors and their institutions.

\section{Ethical approval statement}

This material is the authors' own original work, which has not been previously published elsewhere. 


\section{Data availability statement}

The data that support the findings of this study are available from the corresponding author, [SR], upon reasonable request 


\section{References}

Aghazadeh, A., Persson G.R., Renvert,S. (2012) A single-centre randomized controlled clinical trial on the adjunct treatment of intra-bony defects with autogenous bone or a xenograft: results after 12 months. Journal of Clinical Periodontology 39: 666-673. doi: 10.1111/j.1600-051X.2012.01880.x.

Carcuac, O., Derks,J., Charalampakis, G., Abrahamsson,I., Wennstrom, J., Berglundh, T. (2016) Adjunctive Systemic and Local Antimicrobial Therapy in the Surgical Treatment of Peri-implantitis: A Randomized Controlled Clinical Trial. Journal of Dental Research 95:5057. https://doi.org/10.1111/clr.1365

Chan, H.L., Lin, G.H., Suarez, F., MacEachern, M., Wang, H.L. (2014) Surgical management of peri-implantitis: a systematic review and meta-analysis of treatment outcomes. Journal of Periodontology 85: 1027-1041. doi: 10.1902/jop.2013.130563.

Clem, D., Gunsolley, J.C. (2019)Peri-implantitis Treatment Using Er: YAG Laser and Bone Grafting. A Prospective Consecutive Case Series Evaluation: 1 Year Posttherapy. International Journal of Periodontics and Restorative Dentistry 39: 479-489. doi: 10.11607/prd.4158

Costa FO, Takenaka-Martinez S, Cota LOM, Ferreira SD, Silva GLM, Costa JE, (2012) Peri implant disease in subjects with and without preventive maintenance: a 5-year follow-up. Journal of Clinical Periodontolology 39: 173-181.doi: 10.1111/j.1600-051X.2011.01819.x. 
Derks, J., \& Tomasi, C. (2015) Peri-implant health and disease. A systematic review of current epidemiology. Journal of Clinical Periodontology 42: S158-S171. https://doi.org/10.1111/jcpe.12334

Frisch, E., Vach, K., Ratka-Krueger, P. (2020) Impact of supportive implant therapy on periimplant diseases: A retrospective 7-year study. Journal of Clinical Periodontology 47:101109. doi: $10.1111 /$ jcpe.13206.

Heitz-Mayfield, L.J.A., Salvi, G.E., Mombelli, A., Loup, P.J., Heitz. F., Kruger. E., Lang, N.P. (2018) Supportive peri-implant therapy following anti-infective surgical peri-implantitis treatment: 5-year survival and success. Clinical Oral Implants Resaerch, 29: 1-6. doi: 10.1111/clr.12910.

Hu C, Lang NP, Ong MM-A, Lim LP, Tan WC. (2020) Influence of periodontal maintenance and periodontitis susceptibility on implant success: A 5-year retrospective cohort on moderately rough-surfaced implants. Clinical Oral Implants Research 31:727-736. doi.org/10.1111/ clr.13621

Jepsen, K., Jepsen, S., Laine, M. L., Anssari Moin D., Pilloni, A., Zeza B., Sanz M., Ortiz-Vigon A., Roos-Jansåker A. M., Renvert, S.(2016) Reconstruction of Peri-implant Osseous Defects: A Multicenter Randomized Trial. Journal of Dental Research 95: 58-66. 
La Monaca, G., Pranno N., Annibali, S., Cristalli, M. P., and Polimeni, A. (2018) Clinical and radiographic outcomes of a surgical reconstructive approach in the treatment of periimplantitis lesions: A 5-year prospective case series. Clinical Oral Implants Research 29: doi: 10.1111/clr.13369.

Mercado, F., S. Hamlet, S. Ivanovski. (2018) Regenerative surgical therapy for peri-implantitis using deproteinized bovine bone mineral with $10 \%$ collagen, enamel matrix derivative and Doxycycline-A prospective 3-year cohort study.Clinical Oral Implants Research 29: 583-91.

Monje, A., Aranda, L., Diaz, K. T., Alarcon, M. A., Bagramian, R. A., Wang, H. L., \& Catena, A. (2016) Impact of maintenance therapy for the prevention of peri-implant diseases: A systematic review and meta-analysis. Journal of Dental Research95(4):372-379.doi. org/10.1177/00220 34515622432

Monje, A., Wang, H.L., Nart, J.(2017)Association of Preventive Maintenance Therapy Compliance and Peri-Implant Diseases: A Cross-Sectional Study. Journal of Periodontology 88: 1030-1041. doi: 10.1902/jop.2017.170135.

Nart, J., de Tapia, B., Pujol, À., Pascual, A., Valles, C..(2018) Vancomycin and tobramycin impregnated mineralized allograft for the surgical regenerative treatment of peri-implantitis: a 1-year follow-up case series. Clinical Oral Investigations22(6):2199-2207. doi: 10.1007/s00784-017-2310-0. 
Pjetursson, B. E., Helbling, C., Weber, H.-P., Matuliene, G., Salvi, G.E., Brägger, U., Lang, N. P. (2012) Peri-implantitis susceptibility as it relates to periodontal therapy and supportive care. Clinical Oral Implants Research 23: 888-894.doi. org/10.1111/j.1600-0501.2012.02474.x

Ramanauskaite, A., Becker, K., Juodzbalys, G., Schwarz, F.(2018)Clinical outcomes following surgical treatment of peri-implantitis at grafted and non-grafted implant sites: a retrospective analysis. Internation Journal of Implant Dentistry 9,4(1),27. doi: 10.1186/s40729-018-0135-5.

Ravidà, A., Siqueira, R., Saleh, I., Saleh, M.H.A., Giannobile, A., Wang,H.L . (2020) Lack of Clinical Benefit of Implantoplasty to Improve Implant Survival Rate. Journal of Dental Research, 99:1348-1355. Doi: 10.1177/0022034520944158.

Renvert, S., Roos-Jansåker, A.M., Claffey, N. (2008) Non-surgical treatment of peri-implant mucositis and peri-implantitis: a literature review. Journal of Clinical Periodontology, 35 : 305-315. doi: 10.1111/j.1600-051X.2008.01276.x.

Renvert, S., Roos-Jansaker, A.M., Persson, G. R.(2018) Surgical treatment of peri-implantitis lesions with or without the use of a bone substitute-a randomized clinical trial. Journal of Clinical Periodontology 45: 1266-1274. doi: 10.1111/jcpe.12986.

Rinke, S., Ohl, S., Ziebolz, D., Lange, K., Eickholz, P. (2011) Prevalence of peri-implant disease in partially edentulous patients: a practice-based cross-sectional study. Clinical Oral Implants Research 22: 826-833. doi: 10.1111/j.1600-0501.2010.02061. 
Roccuzzo, M., De Angelis, N., Bonino, L., Aglietta, M. (2010) Ten-year results of a three arms prospective cohort study on implants in periodontally compromised patients. Part 1: implant loss and radiographic bone loss. Clinical Oral Implants Research 21: 490-496. doi: 10.1111/j.1600-0501.2009.01886.

Roccuzzo, M., Gaudioso, L., Lungo, M., Dalmasso, P. (2016) Surgical therapy of single periimplantitis intrabony defects, by means of deproteinized bovine bone mineral with $10 \%$ collagen. Journal of Clinical Periodontology 43: 311-318. doi: 10.1111/jcpe.12516.

Roccuzzo M, Pittoni D, Roccuzzo A, Charrier L, Dalmasso P.(2017) Surgical treatment of periimplantitis intrabony lesions by means of deproteinized bovine bone mineral with $10 \%$ collagen: 7-year-results. Clinical Oral Implants Research 28: 1577-1583 doi: $10.1111 /$ clr.13028

Roccuzzo, M., Layton, D.M., Roccuzzo, A., Heitz-Mayfield, L.J. (2018) Clinical outcomes of peri-implantitis treatment and supportive care: A systematic review. Clinical Oral Implants Research 29 (Suppl 16):331-350. doi: 10.1111/clr.13287.

Roos-Jansåker, A. M., Renvert H., Lindahl C., Renvert, S. (2007) Surgical treatment of periimplantitis using a bone substitute with or without a resorbable membrane: a prospective cohort study, Journal of Clinical Periodontology 34: 625-632. doi: 10.1111/j.1600051X.2007.01102.x. 
Roos-Jansaker, A. M., Lindahl C., Persson G. R., Renvert, S. (2011) Long-term stability of surgical bone regenerative procedures of peri-implantitis lesions in a prospective casecontrol study over 3 years, Journal of Clinical Periodontology 38: 590-597. doi: 10.1111/j.1600-051X.2011.01729.x.

Roos-Jansåker, A. M., Persson G. R., Lindahl C., Renvert S.. (2014) Surgical treatment of periimplantitis using a bone substitute with or without a resorbable membrane: a 5-year followup. Journal of Clinical Periodontology 41: 1108-1114. doi: 10.1111/jcpe.12308

Schwarz, F., Sahm N., Bieling, K., Becker, J. (2009) Surgical regenerative treatment of periimplantitis lesions using a nanocrystalline hydroxyapatite or a natural bone mineral in combination with a collagen membrane: a four-year clinical follow-up report. Journal of Clinical Periodontology 36:807-14. doi: 10.1111/j.1600-051X.2009.01443.x.

Schwarz F, Derks J, Monje A, Wang HL. (2018). Peri-implantitis. Journal of Periodontology 89(Suppl 1):267-290. doi.org/10.1002/JPER.16-0350

Serino, G., Turri, A., Lang, N.P.(2015) Maintenance therapy in patients following the surgical treatment of peri-implantitis: a 5-year follow-up study. Clinical Oral Implants Research 26(8):950-956. doi: 10.1111/clr.12418.

Serino, G., Wada, M., Mameno, T., Renvert, S. (2021) Two-and ten-year follow-up of patients responding and non-responding to the surgical treatment of peri-implantitis: A retrospective evaluation. Clinical Oral Implants Research 00:1-12. doi.org/10.1111/clr.13711 

ISBN 978-91-7877-196-7 (print)

ISBN 978-91-7877-197-4 (pdf)

MALMÖ UNIVERSITY 20506 MALMÖ, SWEDEN WWW.MAU.SE 